\title{
Rational design of calpain inhibitors based on calpastatin peptidomimetics
}

Kristin E. Low, ${ }^{1}$ Spencer Ler, ${ }^{2}$ Kevin J. Chen, ${ }^{1}$ Robert L. Campbell, ${ }^{1}$ Jennifer L. Hickey, ${ }^{3}$ Joanne Tan, ${ }^{2}$ Conor C. G. Scully, ${ }^{2}$ Peter L. Davies, ${ }^{1 *}$ Andrei K. Yudin, ${ }^{2 *}$ and Serge Zaretsky $^{2 *}$

${ }^{1}$ Department of Biomedical and Molecular Sciences, Queen's University, Kingston, ON, K7L 3N6, Canada

${ }^{2}$ Department of Chemistry, University of Toronto, Toronto, ON, M5S 3H6, Canada

${ }^{3}$ Encycle Therapeutics Inc., 101 College Street, Suite 314, Toronto, Ontario M5G 1L7, Canada 


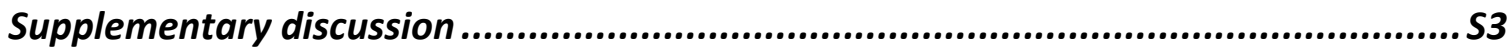

Determination of the appropriate time scale for kinetics calculations..............................S3

Calpain kinetics after fitting data to the mixed enzyme inhibition equation ......................S3

Synthesis of photo-reactive calpain inhibitor compounds...............................................S4

Assessing inhibition of photo-reactive vs original calpain inhibitor compounds .................S7

Identification of peptide binding sites by calpain photo-adduct tryptic digest peptides......S7

Supplementary methods ...................................................................... 59

Characterization of compounds................................................................... S11

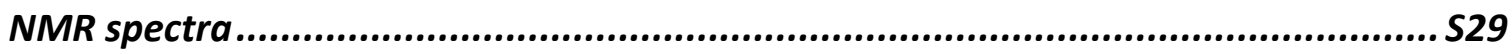

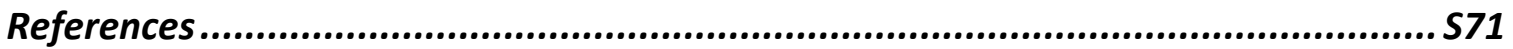




\section{Supplementary discussion}

\section{Determination of the appropriate time scale for kinetics calculations}

Cleavage of the fluorescent substrate (EDANS)-EPLFAERK-(DABCYL) by calpain was monitored over $5 \mathrm{~min}$. It was noted that autoproteolysis became a significant problem, as seen by the plateau of the progress curve seen in Supplementary Figure 1. However, the sensitivity of the fluorimeter and frequency of recorded data points showed the initial calpain activity to remain linear, prior to significant autoproteolysis, within the first 10 s (Supplementary Figure 1 inlay).

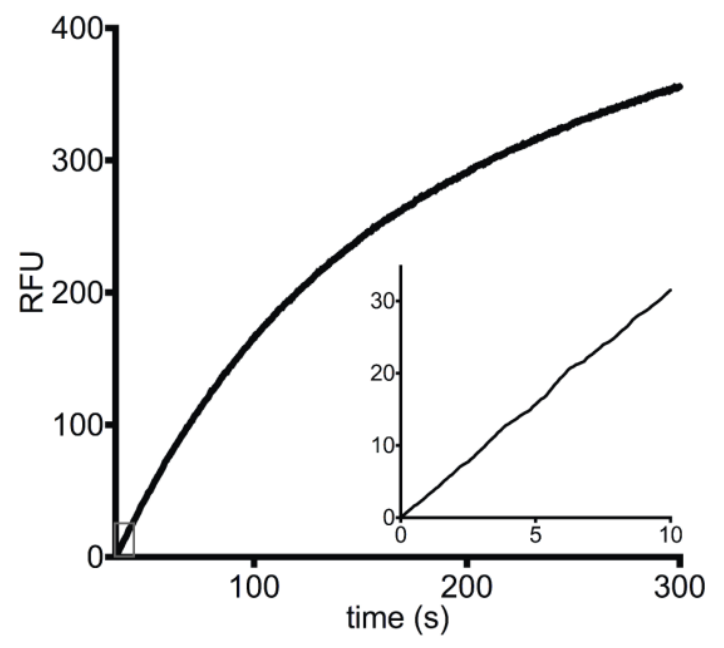

Supplementary Figure 1 Calpain activity progress curve with the fluorescence-based hydrolysis assay. (RFU, relative fluorescence units)

\section{Calpain kinetics after fitting data to the mixed enzyme inhibition equation}

$\mathrm{K}_{\mathrm{cat}}$ and $\mathrm{K}_{\mathrm{m}}$ data are important to include for the purpose of reproducibility in the calpain inhibitor field; often calpain purifications vary in activity even with the same isoform and construct used. As such, these data are presented in Supplementary Table 1. Despite perhaps using different preparations of the enzyme, it can be seen that substrate affinity and enzyme turnover rates were within error for each reaction condition. 
Supplementary Table 1 Full enzyme kinetics after fitting data to the full mixed enzyme inhibition equation.

\begin{tabular}{|c|c|c|c|c|c|}
\hline Compound & $\mathbf{k}_{\mathbf{c a t}}\left(\mathbf{s}^{-\mathbf{1}}\right)$ & $\mathbf{K}_{\mathbf{m}}(\boldsymbol{\mu M})$ & $\mathbf{K}_{\mathbf{i 1}}(\boldsymbol{\mu M})$ & $\mathbf{K}_{\mathbf{i} 2}(\boldsymbol{\mu M})$ & $\begin{array}{c}\text { Inhibition } \\
\mathbf{m o d e l}\end{array}$ \\
\hline $\begin{array}{c}\text { B27 WT } \\
\text { peptide }\end{array}$ & $5.2 \pm 0.4$ & $72.1 \pm 7.7$ & $\begin{array}{c}13.7 \times 10^{-3} \pm \\
1.8 \times 10^{-3}\end{array}$ & $\begin{array}{c}95.5 \times 10^{-3} \pm \\
109.6 \times 10^{-3}\end{array}$ & competitive \\
\hline am*[PLKG] & $5.6 \pm 0.4$ & $76.8 \pm 7.8$ & $10.8 \pm 0.8$ & $\begin{array}{r}1.2 \times 10^{7} \pm \\
1.4 \times 10^{12}\end{array}$ & competitive \\
\hline $\mathrm{c}^{*}[$ PGALK] & $5.4 \pm 0.4$ & $75.8 \pm 7.5$ & $14.7 \pm 1.0$ & $427.4 \pm 1212$ & competitive \\
\hline $\mathrm{c}^{*}[$ PGSGO] & $5.6 \pm 0.5$ & $75.8 \pm 9.1$ & $20.3 \pm 2.0$ & $45.6 \pm 19.8$ & mixed \\
\hline am*[PGLo] & $5.6 \pm 0.5$ & $78.0 \pm 8.9$ & $153.7 \pm 27.6$ & $119.4 \pm 37.9$ & $\begin{array}{c}\text { non- } \\
\text { competitive }\end{array}$ \\
\hline
\end{tabular}

\section{Synthesis of photo-reactive calpain inhibitor compounds.}

We used the enabling features of the conjugation-capable ring-opening strategy to prepare the photo-reactive compounds. ${ }^{1}$ The aziridine electrophile, and the imidate counter-part in amidines, is an ideal site for installing functionality at a late stage of synthesis that would avoid prolonged exposure of the sensitive photo-crosslinking reagents. With a free thiol, a photo-crosslinking moiety can be conjugated to the chemical probe via maleimide addition. ${ }^{2}$

The synthesis of maleimide $\mathbf{S 1}$ was accomplished according to literature procedures by combining 4-aminobenzophenone with maleic anhydride and sodium acetate in acetic anhydride (Supplementary Scheme 1). ${ }^{3,4}$ The crude material was sufficiently pure (by NMR), such that recrystallization was not necessary.<smiles>Nc1ccc(C(=O)c2ccccc2)cc1</smiles>

Supplementary Scheme 1 Synthesis of benzophenone-4-maleimide, S1

With $\mathbf{S 1}$ in hand, the synthesis of crosslinking-capable $\mathbf{c}^{*}[\mathbf{P G A L K}]$ and am*[PGLo] proceeded by first making the sulfhydryl-containing peptide analogue. For the $\mathbf{c}^{*}[\mathbf{P G A L K}]$ analogue, cyclic aziridine amide $\mathbf{S 2}$ was not isolated and instead, it was 
directly exposed to thiobenzoic acid to yield thioester S3 (Supplementary Scheme 2).

Following deacylation conditions, thiol $\mathbf{S 4}$ was isolated in $23 \%$ yield. The conjugation to S1 required 2 eq. of the reagent and 20 min stirring at room temperature. Finally, the Boc group was removed with TFA and the final product was isolated by reversed-phase purification to afford $3.2 \mathrm{mg}$ of the crosslinking probe photo-c*[PGALK].<smiles>CC(C)C[C@H](NC(=O)[C@H](C)NC(=O)CNC(=O)C1CCCN1)C(=O)N[C@@H](CCCCNC(=O)OC(C)(C)C)C(=O)O</smiles><smiles>CC(C)C[C@H]1NC(=O)[C@H](C)NC(=O)CNC(=O)[C@@H]2CCCN2[C@@H](C(=O)NC(C)(C)C)[C@H](CS)NC(=O)[C@H](CCCCNC(=O)OC(C)(C)C)NC1=O</smiles><smiles>CC(C)C[C@H]1NC(=O)[C@H](C)NC(=O)CNC(=O)[C@@H]2CCCN2[C@@H](C(=O)NC(C)C)[C@H](CSC(=O)c2ccccc2)NC(=O)[C@H](CCCCNC(=O)OC(C)(C)C)NC1=O</smiles>

S1 DMF, $90 \mathrm{~min}, \mathrm{rt}$
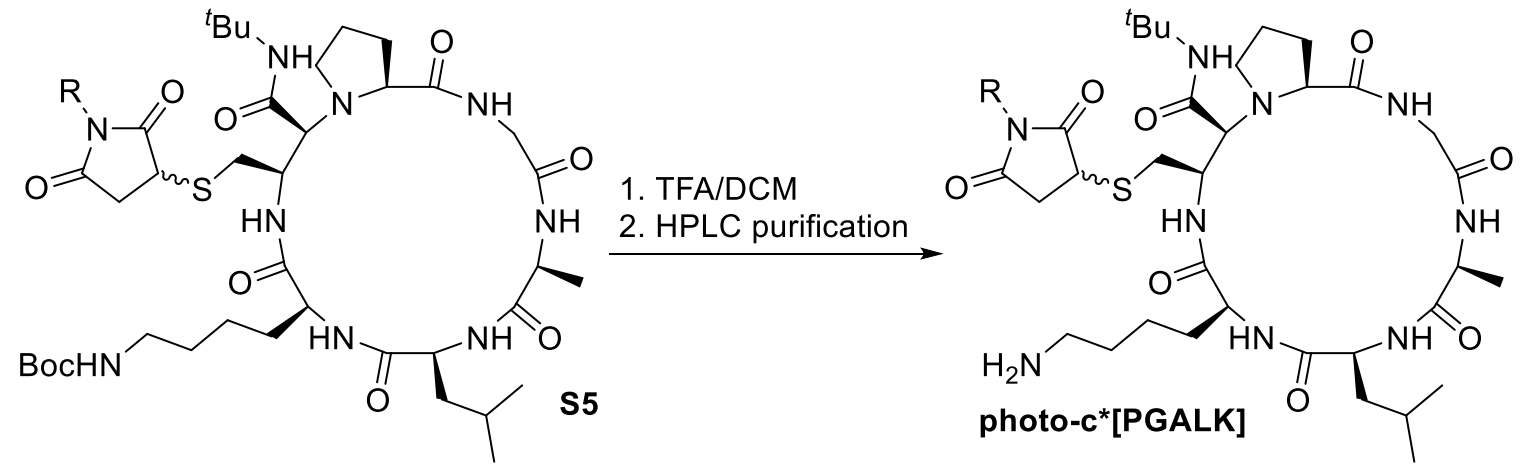
Supplementary Scheme 2 Synthesis of photo-c*[PGALK], photo-crosslinkable analogue of $\mathbf{c} *$ PGALK] $(\mathrm{R}=4$-benzophenone $)$

The synthesis of the photo-crosslinkable derivative of am*[PGLo] proceeded in a similar manner (Supplementary Scheme 3). In this case, the thioester $\mathbf{S 7}$ was isolated by RP-Combiflash purification before proceeding with the rest of the synthesis. The final product was isolated by reversed-phase purification to afford $4.5 \mathrm{mg}$ of the crosslinking probe photo-am*[PGLo] in $27 \%$ yield from the thioester. Two compounds were obtained from purification because in a small proportion of the sample the maleimide ring had been hydrolyzed.<smiles>[R6]C([R6])NCCC[C@H](NC(=O)[C@H](CC(C)C)NC(=O)CNC(=O)[C@@H]1CCCN1)C(=O)OCC(C)(C)C</smiles><smiles>CC(C)C[C@H](NC(=O)CN=C1N[C@@H]2CO/C(=N/C(C)C)[C@H]2N2CCC[C@@H]12)C(=O)N[C@@H](CCCNC(=O)OCc1ccccc1)C(=O)O</smiles>

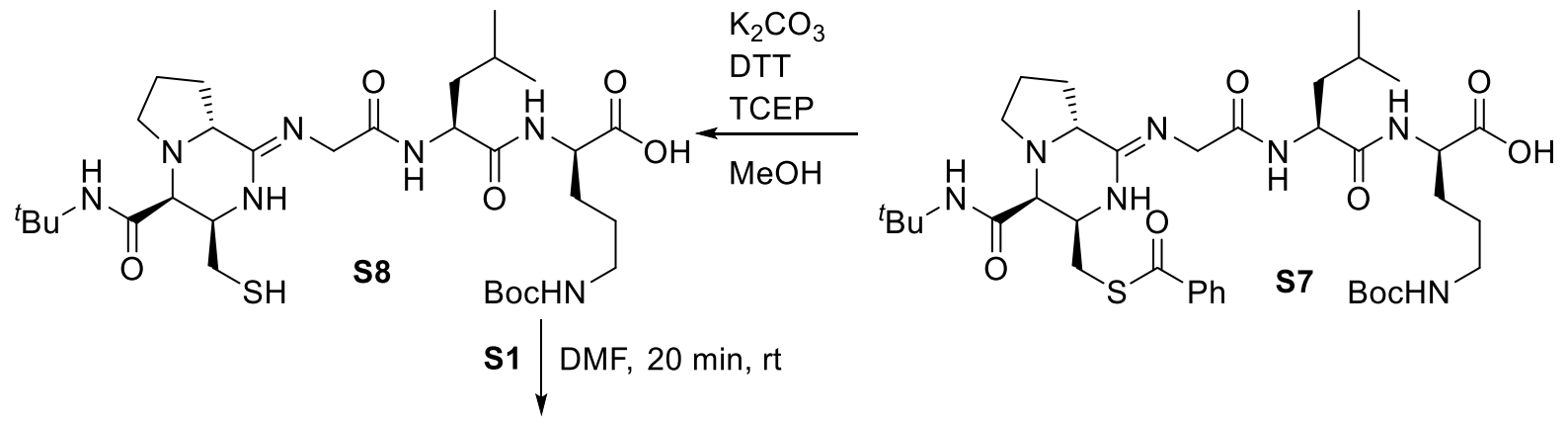

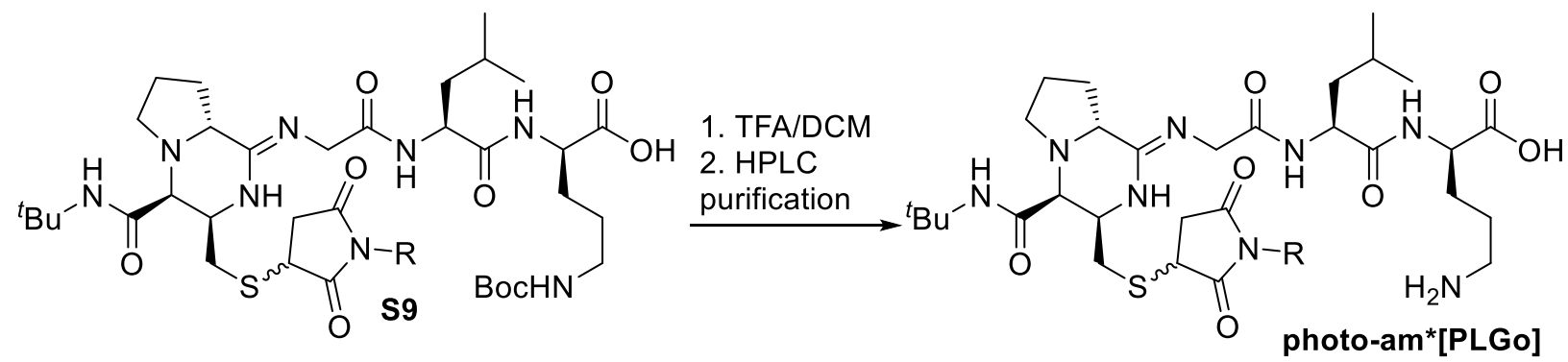

Supplementary Scheme 3 Synthesis of photo-am*[PGLo], photo-crosslinkable analogue of am*[PGLo] ( $\mathrm{R}=$ 4-benzophenone) 


\section{Assessing inhibition of photo-reactive vs original calpain inhibitor compounds}

In order to assess whether the addition of photo-reactive groups to am*[PGLo] and $c^{*}[\mathrm{PGALK}]$ would modify the inhibition profile of these compounds, the fluorescence-based calpain activity assay was employed as in Figure 7. It was found that the photo-crosslinking moiety did not affect inhibition of the compounds, as both were found to inhibit calpain-2 with approximately the same potency as the original compound (Supplementary Figure 2).

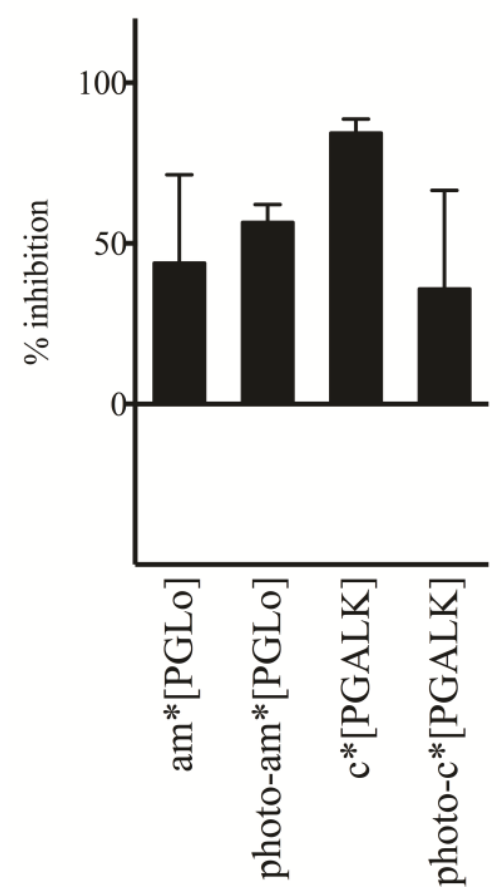

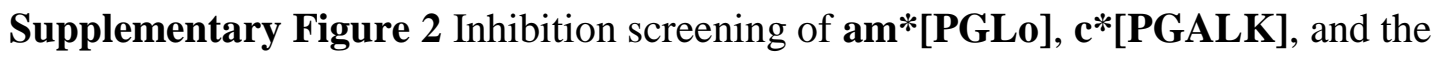
corresponding photo-reactive compounds.

\section{Identification of peptide binding sites by calpain photo-adduct tryptic digest peptides.}

Calpain-2 reacted to either photo-am*[PGLo] or photo-c*[PGALK] was digested by trypsin. The resulting peptides were subjected to MALDI-TOF peptide fingerprinting from a CHCA matrix. Peptide masses were compared between photo-reactions and a DMSO control. Up to 2 missed cuts by trypsin were considered valid fragments. The 
sequences with a mass difference equal to the photo-reactive compound are summarized in Supplementary Table 2.

Supplementary Table 2 Summary of photo-adducts linked to calpain-2 tryptic fragments following reaction under UV with photo-am*[PGLo] and photo-c*[PGALK].

\begin{tabular}{|c|c|c|c|}
\hline \multirow[t]{2}{*}{ Compound } & \multicolumn{3}{|c|}{$\begin{array}{l}\text { Tryptic digest fragments with photo-adduct } \\
\text { (calpain-2 residues) }\end{array}$} \\
\hline & \multicolumn{2}{|c|}{ Large subunit } & Small subunit \\
\hline $\begin{array}{c}\text { photo- } \\
\text { am*[PGLo }]\end{array}$ & $\begin{array}{l}\text { maleimimide intact: } \\
\text { maleimide opened: }\end{array}$ & $\begin{array}{l}368-375,501-505,604-609, \\
669-674 \\
1-7,13-26,356-360,361-366 \\
417-420\end{array}$ & $16-19$ \\
\hline $\begin{array}{c}\text { photo- } \\
\text { c*[PGALK }]\end{array}$ & \multicolumn{2}{|c|}{$338-357,462-469,475-493,569-591$} & \\
\hline
\end{tabular}




\section{Supplementary methods}

RP-HPLC/MS Method A: Low resolution mass spectra (ESI) were collected on an Agilent Technologies 1200 series HPLC paired to a 6130 Mass Spectrometer.

Compounds were resolved on an Agilent Poroshell 120 EC-C $18,2.7 \mu \mathrm{m}, 4.6$ x $50 \mathrm{~mm}^{2}$

column at room temperature with a flow of $1 \mathrm{~mL} / \mathrm{min}$. The gradient consisted of eluents A $(0.1 \%$ formic acid in double distilled water $)$ and B $(0.1 \%$ formic acid in HPLC-grade acetonitrile). The gradient method started with a step of $5 \%$ of B for the first $0.99 \mathrm{~min}$, followed by a linear gradient from $5 \%$ to $95 \% \mathrm{~B}$ in $8.0 \mathrm{~min}$. The column was then washed with $95 \% \mathrm{~B}$ for $1.0 \mathrm{~min}$ and equilibrated at $5 \% \mathrm{~B}$ for $1.5 \mathrm{~min}$.

RP-HPLC/MS Method Iso XX: Low resolution mass spectra (ESI) were collected on an Agilent Technologies 1200 series HPLC paired to a 6130 Mass Spectrometer.

Compounds were resolved on an Agilent Poroshell 120 EC-C ${ }_{18}, 2.7 \mu \mathrm{m}, 4.6$ x 50 mm$^{2}$ column at room temperature with a flow of $1 \mathrm{~mL} / \mathrm{min}$. The gradient consisted of eluents A $(0.1 \%$ formic acid in double distilled water) and B (0.1\% formic acid in HPLC-grade acetonitrile). The gradient method started with a step of $5 \%$ of B for the first $0.99 \mathrm{~min}$, followed by xx\% B for $8.0 \mathrm{~min}$. The column was then washed with $95 \%$ B for $1.0 \mathrm{~min}$ and equilibrated at $5 \% \mathrm{~B}$ for $1.5 \mathrm{~min}$.

RP-HPLC/MS Method C8: Low resolution mass spectra (ESI) were collected on an Agilent Technologies 1200 series HPLC paired to a 6130 Mass Spectrometer.

Compounds were resolved on an Agilent Poroshell 120 EC-C $8,2.7 \mu \mathrm{m}, 2.1$ x $150 \mathrm{~mm}^{2}$ column at room temperature with a flow of $1 \mathrm{~mL} / \mathrm{min}$. The gradient consisted of eluents A $(0.1 \%$ formic acid in double distilled water $)$ and B $(0.1 \%$ formic acid in HPLC-grade acetonitrile). The gradient method started with a step of $5 \%$ of B for the first $0.99 \mathrm{~min}$, followed by a linear gradient from $5 \%$ to $95 \%$ B in $15.0 \mathrm{~min}$. The column was then washed with $95 \%$ B for 2.0 min and equilibrated at $5 \%$ B for $4.5 \mathrm{~min}$.

Peptide NMR: ${ }^{1} \mathrm{H}$ and ${ }^{13} \mathrm{C}$ NMR spectra were recorded on Varian Mercury 400 and Agilent $500 \mathrm{MHz}$ or $600 \mathrm{MHz}$ spectrometers. ${ }^{1} \mathrm{H}$ NMR spectra were referenced to $\mathrm{CDCl}_{3}$ 
(7.26 ppm), $\mathrm{CD}_{3} \mathrm{OD}$ (3.30 ppm), DMSO-d $(2.50 \mathrm{ppm}) .{ }^{13} \mathrm{C}$ NMR spectra were referenced to $\mathrm{CDCl}_{3}$ (77.2 ppm), $\mathrm{CD}_{3} \mathrm{OD}$ (49.0 ppm), and DMSO-d $d_{6}$ (39.52 ppm). NMR spectra were recorded at $25{ }^{\circ} \mathrm{C}$ unless otherwise specified. Peak multiplicities are designated by the following abbreviations: s, singlet; bs, broad singlet; d, doublet; t, triplet; q, quartet; m, multiplet; ds, doublet of singlets; dd, doublet of doublets; ddd, doublet of doublet of doublets; bt, broad triplet; td, triplet of doublets; tdd, triplet of doublets of doublets. 


\section{Characterization of compounds}

\section{**[PGLGK]}

After cyclization, filtration, and deprotection, $92.9 \mathrm{mg}$ of peptide was recovered.

Following purification by RP-HPLC SP 5 to 10, the pure fractions were pooled to afford $24.1 \mathrm{mg}$ of the title compound in $26 \%$ overall yield. ESI MS [M+H] ${ }^{+}$expected: 609.4 , experimental: 609.4; $[\mathrm{M}+2 \mathrm{H}]^{2+}$ expected: 305.2, experimental: 305.2. ESI-TOF MS $[\mathrm{M}+2 \mathrm{H}]^{2+}$ expected: 305.2078, experimental: 305.2088. LC/MS Method A retention time $3.793 \mathrm{~min} .{ }^{1} \mathrm{H} \mathrm{NMR}\left(\mathrm{CD}_{3} \mathrm{OD}, 400 \mathrm{MHz}\right) \delta 4.27$ (ddd, $\left.J=22.4,12.1,5.6 \mathrm{~Hz}, 4 \mathrm{H}\right), 4.08-$ $3.95(\mathrm{~m}, 2 \mathrm{H}), 3.84-3.75(\mathrm{~m}, 1 \mathrm{H}), 3.59$ (d, $J=15.8 \mathrm{~Hz}, 1 \mathrm{H}), 3.38(\mathrm{dd}, J=8.8,5.1 \mathrm{~Hz}$, 1H), $3.17-3.02(\mathrm{~m}, 3 \mathrm{H}), 2.93(\mathrm{dd}, J=16.3,8.8 \mathrm{~Hz}, 3 \mathrm{H}), 2.13-1.94(\mathrm{~m}, 2 \mathrm{H}), 1.84-$ $1.60(\mathrm{~m}, 10 \mathrm{H}), 1.52-1.38(\mathrm{~m}, 3 \mathrm{H}), 1.34(\mathrm{~d}, J=9.3 \mathrm{~Hz}, 12 \mathrm{H}), 1.30(\mathrm{~d}, J=6.7 \mathrm{~Hz}, 3 \mathrm{H})$, $0.97(\mathrm{dd}, J=6.0,4.8 \mathrm{~Hz}, 6 \mathrm{H})$.

\section{c*[PGALK]}

After cyclization, filtration, and deprotection, $80.5 \mathrm{mg}$ of peptide was recovered.

Following purification by RP-HPLC SP 10 to 15, the pure fractions were pooled to afford $2.6 \mathrm{mg}$ of the title compound in $2.8 \%$ yield. ESI MS $[\mathrm{M}+\mathrm{H}]^{+}$expected: 623.4 , experimental: 623.4. LC/MS Method A retention time $4.337 \mathrm{~min} .{ }^{1} \mathrm{H}$ NMR $\left(\mathrm{CD}_{3} \mathrm{OD}, 400\right.$ MHz) $\delta 4.25-4.14(\mathrm{~m}, 2 \mathrm{H}), 4.14-4.01(\mathrm{~m}, 2 \mathrm{H}), 3.79(\mathrm{dd}, J=10.5,4.4 \mathrm{~Hz}, 1 \mathrm{H}), 3.55$ $(\mathrm{d}, J=15.9 \mathrm{~Hz}, 1 \mathrm{H}), 3.40(\mathrm{dd}, J=8.7,5.1 \mathrm{~Hz}, 1 \mathrm{H}), 3.17(\mathrm{~d}, J=8.7 \mathrm{~Hz}, 1 \mathrm{H}), 3.00(\mathrm{dd}, J$ $=17.1,7.8 \mathrm{~Hz}, 1 \mathrm{H}), 2.95-2.86(\mathrm{~m}, 1 \mathrm{H}), 2.87-2.77(\mathrm{~m}, 2 \mathrm{H}), 2.03-1.82(\mathrm{~m}, 3 \mathrm{H}), 1.80$ $-1.47(\mathrm{~m}, 8 \mathrm{H}), 1.40(\mathrm{~d}, J=7.1 \mathrm{~Hz}, 3 \mathrm{H}), 1.29-1.24(\mathrm{~m}, 9 \mathrm{H}), 1.09(\mathrm{~d}, J=6.6 \mathrm{~Hz}, 3 \mathrm{H})$, $0.95-0.82(\mathrm{~m}, 6 \mathrm{H})$.

\section{c*[PGAlk]}

After cyclization, filtration, and deprotection, $82.3 \mathrm{mg}$ of peptide was recovered.

Following purification by RP-HPLC SP 5 to 20, the pure fractions were pooled to afford $4.0 \mathrm{mg}$ of the title compound in $4.3 \%$ yield. ESI MS [M+H] $]^{+}$expected: 623.4 , experimental: 623.4. LC/MS Method A retention time $4.357 \mathrm{~min} .{ }^{1} \mathrm{H}$ NMR $\left(\mathrm{CD}_{3} \mathrm{OD}, 400\right.$ MHz) $\delta 4.16-3.98(\mathrm{~m}, 5 \mathrm{H}), 3.63(\mathrm{~d}, J=15.7 \mathrm{~Hz}, 1 \mathrm{H}), 3.41(\mathrm{dt}, J=11.4,5.6 \mathrm{~Hz}, 1 \mathrm{H})$, 
$2.96-2.86(\mathrm{~m}, 1 \mathrm{H}), 2.86-2.76(\mathrm{~m}, 3 \mathrm{H}), 1.96(\mathrm{dq}, J=12.4,8.5 \mathrm{~Hz}, 1 \mathrm{H}), 1.90-1.65(\mathrm{~m}$, $6 \mathrm{H}), 1.64-1.49(\mathrm{~m}, 4 \mathrm{H}), 1.31(\mathrm{~d}, J=7.1 \mathrm{~Hz}, 3 \mathrm{H}), 1.29-1.22(\mathrm{~m}, 9 \mathrm{H}), 1.08$ (t, $J=7.3$ $\mathrm{Hz}, 3 \mathrm{H}), 0.86(\mathrm{dt}, J=20.9,7.7 \mathrm{~Hz}, 6 \mathrm{H})$.

\section{c*[PGLG-Dab]}

After cyclization, filtration, and deprotection, $85.3 \mathrm{mg}$ of peptide was recovered.

Following purification by RP-HPLC SP 2 to 15, the pure fractions were pooled to afford $17.4 \mathrm{mg}$ of the title compound in $20 \%$ yield. ESI MS $[\mathrm{M}+\mathrm{H}]^{+}$expected: 581.4 , experimental: 581.4. LC/MS Method A retention time $3.703 \mathrm{~min} .{ }^{1} \mathrm{H}$ NMR $\left(\mathrm{CD}_{3} \mathrm{OD}, 400\right.$ $\mathrm{MHz}) \delta 4.34(\mathrm{dd}, J=9.1,4.9 \mathrm{~Hz}, 1 \mathrm{H}), 4.17-4.06(\mathrm{~m}, 2 \mathrm{H}), 3.91(\mathrm{t}, J=15.8 \mathrm{~Hz}, 2 \mathrm{H})$, $3.71(\mathrm{~d}, J=16.4 \mathrm{~Hz}, 1 \mathrm{H}), 3.54(\mathrm{~d}, J=16.2 \mathrm{~Hz}, 1 \mathrm{H}), 3.36(\mathrm{dd}, J=8.8,4.6 \mathrm{~Hz}, 1 \mathrm{H}), 3.00$ $(\mathrm{t}, J=6.0 \mathrm{~Hz}, 1 \mathrm{H}), 2.98-2.83(\mathrm{~m}, 4 \mathrm{H}), 2.20(\mathrm{td}, J=13.2,7.6 \mathrm{~Hz}, 1 \mathrm{H}), 2.04-1.82(\mathrm{~m}$, 2H), 1.69 (dddd, $J=22.3,20.6,8.5,4.7 \mathrm{~Hz}, 3 \mathrm{H}), 1.55$ (q, $J=5.5 \mathrm{~Hz}, 3 \mathrm{H}), 1.18$ (d, $J=$ $6.7 \mathrm{~Hz}, 3 \mathrm{H}), 0.87$ (dd, $J=7.7,6.2 \mathrm{~Hz}, 6 \mathrm{H})$.

\section{c*[PGLG-Dap]}

After cyclization, filtration, and deprotection, $78.9 \mathrm{mg}$ of peptide was recovered.

Following purification by RP-HPLC SP 2 to 15, the pure fractions were pooled to afford $11.8 \mathrm{mg}$ of the title compound in $14 \%$ yield. ESI MS [M+H] ${ }^{+}$expected: 567.4 , experimental: 567.4. LC/MS Method A retention time $3.876 \mathrm{~min} .{ }^{1} \mathrm{H}$ NMR $\left(\mathrm{CD}_{3} \mathrm{OD}, 400\right.$ MHz) $\delta 4.49(\mathrm{dd}, J=7.2,5.4 \mathrm{~Hz}, 1 \mathrm{H}), 4.28-4.18(\mathrm{~m}, 2 \mathrm{H}), 3.83(\mathrm{dt}, J=30.1,14.5 \mathrm{~Hz}$, $3 \mathrm{H}), 3.59(\mathrm{~d}, J=15.9 \mathrm{~Hz}, 1 \mathrm{H}), 3.35(\mathrm{ddd}, J=18.7,10.6,4.8 \mathrm{~Hz}, 2 \mathrm{H}), 3.15(\mathrm{dd}, J=13.2$, $7.4 \mathrm{~Hz}, 1 \mathrm{H}), 3.02-2.94(\mathrm{~m}, 2 \mathrm{H}), 2.04-1.96(\mathrm{~m}, 1 \mathrm{H}), 1.75-1.64(\mathrm{~m}, 3 \mathrm{H}), 1.63-1.52$ (m, 3H), $1.21(\mathrm{~d}, J=6.7 \mathrm{~Hz}, 3 \mathrm{H}), 0.87(\mathrm{dd}, J=5.8,4.2 \mathrm{~Hz}, 6 \mathrm{H})$.

\section{c*[PGLGo]}

After cyclization, filtration, and deprotection, $59.7 \mathrm{mg}$ of peptide was recovered. Following purification by RP-HPLC SP 2 to 12.5, the pure fractions were pooled to afford $3.8 \mathrm{mg}$ of the title compound in $4.2 \%$ yield. ESI MS $[\mathrm{M}+\mathrm{H}]^{+}$expected: 595.4 , experimental: 595.4. LC/MS Method A retention time $4.038 \mathrm{~min} .{ }^{1} \mathrm{H}$ NMR $\left(\mathrm{CD}_{3} \mathrm{OD}, 400\right.$ $\mathrm{MHz}) \delta 4.48(\mathrm{~s}, 3 \mathrm{H}), 4.32(\mathrm{~d}, J=9.0 \mathrm{~Hz}, 1 \mathrm{H}), 4.27-4.22(\mathrm{~m}, 1 \mathrm{H}), 4.10(\mathrm{~s}, 1 \mathrm{H}), 4.06-$ 
$4.00(\mathrm{~m}, 1 \mathrm{H}), 3.96(\mathrm{~d}, J=16.7 \mathrm{~Hz}, 1 \mathrm{H}), 3.58(\mathrm{~d}, J=16.6 \mathrm{~Hz}, 1 \mathrm{H}), 3.34$ (d, $J=4.2 \mathrm{~Hz}$, 1H), $3.04-2.97(\mathrm{~m}, 2 \mathrm{H}), 2.83$ (dd, $J=16.8,10.3 \mathrm{~Hz}, 3 \mathrm{H}), 2.42$ (s, 1H), 1.67 (ddd, $J=$ 37.1, 20.7, 10.7 Hz, 9H), $1.41(\mathrm{dd}, J=20.3,12.6 \mathrm{~Hz}, 2 \mathrm{H}), 1.29-1.21(\mathrm{~m}, 9 \mathrm{H}), 0.95$ $0.82(\mathrm{~m}, 6 \mathrm{H})$.

\section{c*[PGLGO]}

After cyclization, filtration, and deprotection, $84.2 \mathrm{mg}$ of peptide was recovered.

Following purification by RP-HPLC SP 2 to 15, the pure fractions were pooled to afford $9.1 \mathrm{mg}$ of the title compound in $10.2 \%$ yield. ESI MS $[\mathrm{M}+\mathrm{H}]^{+}$expected: 595.4 , experimental: 595.4. LC/MS Method A retention time $3.768 \mathrm{~min} .{ }^{1} \mathrm{H}$ NMR $\left(\mathrm{CD}_{3} \mathrm{OD}, 400\right.$ $\mathrm{MHz}) \delta 4.29-4.22(\mathrm{~m}, 1 \mathrm{H}), 4.17-4.06(\mathrm{~m}, 2 \mathrm{H}), 3.92(\mathrm{dd}, J=16.2,5.6 \mathrm{~Hz}, 2 \mathrm{H}), 3.72$ $(\mathrm{d}, J=16.4 \mathrm{~Hz}, 1 \mathrm{H}), 3.48(\mathrm{t}, J=11.1 \mathrm{~Hz}, 1 \mathrm{H}), 3.32(\mathrm{dd}, J=8.9,4.7 \mathrm{~Hz}, 1 \mathrm{H}), 3.05-2.98$ (m, 1H), $2.95(\mathrm{dd}, J=9.3,4.7 \mathrm{~Hz}, 2 \mathrm{H}), 2.86(\mathrm{dq}, J=15.7,6.3 \mathrm{~Hz}, 2 \mathrm{H}), 2.03-1.90$ (m, $2 \mathrm{H}), 1.79-1.52(\mathrm{~m}, 9 \mathrm{H}), 1.26(\mathrm{~s}, 9 \mathrm{H}), 1.20(\mathrm{dd}, J=11.9,4.6 \mathrm{~Hz}, 3 \mathrm{H}), 0.87(\mathrm{t}, J=6.3$ $\mathrm{Hz}, 6 \mathrm{H})$.

\section{c*[PGLOF $]$}

After cyclization, filtration, and deprotection, $89.7 \mathrm{mg}$ of peptide was recovered.

Following purification by RP-HPLC SP 15 to 25, the pure fractions were pooled to afford $8.4 \mathrm{mg}$ of the title compound in $8.2 \%$ yield. ESI MS $[\mathrm{M}+\mathrm{H}]^{+}$expected: 685.3 , experimental: 685.3. LC/MS Method A retention time 5.072 min. ${ }^{1} \mathrm{H}$ NMR $\left(\mathrm{CD}_{3} \mathrm{OD}, 400\right.$ MHz) $\delta 7.16-7.07(\mathrm{~m}, 5 \mathrm{H}), 4.34-4.26(\mathrm{~m}, 2 \mathrm{H}), 4.18(\mathrm{dd}, J=9.7,6.5 \mathrm{~Hz}, 1 \mathrm{H}), 3.77$ (dt, $J=14.4,11.3 \mathrm{~Hz}, 3 \mathrm{H}), 3.26(\mathrm{dd}, J=9.8,5.3 \mathrm{~Hz}, 1 \mathrm{H}), 3.14-3.02(\mathrm{~m}, 3 \mathrm{H}), 2.97-2.78$ $(\mathrm{m}, 3 \mathrm{H}), 2.70(\mathrm{t}, J=6.7 \mathrm{~Hz}, 2 \mathrm{H}), 1.66(\mathrm{ddt}, J=38.7,31.5,10.2 \mathrm{~Hz}, 9 \mathrm{H}), 1.51-1.36(\mathrm{~m}$, $4 \mathrm{H}), 1.28-1.21(\mathrm{~m}, 12 \mathrm{H}), 1.10(\mathrm{t}, J=7.1 \mathrm{~Hz}, 3 \mathrm{H}), 0.95-0.87(\mathrm{~m}, 6 \mathrm{H})$.

\section{c*[PGSGO]}

After cyclization, filtration, and deprotection, $68.6 \mathrm{mg}$ of peptide was recovered. Following purification by RP-HPLC SP 2 to 10, the pure fractions were pooled to afford $6.5 \mathrm{mg}$ of the title compound in $7.6 \%$ yield. ESI MS $[\mathrm{M}+\mathrm{H}]^{+}$expected: 569.3 , experimental: 569.3. LC/MS Method A retention time $3.289 \mathrm{~min} .{ }^{1} \mathrm{H}$ NMR $\left(\mathrm{CD}_{3} \mathrm{OD}, 400\right.$ 
MHz) $\delta 4.41(\mathrm{t}, J=3.3 \mathrm{~Hz}, 1 \mathrm{H}), 4.37-4.31(\mathrm{~m}, 1 \mathrm{H}), 4.20(\mathrm{dd}, J=9.7,6.7 \mathrm{~Hz}, 1 \mathrm{H}), 4.14$ (s, 1H), $4.07-4.00(\mathrm{~m}, 1 \mathrm{H}), 4.00-3.94(\mathrm{~m}, 1 \mathrm{H}), 3.87(\mathrm{dd}, J=11.1,3.2 \mathrm{~Hz}, 1 \mathrm{H}), 3.81-$ $3.75(\mathrm{~m}, 2 \mathrm{H}), 3.69$ (t, $J=11.3 \mathrm{~Hz}, 1 \mathrm{H}), 3.37-3.27(\mathrm{~m}, 1 \mathrm{H}), 3.10(\mathrm{~d}, J=9.7 \mathrm{~Hz}, 1 \mathrm{H})$, $3.06-2.91(\mathrm{~m}, 1 \mathrm{H}), 2.84(\mathrm{dd}, J=11.8,6.4 \mathrm{~Hz}, 2 \mathrm{H}), 2.08-1.46(\mathrm{~m}, 11 \mathrm{H}), 1.30-1.22$ $(\mathrm{m}, 13 \mathrm{H}), 1.20(\mathrm{~d}, J=6.6 \mathrm{~Hz}, 3 \mathrm{H})$.

\section{c*[PLKGF]}

After cyclization, filtration, and deprotection, $89.7 \mathrm{mg}$ of peptide was recovered.

Following purification by RP-HPLC SP 20 to 35, the pure fractions were pooled to afford $9.1 \mathrm{mg}$ of the title compound in $8.7 \%$ yield. ESI MS $[\mathrm{M}+\mathrm{H}]^{+}$expected: 699.4 , experimental: 699.4. LC/MS Method A retention time $5.613 \mathrm{~min} .{ }^{1} \mathrm{H}$ NMR $\left(\mathrm{CD}_{3} \mathrm{OD}, 400\right.$ MHz) $\delta 7.24-7.03(\mathrm{~m}, 5 \mathrm{H}), 4.39-4.14(\mathrm{~m}, 4 \mathrm{H}), 3.71$ (d, $J=15.3 \mathrm{~Hz}, 1 \mathrm{H}), 3.42-3.25$ (m, 3H), $3.01(\mathrm{dd}, J=11.5,8.6 \mathrm{~Hz}, 1 \mathrm{H}), 2.94(\mathrm{~d}, J=8.6 \mathrm{~Hz}, 1 \mathrm{H}), 2.79(\mathrm{dd}, J=15.7,8.5$ $\mathrm{Hz}, 3 \mathrm{H}), 1.86(\mathrm{dd}, J=14.1,7.6 \mathrm{~Hz}, 1 \mathrm{H}), 1.78-1.50(\mathrm{~m}, 9 \mathrm{H}), 1.30(\mathrm{~d}, J=6.7 \mathrm{~Hz}, 3 \mathrm{H})$, $1.24(\mathrm{~s}, 9 \mathrm{H}), 0.86(\mathrm{dd}, J=18.6,5.9 \mathrm{~Hz}, 6 \mathrm{H})$.

\section{c*[PLKGA]}

After cyclization, filtration, and deprotection, $72.0 \mathrm{mg}$ of peptide was recovered.

Following purification by RP-HPLC SP 15 to 25, the pure fractions were pooled to afford $6.9 \mathrm{mg}$ of the title compound in $7.4 \%$ yield. ESI MS $[\mathrm{M}+\mathrm{H}]^{+}$expected: 623.4 , experimental: 623.4. LC/MS Method A retention time $4.917 \mathrm{~min} .{ }^{1} \mathrm{H}$ NMR $\left(\mathrm{CD}_{3} \mathrm{OD}, 400\right.$ $\mathrm{MHz}) \delta 4.39-4.14(\mathrm{~m}, 4 \mathrm{H}), 3.80(\mathrm{~d}, J=19.1 \mathrm{~Hz}, 2 \mathrm{H}), 3.30-3.23(\mathrm{~m}, 2 \mathrm{H}), 3.14-3.00$ $(\mathrm{m}, 3 \mathrm{H}), 2.96-2.80(\mathrm{~m}, 2 \mathrm{H}), 2.70(\mathrm{t}, J=6.7 \mathrm{~Hz}, 2 \mathrm{H}), 1.99-1.90(\mathrm{~m}, 1 \mathrm{H}), 1.66$ (ddt, $J=$ $38.7,31.5,10.2 \mathrm{~Hz}, 9 \mathrm{H}), 1.43(\mathrm{dd}, J=12.7,8.7 \mathrm{~Hz}, 4 \mathrm{H}), 1.27-1.19(\mathrm{~m}, 12 \mathrm{H}), 1.10(\mathrm{t}, J$ $=7.1 \mathrm{~Hz}, 3 \mathrm{H}), 0.95-0.86(\mathrm{~m}, 7 \mathrm{H})$.

\section{am*[PGIGk]}

After cyclization, filtration, and deprotection, $63.1 \mathrm{mg}$ of peptide was recovered. Following purification by RP-HPLC SP 5 to 15, the pure fractions were pooled to afford $7.9 \mathrm{mg}$ of the title compound in $8.6 \%$ overall yield. ESI MS $[\mathrm{M}+\mathrm{H}]^{+}$expected: 609.4 , experimental: 609.4; $[\mathrm{M}+2 \mathrm{H}]^{2+}$ expected: 305.2, experimental: 305.2. ESI-TOF MS 
$[\mathrm{M}+2 \mathrm{H}]^{2+}$ expected: 305.2078, experimental: 305.2089. LC/MS Method A retention time $3.899 \min .{ }^{1} \mathrm{H} \mathrm{NMR}\left(\mathrm{CD}_{3} \mathrm{OD}, 400 \mathrm{MHz}\right) \delta 4.33(\mathrm{~d}, J=5.8 \mathrm{~Hz}, 1 \mathrm{H}), 4.15(\mathrm{t}, J=7.5 \mathrm{~Hz}$, 1H), 4.09 (d, $J=6.2 \mathrm{~Hz}, 1 \mathrm{H}), 4.04-3.88(\mathrm{~m}, 3 \mathrm{H}), 3.61-3.52(\mathrm{~m}, 1 \mathrm{H}), 3.32$ (d, $J=4.1$ $\mathrm{Hz}, 1 \mathrm{H}), 3.07-2.99(\mathrm{~m}, 1 \mathrm{H}), 2.81(\mathrm{t}, J=7.4 \mathrm{~Hz}, 2 \mathrm{H}), 2.69(\mathrm{~d}, J=6.1 \mathrm{~Hz}, 1 \mathrm{H}), 2.38$ (d, $J$ $=7.3 \mathrm{~Hz}, 1 \mathrm{H}), 1.90-1.72(\mathrm{~m}, 4 \mathrm{H}), 1.68-1.49(\mathrm{~m}, 6 \mathrm{H}), 1.25(\mathrm{~s}, 9 \mathrm{H}), 1.17(\mathrm{~d}, J=6.8 \mathrm{~Hz}$, $3 \mathrm{H}), 0.86(\mathrm{dd}, J=13.4,6.0 \mathrm{~Hz}, 6 \mathrm{H})$.

\section{am*[PGlk]}

After cyclization, filtration, and deprotection, $49.2 \mathrm{mg}$ of peptide was recovered.

Following purification by RP-HPLC SP 5 to 15 , the pure fractions were pooled to afford $4.9 \mathrm{mg}$ of the title compound in $5.9 \%$ overall yield. ESI MS $[\mathrm{M}+\mathrm{H}]^{+}$expected: 552.4 , experimental: 552.4; $[\mathrm{M}+2 \mathrm{H}]^{2+}$ expected: 276.7, experimental: 276.8. LC/MS Method A retention time $3.858 \mathrm{~min} .{ }^{1} \mathrm{H}$ NMR $\left(\mathrm{CD}_{3} \mathrm{OD}, 400 \mathrm{MHz}\right) \delta 4.21(\mathrm{dd}, J=8.8,6.0 \mathrm{~Hz}, 1 \mathrm{H})$, $4.10(\mathrm{ddd}, J=18.9,13.7,6.3 \mathrm{~Hz}, 4 \mathrm{H}), 3.96-3.88$ (m, 1H), 3.34 (d, $J=4.3 \mathrm{~Hz}, 1 \mathrm{H}), 3.02$ $(\mathrm{dd}, J=9.9,3.9 \mathrm{~Hz}, 1 \mathrm{H}), 2.81(\mathrm{t}, J=7.4 \mathrm{~Hz}, 2 \mathrm{H}), 2.71(\mathrm{~d}, J=5.8 \mathrm{~Hz}, 1 \mathrm{H}), 2.35(\mathrm{~s}, 1 \mathrm{H})$, $1.89-1.69(\mathrm{~m}, 4 \mathrm{H}), 1.67-1.50(\mathrm{~m}, 6 \mathrm{H}), 1.37-1.29(\mathrm{~m}, 2 \mathrm{H}), 1.25(\mathrm{~s}, 9 \mathrm{H}), 1.20(\mathrm{~d}, J=$ $6.8 \mathrm{~Hz}, 3 \mathrm{H}), 0.86(\mathrm{dd}, J=14.9,6.3 \mathrm{~Hz}, 6 \mathrm{H})$.

\section{am*[PGLK]}

After cyclization, filtration, and deprotection, $64.5 \mathrm{mg}$ of peptide was recovered.

Following purification by RP-HPLC SP 5 to 15, the pure fractions were pooled to afford $8.1 \mathrm{mg}$ of the title compound in $9.8 \%$ overall yield. ESI MS $[\mathrm{M}+\mathrm{H}]^{+}$expected: 552.4 , experimental: 552.4; [M+2H] ${ }^{2+}$ expected: 276.7, experimental: 276.6. ESI MS [M+H] $]^{+}$ expected: 552.3868, experimental: 552.3862. LC/MS Method A retention time 3.848 $\min .{ }^{1} \mathrm{H}$ NMR $\left(\mathrm{CD}_{3} \mathrm{OD}, 400 \mathrm{MHz}\right) \delta 4.34(\mathrm{dd}, J=9.6,5.3 \mathrm{~Hz}, 1 \mathrm{H}), 4.21(\mathrm{dd}, J=18.0$, $12.3 \mathrm{~Hz}, 3 \mathrm{H}), 4.10(\mathrm{~d}, J=17.4 \mathrm{~Hz}, 1 \mathrm{H}), 4.07-3.97(\mathrm{~m}, 1 \mathrm{H}), 3.46(\mathrm{~d}, J=4.3 \mathrm{~Hz}, 1 \mathrm{H})$, $3.15-3.08(\mathrm{~m}, 1 \mathrm{H}), 2.90(\mathrm{dd}, J=13.8,6.3 \mathrm{~Hz}, 2 \mathrm{H}), 2.88-2.80(\mathrm{~m}, 1 \mathrm{H}), 2.46(\mathrm{dd}, J=$ 15.6, 8.4 Hz, 1H), 1.89 (ddd, $J=21.8,15.7,6.5 \mathrm{~Hz}, 4 \mathrm{H}), 1.76-1.59$ (m, 6H), $1.49-1.38$ (m, 2H), $1.35(\mathrm{~m}), 0.96(\mathrm{dd}, J=18.2,6.2 \mathrm{~Hz}, 6 \mathrm{H})$.

\section{am*[PGlkF]}


After cyclization, filtration, and deprotection, $83.0 \mathrm{mg}$ of peptide was recovered.

Following purification by RP-HPLC SP 10 to 20, the pure fractions were pooled to afford $9.8 \mathrm{mg}$ of the title compound in $9.3 \%$ overall yield. ESI MS $[\mathrm{M}+\mathrm{H}]^{+}$expected: 699.4 , experimental: 699.4; $[\mathrm{M}+2 \mathrm{H}]^{2+}$ expected: 350.2, experimental: 350.2. LC/MS Method A retention time $4.606 \mathrm{~min} .{ }^{1} \mathrm{H} \mathrm{NMR}\left(\mathrm{CD}_{3} \mathrm{OD}, 400 \mathrm{MHz}\right) \delta 7.11(\mathrm{~d}, J=4.3 \mathrm{~Hz}, 4 \mathrm{H}), 7.04$ $(\mathrm{dd}, J=8.5,4.2 \mathrm{~Hz}, 1 \mathrm{H}), 4.34(\mathrm{dd}, J=9.1,4.0 \mathrm{~Hz}, 1 \mathrm{H}), 4.18(\mathrm{dd}, J=9.6,5.1 \mathrm{~Hz}, 2 \mathrm{H})$, $4.12(\mathrm{~d}, J=18.3 \mathrm{~Hz}, 2 \mathrm{H}), 3.87(\mathrm{dd}, J=6.7,4.4 \mathrm{~Hz}, 1 \mathrm{H}), 3.31(\mathrm{~d}, J=4.1 \mathrm{~Hz}, 1 \mathrm{H}), 3.13$ $(\mathrm{dd}, J=13.6,4.0 \mathrm{~Hz}, 1 \mathrm{H}), 3.05-2.98(\mathrm{~m}, 1 \mathrm{H}), 2.83(\mathrm{dd}, J=13.6,9.3 \mathrm{~Hz}, 1 \mathrm{H}), 2.75$ (ddd, $J=13.1,8.2,4.8 \mathrm{~Hz}, 2 \mathrm{H}), 2.69$ (s, 1H), 2.42 (s, 1H), $1.86-1.73$ (m, 4H), 1.68 1.59 (m, 1H), 1.49 (tdd $J=13.8,9.3,4.4 \mathrm{~Hz}, 5 \mathrm{H}), 1.29-1.22(\mathrm{~m}, 10 \mathrm{H}), 1.17$ (d, $J=6.8$ $\mathrm{Hz}, 3 \mathrm{H}), 0.87$ (dd, $J=12.9,6.5 \mathrm{~Hz}, 6 \mathrm{H})$.

\section{am*[PGlo]}

After cyclization, filtration, and deprotection, $60.0 \mathrm{mg}$ of peptide was recovered.

Following purification by RP-HPLC SP 2 to 15, the pure fractions were pooled to afford $4.8 \mathrm{mg}$ of the title compound in 5.9\% yield. ESI MS $[\mathrm{M}+\mathrm{H}]^{+}$expected: 538.4 , experimental: 538.4. LC/MS Method A retention time $3.957 \mathrm{~min} .{ }^{1} \mathrm{H}$ NMR $\left(\mathrm{CD}_{3} \mathrm{OD}, 400\right.$ $\mathrm{MHz}) \delta 4.24-4.17(\mathrm{~m}, 1 \mathrm{H}), 4.13(\mathrm{t}, J=8.5 \mathrm{~Hz}, 1 \mathrm{H}), 4.08(\mathrm{dd}, J=12.5,4.9 \mathrm{~Hz}, 3 \mathrm{H})$, $3.96-3.88(\mathrm{~m}, 1 \mathrm{H}), 3.35(\mathrm{~d}, J=4.2 \mathrm{~Hz}, 1 \mathrm{H}), 3.06-2.98(\mathrm{~m}, 1 \mathrm{H}), 2.87(\mathrm{dd}, J=12.7,7.2$ $\mathrm{Hz}, 2 \mathrm{H}), 2.71(\mathrm{dd}, J=14.2,8.4 \mathrm{~Hz}, 1 \mathrm{H}), 2.36(\mathrm{t}, J=8.8 \mathrm{~Hz}, 1 \mathrm{H}), 1.90-1.73(\mathrm{~m}, 4 \mathrm{H})$, $1.68-1.53(\mathrm{~m}, 6 \mathrm{H}), 1.25(\mathrm{~s}, 9 \mathrm{H}), 1.20(\mathrm{~d}, J=6.8 \mathrm{~Hz}, 3 \mathrm{H}), 0.87(\mathrm{dd}, J=15.0,6.4 \mathrm{~Hz}$, $6 \mathrm{H})$.

\section{am*[PGLo]}

After cyclization, filtration, and deprotection, $58.0 \mathrm{mg}$ of peptide was recovered.

Following purification by RP-HPLC SP 2 to 15, the pure fractions were pooled to afford $2.0 \mathrm{mg}$ of the title compound in $2.5 \%$ yield. ESI MS $[\mathrm{M}+\mathrm{H}]^{+}$expected: 538.4 , experimental: 538.4. LC/MS Method A retention time $4.002 \mathrm{~min}$.

\section{am*[PGIO]}


After cyclization, filtration, and deprotection, $130.0 \mathrm{mg}$ of peptide was recovered.

Following purification by RP-HPLC SP 5 to 15, the pure fractions were pooled to afford $7.5 \mathrm{mg}$ of the title compound in $9.3 \%$ yield. ESI MS $[\mathrm{M}+\mathrm{H}]^{+}$expected: 538.4 , experimental: 538.4. LC/MS Method A retention time $4.020 \mathrm{~min} .{ }^{1} \mathrm{H}$ NMR $\left(\mathrm{CD}_{3} \mathrm{OD}, 400\right.$ $\mathrm{MHz}) \delta 4.33(\mathrm{dd}, J=15.5,6.2 \mathrm{~Hz}, 1 \mathrm{H}), 4.28(\mathrm{t}, J=6.8 \mathrm{~Hz}, 1 \mathrm{H}), 4.12(\mathrm{t}, J=8.4 \mathrm{~Hz}, 1 \mathrm{H})$, $3.97-3.88(\mathrm{~m}, 1 \mathrm{H}), 3.78(\mathrm{~d}, J=17.2 \mathrm{~Hz}, 1 \mathrm{H}), 3.65-3.51(\mathrm{~m}, 2 \mathrm{H}), 3.36(\mathrm{t}, J=6.2 \mathrm{~Hz}$, $1 \mathrm{H}), 3.07-2.95(\mathrm{~m}, 1 \mathrm{H}), 2.87-2.76(\mathrm{~m}, 3 \mathrm{H}), 1.81-1.52(\mathrm{~m}, 9 \mathrm{H}), 1.40(\mathrm{dt}, J=15.9,7.8$ $\mathrm{Hz}, 2 \mathrm{H}), 1.25(\mathrm{~d}, J=9.3 \mathrm{~Hz}, 12 \mathrm{H}), 0.88(\mathrm{dq}, J=12.3,6.3 \mathrm{~Hz}, 6 \mathrm{H})$.

\section{am*[PGLO]}

After cyclization, filtration, and deprotection, $78.3 \mathrm{mg}$ of peptide was recovered.

Following purification by RP-HPLC SP 10 to 15, the pure fractions were pooled to afford $4.1 \mathrm{mg}$ of the title compound in $5.1 \%$ yield. ESI MS $[\mathrm{M}+\mathrm{H}]^{+}$expected: 538.4 , experimental: 538.4. LC/MS Method A retention time $4.042 \mathrm{~min} .{ }^{1} \mathrm{H}$ NMR $\left(\mathrm{CD}_{3} \mathrm{OD}, 400\right.$ $\mathrm{MHz}) \delta 4.28-4.20(\mathrm{~m}, 1 \mathrm{H}), 4.18-4.07(\mathrm{~m}, 3 \mathrm{H}), 4.01$ (d, J=17.4 Hz, 1H), $3.97-3.87$ (m, 1H), 3.37 (t, $J=4.3 \mathrm{~Hz}, 1 \mathrm{H}), 3.06-2.97(\mathrm{~m}, 1 \mathrm{H}), 2.92-2.82(\mathrm{~m}, 2 \mathrm{H}), 2.80-2.71$ (m, 1H), $2.36(\mathrm{dd}, J=13.1,5.8 \mathrm{~Hz}, 1 \mathrm{H}), 1.92-1.72(\mathrm{~m}, 4 \mathrm{H}), 1.70-1.52(\mathrm{~m}, 6 \mathrm{H}), 1.30-$ $1.18(\mathrm{~m}, 12 \mathrm{H}), 0.87(\mathrm{dd}, J=17.9,6.3 \mathrm{~Hz}, 6 \mathrm{H})$.

\section{am*[PGloF $]$}

After cyclization, filtration, and deprotection, $89.8 \mathrm{mg}$ of peptide was recovered.

Following purification by RP-HPLC SP 15 to 30, the pure fractions were pooled to afford $2.5 \mathrm{mg}$ of the title compound in $2.4 \%$ yield. ESI MS $[\mathrm{M}+\mathrm{H}]^{+}$expected: 685.4 , experimental: 685.4. LC/MS Method A retention time 5.015 min. ${ }^{1} \mathrm{H}$ NMR $\left(\mathrm{CD}_{3} \mathrm{OD}, 400\right.$ $\mathrm{MHz}) \delta 7.21-6.96(\mathrm{~m}, 5 \mathrm{H}), 4.34(\mathrm{dd}, J=9.3,3.9 \mathrm{~Hz}, 1 \mathrm{H}), 4.21-4.08(\mathrm{~m}, 3 \mathrm{H}), 3.92-$ $3.84(\mathrm{~m}, 1 \mathrm{H}), 3.35-3.27(\mathrm{~m}, 1 \mathrm{H}), 3.14(\mathrm{dd}, J=13.5,3.9 \mathrm{~Hz}, 1 \mathrm{H}), 3.06-2.97(\mathrm{~m}, 1 \mathrm{H})$, $2.82-2.67(\mathrm{~m}, 3 \mathrm{H}), 1.94-1.37(\mathrm{~m}, 11 \mathrm{H}), 1.32-1.18(\mathrm{~m}, 10 \mathrm{H}), 1.14(\mathrm{t}, J=14.7 \mathrm{~Hz}$, $2 \mathrm{H}), 0.94-0.79(\mathrm{~m}, 6 \mathrm{H})$.

\section{$\mathbf{a m} *[\mathbf{P l k F}]$}


After cyclization, filtration, and deprotection, $40.3 \mathrm{mg}$ of peptide was recovered.

Following purification by RP-HPLC SP 15 to 30, the pure fractions were pooled to afford $6.3 \mathrm{mg}$ of the title compound in $6.5 \%$ yield. ESI MS $[\mathrm{M}+\mathrm{H}]^{+}$expected: 642.4 , experimental: 642.4. LC/MS Method A retention time $5.185 \mathrm{~min} .{ }^{1} \mathrm{H}$ NMR $\left(\mathrm{CD}_{3} \mathrm{OD}, 400\right.$ MHz) $\delta 7.27-6.96(\mathrm{~m}, 5 \mathrm{H}), 4.43(\mathrm{dd}, J=10.2,3.9 \mathrm{~Hz}, 1 \mathrm{H}), 4.37(\mathrm{dd}, J=8.3,4.8 \mathrm{~Hz}$, $1 \mathrm{H}), 4.24(\mathrm{dd}, J=7.6,5.8 \mathrm{~Hz}, 1 \mathrm{H}), 4.11(\mathrm{t}, J=8.3 \mathrm{~Hz}, 1 \mathrm{H}), 3.97-3.85(\mathrm{~m}, 1 \mathrm{H}), 3.33(\mathrm{~d}$, $J=4.1 \mathrm{~Hz}, 1 \mathrm{H}), 3.15(\mathrm{dd}, J=13.9,4.7 \mathrm{~Hz}, 1 \mathrm{H}), 3.01(\mathrm{dd}, J=13.1,6.8 \mathrm{~Hz}, 1 \mathrm{H}), 2.89-$ $2.75(\mathrm{~m}, 2 \mathrm{H}), 2.72(\mathrm{dd}, J=14.4,6.9 \mathrm{~Hz}, 2 \mathrm{H}), 2.40(\mathrm{~s}, 1 \mathrm{H}), 1.84(\mathrm{~d}, J=4.8 \mathrm{~Hz}, 1 \mathrm{H}), 1.79$ $-1.61(\mathrm{~m}, 4 \mathrm{H}), 1.55(\mathrm{dd}, J=12.0,7.6 \mathrm{~Hz}, 2 \mathrm{H}), 1.43$ (dt, $J=15.5,7.7 \mathrm{~Hz}, 3 \mathrm{H}), 1.23$ (d, $J$ $=3.4 \mathrm{~Hz}, 10 \mathrm{H}), 1.11(\mathrm{dd}, J=15.6,7.9 \mathrm{~Hz}, 2 \mathrm{H}), 0.85(\mathrm{dd}, J=14.7,6.4 \mathrm{~Hz}, 5 \mathrm{H})$.

\section{am*[PLKF $]$}

After cyclization, filtration, and deprotection, $85.8 \mathrm{mg}$ of peptide was recovered.

Following purification by RP-HPLC SP 20 to 30, the pure fractions were pooled to afford $2.7 \mathrm{mg}$ of the title compound in $2.8 \%$ yield. ESI MS $[\mathrm{M}+\mathrm{H}]^{+}$expected: 642.4 , experimental: 642.4. LC/MS Method A retention time $5.502 \mathrm{~min} .{ }^{1} \mathrm{H}$ NMR $\left(\mathrm{CD}_{3} \mathrm{OD}, 400\right.$ MHz) $\delta 4.50(\mathrm{dd}, J=8.0,5.0 \mathrm{~Hz}, 1 \mathrm{H}), 4.32-4.24(\mathrm{~m}, 1 \mathrm{H}), 4.21(\mathrm{t}, J=7.3 \mathrm{~Hz}, 1 \mathrm{H}), 4.07$ $(\mathrm{t}, J=8.6 \mathrm{~Hz}, 1 \mathrm{H}), 3.92(\mathrm{dd}, J=6.8,4.1 \mathrm{~Hz}, 1 \mathrm{H}), 3.36(\mathrm{~d}, J=4.0 \mathrm{~Hz}, 1 \mathrm{H}), 3.06(\mathrm{ddd}, J=$ 14.0, 11.7, $5.9 \mathrm{~Hz}, 2 \mathrm{H}), 2.89$ (dd, $J=13.9,8.1 \mathrm{~Hz}, 1 \mathrm{H}), 2.80$ (t, $J=7.5 \mathrm{~Hz}, 3 \mathrm{H}), 2.38$ (dd, $J=15.3,9.7 \mathrm{~Hz}, 1 \mathrm{H}), 1.85(\mathrm{~s}, 1 \mathrm{H}), 1.81-1.47(\mathrm{~m}, 9 \mathrm{H}), 1.36(\mathrm{dt}, J=15.3,8.2 \mathrm{~Hz}, 2 \mathrm{H})$, $1.28-1.24(\mathrm{~m}, 3 \mathrm{H}), 1.23(\mathrm{~s}, 8 \mathrm{H}), 0.85(\mathrm{dd}, J=25.3,6.5 \mathrm{~Hz}, 6 \mathrm{H})$.

\section{am*[PlkG]}

After cyclization, filtration, and deprotection $68.0 \mathrm{mg}$ of peptide was recovered.

Following purification by RP-HPLC SP 10 to 15, the pure fractions were pooled to afford $5.1 \mathrm{mg}$ of the title compound in $6.1 \%$ yield. ESI MS $[\mathrm{M}+\mathrm{H}]^{+}$expected: 552.3 , experimental: 552.3. LC/MS Method A retention time 4.282 min. ${ }^{1} \mathrm{H}$ NMR $\left(\mathrm{CD}_{3} \mathrm{OD}, 400\right.$ MHz) $\delta 4.37-4.32(\mathrm{~m}, 1 \mathrm{H}), 4.28(\mathrm{t}, J=6.8 \mathrm{~Hz}, 1 \mathrm{H}), 4.12(\mathrm{t}, J=8.4 \mathrm{~Hz}, 1 \mathrm{H}), 3.96-3.87$ $(\mathrm{m}, 1 \mathrm{H}), 3.78(\mathrm{~d}, J=17.2 \mathrm{~Hz}, 1 \mathrm{H}), 3.55(\mathrm{dd}, J=14.8,9.9 \mathrm{~Hz}, 1 \mathrm{H}), 3.36(\mathrm{t}, J=6.2 \mathrm{~Hz}$, $1 \mathrm{H}), 3.04-2.98(\mathrm{~m}, 1 \mathrm{H}), 2.88-2.74(\mathrm{~m}, 3 \mathrm{H}), 2.42(\mathrm{~s}, 1 \mathrm{H}), 1.80-1.50(\mathrm{~m}, 9 \mathrm{H}), 1.40(\mathrm{dt}$, $J=15.9,7.8 \mathrm{~Hz}, 3 \mathrm{H}), 1.25(\mathrm{~d}, J=9.3 \mathrm{~Hz}, 12 \mathrm{H}), 0.93-0.83(\mathrm{~m}, 6 \mathrm{H})$. 


\section{am*[PLKG]}

After cyclization, filtration, and deprotection, $85.3 \mathrm{mg}$ of peptide was recovered.

Following purification by RP-HPLC SP 5 to 15, the pure fractions were pooled to afford $1.4 \mathrm{mg}$ of the title compound in $1.7 \%$ overall yield. ESI MS $[\mathrm{M}+\mathrm{H}]^{+}$expected: 552.4 , experimental: 552.4. LC/MS Method A retention time 4.073 min. ${ }^{1} \mathrm{H}$ NMR $\left(\mathrm{CD}_{3} \mathrm{OD}, 400\right.$ $\mathrm{MHz}) \delta 4.48(\mathrm{~d}, J=6.7 \mathrm{~Hz}, 1 \mathrm{H}), 4.42(\mathrm{t}, J=7.2 \mathrm{~Hz}, 1 \mathrm{H}), 4.20(\mathrm{t}, J=8.7 \mathrm{~Hz}, 1 \mathrm{H}), 4.06$ $(\mathrm{dd}, J=6.7,4.1 \mathrm{~Hz}, 1 \mathrm{H}), 3.87(\mathrm{~d}, J=17.1 \mathrm{~Hz}, 1 \mathrm{H}), 3.63(\mathrm{~d}, J=17.2 \mathrm{~Hz}, 1 \mathrm{H}), 3.51-3.44$ (m, 1H), $3.16(\mathrm{~s}, 1 \mathrm{H}), 3.02-2.87(\mathrm{~m}, 3 \mathrm{H}), 2.50(\mathrm{~s}, 1 \mathrm{H}), 2.10-1.63(\mathrm{~m}, 9 \mathrm{H}), 1.62-1.50$ $(\mathrm{m}, 2 \mathrm{H}), 1.42-1.27(\mathrm{~m}, 10 \mathrm{H}), 1.03(\mathrm{~d}, J=6.5 \mathrm{~Hz}, 3 \mathrm{H}), 0.97(\mathrm{~d}, J=6.4 \mathrm{~Hz}, 3 \mathrm{H})$.

\section{am*[PlkGA]}

After cyclization, filtration, and deprotection, $69.4 \mathrm{mg}$ of peptide was recovered.

Following purification by RP-HPLC SP 15 to 25, the pure fractions were pooled to afford $1.0 \mathrm{mg}$ of the title compound in $1.1 \%$ yield. ESI MS $[\mathrm{M}+\mathrm{H}]^{+}$expected: 623.4 ,

experimental: 623.4. LC/MS Method A retention time $4.902 \mathrm{~min} .{ }^{1} \mathrm{H}$ NMR $\left(\mathrm{CD}_{3} \mathrm{OD}, 400\right.$ $\mathrm{MHz}) \delta 4.48(\mathrm{~s}, 3 \mathrm{H}), 4.32(\mathrm{~d}, J=9.0 \mathrm{~Hz}, 1 \mathrm{H}), 4.27-4.22(\mathrm{~m}, 1 \mathrm{H}), 4.10(\mathrm{~s}, 1 \mathrm{H}), 4.06-$ $4.00(\mathrm{~m}, 1 \mathrm{H}), 3.96(\mathrm{~d}, J=16.7 \mathrm{~Hz}, 1 \mathrm{H}), 3.58(\mathrm{~d}, J=16.6 \mathrm{~Hz}, 1 \mathrm{H}), 3.34$ (d, $J=4.2 \mathrm{~Hz}$, 1H), $3.04-2.97(\mathrm{~m}, 2 \mathrm{H}), 2.83(\mathrm{dd}, J=16.8,10.3 \mathrm{~Hz}, 3 \mathrm{H}), 2.42(\mathrm{~s}, 1 \mathrm{H}), 1.67$ (ddd, $J=$ $37.1,20.7,10.7 \mathrm{~Hz}, 9 \mathrm{H}), 1.41$ (dd, $J=20.3,12.6 \mathrm{~Hz}, 2 \mathrm{H}), 1.29-1.21(\mathrm{~m}, 12 \mathrm{H}), 0.95-$ $0.82(\mathrm{~m}, 6 \mathrm{H})$.

\section{am*[PlkGF]}

After cyclization, filtration, and deprotection, $86.2 \mathrm{mg}$ of peptide was recovered.

Following purification by RP-HPLC SP 15 to 30, the pure fractions were pooled to afford $3.7 \mathrm{mg}$ of the title compound in $3.5 \%$ yield. ESI MS $[\mathrm{M}+\mathrm{H}]^{+}$expected: 699.4 , experimental: 699.4. LC/MS Method A retention time 5.141 min. ${ }^{1} \mathrm{H}$ NMR $\left(\mathrm{CD}_{3} \mathrm{OD}, 400\right.$ MHz) $\delta 7.22-6.94(\mathrm{~m}, 5 \mathrm{H}), 4.40(\mathrm{~d}, J=9.8 \mathrm{~Hz}, 1 \mathrm{H}), 4.36-4.27(\mathrm{~m}, 1 \mathrm{H}), 4.16(\mathrm{t}, J=$ $6.9 \mathrm{~Hz}, 1 \mathrm{H}), 4.11(\mathrm{~d}, J=8.3 \mathrm{~Hz}, 1 \mathrm{H}), 4.01(\mathrm{~d}, J=16.8 \mathrm{~Hz}, 1 \mathrm{H}), 3.91(\mathrm{dd}, J=6.7,4.3 \mathrm{~Hz}$, $1 \mathrm{H}), 3.48(\mathrm{~d}, J=16.9 \mathrm{~Hz}, 1 \mathrm{H}), 3.33(\mathrm{~d}, J=4.2 \mathrm{~Hz}, 1 \mathrm{H}), 3.12(\mathrm{dd}, J=13.6,4.6 \mathrm{~Hz}, 1 \mathrm{H})$, $3.00(\mathrm{~d}, J=6.9 \mathrm{~Hz}, 1 \mathrm{H}), 2.92(\mathrm{dd}, J=13.5,6.3 \mathrm{~Hz}, 1 \mathrm{H}), 2.80-2.73(\mathrm{~m}, 1 \mathrm{H}), 2.68(\mathrm{dt}, J$ 
$=12.9,6.6 \mathrm{~Hz}, 1 \mathrm{H}), 2.53-2.37(\mathrm{~m}, 2 \mathrm{H}), 1.79-1.40(\mathrm{~m}, 9 \mathrm{H}), 1.25(\mathrm{~d}, J=9.7 \mathrm{~Hz}, 12 \mathrm{H})$, $0.88(\mathrm{dd}, J=13.8,6.0 \mathrm{~Hz}, 6 \mathrm{H})$.

\section{am*[PGAo]}

Following purification in three parts by RP-HPLC SP 10 to 25 , the pure fractions were pooled to afford $0.7 \mathrm{mg}$ of the title compound in $0.8 \%$ overall yield. ESI MS $[\mathrm{M}+\mathrm{H}]^{+}$ expected: 496.3, experimental: 496.3; $[\mathrm{M}+2 \mathrm{H}]^{2+}$ expected: 248.7 , experimental: 248.7 . LC/MS Method A retention time $3.072 \mathrm{~min}$. LC/MS Method Iso 10 retention time 2.75 $\min$.

\section{am*[PGDo]}

Following purification in three parts by RP-HPLC SP 10 to 25 , the pure fractions were pooled to afford $10.3 \mathrm{mg}$ of the title compound in $10.9 \%$ overall yield. ESI MS $[\mathrm{M}+\mathrm{H}]^{+}$ expected: 540.3, experimental: 540.4; $[\mathrm{M}+2 \mathrm{H}]^{2+}$ expected: 270.7 , experimental: 270.6 . LC/MS Method A retention time $3.054 \mathrm{~min}$. LC/MS Method Iso 15 retention time 2.706 min. ${ }^{1} \mathrm{H}$ NMR (CD $\left.3 \mathrm{OD}, 400 \mathrm{MHz}\right) \delta 4.65(\mathrm{t}, J=6.4 \mathrm{~Hz}, 1 \mathrm{H}), 4.18(\mathrm{~s}, 1 \mathrm{H}), 4.14(\mathrm{~m}, 1 \mathrm{H})$, $4.10-3.94$ (m, 2H), $3.94-3.87$ (m, 1H), 3.35 (d, $J=4.3 \mathrm{~Hz}, 1 \mathrm{H}), 3.01$ (t, $J=7.6 \mathrm{~Hz}$, $1 \mathrm{H}), 2.82(\mathrm{~m}, 2 \mathrm{H}), 2.74(\mathrm{~m}, 1 \mathrm{H}), 2.67-2.56(\mathrm{~m}, 2 \mathrm{H}), 2.37(\mathrm{q}, J=9.0,8.2 \mathrm{~Hz}, 1 \mathrm{H}), 1.92$ $-1.72(\mathrm{~m}, 4 \mathrm{H}), 1.62(\mathrm{~m}, 3 \mathrm{H}), 1.25(\mathrm{~s}, 9 \mathrm{H}), 1.22(\mathrm{~d}, J=6.8 \mathrm{~Hz}, 3 \mathrm{H})$.

\section{am*[PGFo]}

Following purification in three parts by RP-HPLC SP 10 to 25 , the pure fractions were pooled to afford $7.4 \mathrm{mg}$ of the title compound in $7.4 \%$ overall yield. ESI MS $[\mathrm{M}+\mathrm{H}]^{+}$ expected: 572.4, experimental: 572.4; $[\mathrm{M}+2 \mathrm{H}]^{2+}$ expected: 286.7 , experimental: 286.8 . LC/MS Method A retention time 4.267 min. LC/MS Method Iso 15 retention time 4.494 min. ${ }^{1} \mathrm{H}$ NMR (CD $\left.3 \mathrm{OD}, 400 \mathrm{MHz}\right) \delta 7.27-7.03(\mathrm{~m}, 5 \mathrm{H}), 4.61(\mathrm{dd}, J=9.0,6.2 \mathrm{~Hz}, 1 \mathrm{H})$, $4.14-4.03(\mathrm{~m}, 2 \mathrm{H}), 4.03-3.88(\mathrm{~m}, 2 \mathrm{H}), 3.87(\mathrm{~m}, 1 \mathrm{H}), 3.35(\mathrm{~d}, J=4.2 \mathrm{~Hz}, 1 \mathrm{H}), 3.10$ (dd, $J=13.8,6.2 \mathrm{~Hz}, 1 \mathrm{H}), 3.01(\mathrm{~m}, 1 \mathrm{H}), 2.88(\mathrm{dd}, J=13.8,9.1 \mathrm{~Hz}, 1 \mathrm{H}), 2.76(\mathrm{~m}, 3 \mathrm{H})$, $2.32(\mathrm{~m}, 1 \mathrm{H}), 1.86-1.62(\mathrm{~m}, 4 \mathrm{H}), 1.54(\mathrm{~m}, 1 \mathrm{H}), 1.42(\mathrm{~m}, 2 \mathrm{H}), 1.25(\mathrm{~s}, 9 \mathrm{H}), 1.22(\mathrm{~d}, J=$ $6.8 \mathrm{~Hz}, 3 \mathrm{H})$. 


\section{am*[PGI-D-Dab]}

The synthesis was performed at $0.1 \mathrm{mmol}$ scale in peptide. Following purification in three parts by RP-HPLC SP 5 to 10, the pure fractions were pooled to afford $1.2 \mathrm{mg}$ of

the title compound in $2.3 \%$ overall yield. ESI MS $[\mathrm{M}+\mathrm{H}]^{+}$expected: 524.3, experimental: 524.4. LC/MS Method B retention time $2.923 \mathrm{~min} .{ }^{1} \mathrm{H}$ NMR $\left(\mathrm{CD}_{3} \mathrm{OD}, 500 \mathrm{MHz}\right) \delta 4.40$ - $4.36(\mathrm{~m}, 1 \mathrm{H}), 4.31$ (d, J=7.2 Hz, 1H), $4.24-4.06$ (m, 3H), 4.03 - 3.96 (m, 1H), 3.49 $3.44(\mathrm{~m}, 1 \mathrm{H}), 3.11(\mathrm{t}, J=7.3 \mathrm{~Hz}, 1 \mathrm{H}), 3.06-2.99(\mathrm{~m}, 2 \mathrm{H}), 2.90-2.82(\mathrm{~m}, 1 \mathrm{H}), 2.50-$ $2.43(\mathrm{~m}, 1 \mathrm{H}), 2.19(\mathrm{dq}, J=14.1,7.1 \mathrm{~Hz}, 1 \mathrm{H}), 2.09-1.81(\mathrm{~m}, 4 \mathrm{H}), 1.57$ (ddd, $J=13.6$, 7.6, $3.5 \mathrm{~Hz}, 1 \mathrm{H}), 1.35$ (s, 9H), 1.32 (d, $J=6.8 \mathrm{~Hz}, 3 \mathrm{H}), 1.26-1.17(\mathrm{~m}, 1 \mathrm{H}), 1.03-0.89$ $(\mathrm{m}, 6 \mathrm{H})$.

\section{am*[PGIo]}

Following purification in three parts by RP-HPLC SP 10 to 25, the pure fractions were pooled to afford $5.3 \mathrm{mg}$ of the title compound in $5.6 \%$ overall yield. ESI MS $[\mathrm{M}+\mathrm{H}]^{+}$ expected: 538.4, experimental: 538.4; $[\mathrm{M}+2 \mathrm{H}]^{2+}$ expected: 269.7, experimental: 269.8 . LC/MS Method A retention time 3.966 min. LC/MS Method Iso 15 retention time 3.486 $\min .{ }^{1} \mathrm{H}$ NMR $\left(\mathrm{CD}_{3} \mathrm{OD}, 400 \mathrm{MHz}\right) \delta 4.32(\mathrm{~d}, J=7.6 \mathrm{~Hz}, 1 \mathrm{H}), 4.28-4.05(\mathrm{~m}, 4 \mathrm{H}), 4.02$ $(\mathrm{m}, 1 \mathrm{H}), 3.48(\mathrm{~d}, J=4.3 \mathrm{~Hz}, 1 \mathrm{H}), 3.13(\mathrm{dd}, J=8.8,6.2 \mathrm{~Hz}, 1 \mathrm{H}), 2.98(\mathrm{t}, J=7.0 \mathrm{~Hz}, 2 \mathrm{H})$, $2.88(\mathrm{td}, J=9.1,5.4 \mathrm{~Hz}, 1 \mathrm{H}), 2.49(\mathrm{~m}, 1 \mathrm{H}), 1.93(\mathrm{~m}, 4 \mathrm{H}), 1.75(\mathrm{~m}, 3 \mathrm{H}), 1.64-1.51(\mathrm{~m}$, $1 \mathrm{H}), 1.37(\mathrm{~s}, 9 \mathrm{H}), 1.35(\mathrm{~d}, J=6.8 \mathrm{~Hz}, 3 \mathrm{H}), 1.24(\mathrm{ddd}, J=13.8,9.2,7.1 \mathrm{~Hz}, 1 \mathrm{H}), 1.03-$ $0.88(\mathrm{~m}, 6 \mathrm{H})$.

\section{am*[PGLd]}

Following purification in three parts by RP-HPLC SP 10 to 30, the pure fractions were pooled to afford $6.9 \mathrm{mg}$ of the title compound in $7.9 \%$ overall yield. ESI MS $[\mathrm{M}+\mathrm{H}]^{+}$ expected: 539.3, experimental: 539.4. LC/MS Method A retention time $4.479 \mathrm{~min}$. LC/MS Method Iso 15 retention time $5.694 \mathrm{~min} .{ }^{1} \mathrm{H}$ NMR $\left(\mathrm{CD}_{3} \mathrm{OD}, 400 \mathrm{MHz}\right) \delta 4.48(\mathrm{t}$, $J=5.8 \mathrm{~Hz}, 1 \mathrm{H}), 4.40-4.31(\mathrm{~m}, 1 \mathrm{H}), 4.16-4.05(\mathrm{~m}, 2 \mathrm{H}), 4.03-3.88(\mathrm{~m}, 2 \mathrm{H}), 3.36(\mathrm{~d}, J$ $=4.3 \mathrm{~Hz}, 1 \mathrm{H}), 3.00(\mathrm{ddd}, J=9.1,6.6,2.2 \mathrm{~Hz}, 1 \mathrm{H}), 2.76(\mathrm{td}, J=9.1,5.2 \mathrm{~Hz}, 1 \mathrm{H}), 2.69$ $(\mathrm{dd}, J=5.8,3.4 \mathrm{~Hz}, 2 \mathrm{H}), 2.43-2.31(\mathrm{~m}, 1 \mathrm{H}), 1.85(\mathrm{dtd}, J=8.9,6.3,4.9,2.6 \mathrm{~Hz}, 2 \mathrm{H})$, 
$1.81-1.70(\mathrm{~m}, 1 \mathrm{H}), 1.61(\mathrm{dd}, J=13.2,6.5 \mathrm{~Hz}, 1 \mathrm{H}), 1.57-1.49(\mathrm{~m}, 2 \mathrm{H}), 1.25(\mathrm{~s}, 9 \mathrm{H})$, $1.23(\mathrm{~d}, J=7.0 \mathrm{~Hz}, 3 \mathrm{H}), 0.85(\mathrm{dd}, J=14.6,6.2 \mathrm{~Hz}, 6 \mathrm{H})$.

\section{am*[PGL-D-Dab]}

Following purification in three parts by RP-HPLC SP 5 to 20, the pure fractions were pooled to afford $3.5 \mathrm{mg}$ of the title compound in $3.8 \%$ overall yield. ESI MS $[\mathrm{M}+\mathrm{H}]^{+}$ expected: 524.4, experimental: 524.4. LC/MS Method A retention time $4.029 \mathrm{~min}$. LC/MS Method Iso 15 retention time $3.638 \mathrm{~min} .{ }^{1} \mathrm{H}$ NMR $\left(\mathrm{CD}_{3} \mathrm{OD}, 400 \mathrm{MHz}\right) \delta 4.49(\mathrm{t}$, $J=7.2 \mathrm{~Hz}, 1 \mathrm{H}), 4.28-4.10(\mathrm{~m}, 4 \mathrm{H}), 4.03(\mathrm{qd}, J=6.7,4.1 \mathrm{~Hz}, 1 \mathrm{H}), 3.49(\mathrm{~d}, J=4.2 \mathrm{~Hz}$, $1 \mathrm{H}), 3.19-3.11(\mathrm{~m}, 1 \mathrm{H}), 3.07-2.98(\mathrm{~m}, 2 \mathrm{H}), 2.94-2.84(\mathrm{~m}, 1 \mathrm{H}), 2.56-2.43(\mathrm{~m}, 1 \mathrm{H})$, $2.21-2.09(\mathrm{~m}, 1 \mathrm{H}), 1.94(\mathrm{ddt}, J=35.3,16.3,6.7 \mathrm{~Hz}, 4 \mathrm{H}), 1.71(\mathrm{t}, J=5.7 \mathrm{~Hz}, 3 \mathrm{H}), 1.37$ (m, $12 \mathrm{H}), 1.08-0.86(\mathrm{~m}, 6 \mathrm{H})$.

\section{am*[PGL-D-Dap]}

Following purification in three parts by RP-HPLC SP 5 to 20, the pure fractions were pooled to afford $0.8 \mathrm{mg}$ of the title compound in $1.0 \%$ overall yield. ESI MS $[\mathrm{M}+\mathrm{H}]^{+}$ expected: 510.3, experimental: 510.4. LC/MS Method A retention time $4.121 \mathrm{~min} .{ }^{1} \mathrm{H}$ NMR ( $\left.\mathrm{CD}_{3} \mathrm{OD}, 399 \mathrm{MHz}\right) \delta 4.50(\mathrm{t}, J=7.0 \mathrm{~Hz}, 1 \mathrm{H}), 4.27(\mathrm{t}, J=6.8 \mathrm{~Hz}, 1 \mathrm{H}), 4.25-4.05$ (m, 3H), $4.04-3.97(\mathrm{~m}, 1 \mathrm{H}), 3.46(\mathrm{~d}, J=4.3 \mathrm{~Hz}, 1 \mathrm{H}), 3.21-3.06(\mathrm{~m}, 3 \mathrm{H}), 2.92-2.80$ (m, 1H), $2.52-2.41(\mathrm{~m}, 1 \mathrm{H}), 1.99-1.80(\mathrm{~m}, 3 \mathrm{H}), 1.74-1.64(\mathrm{~m}, 3 \mathrm{H}), 1.35(\mathrm{~s}, 9 \mathrm{H}), 1.31$ $(\mathrm{d}, J=3.3 \mathrm{~Hz}, 3 \mathrm{H}), 0.96(\mathrm{dd}, J=17.4,6.0 \mathrm{~Hz}, 6 \mathrm{H})$.

\section{am*[PGLe]}

Following purification in three parts by RP-HPLC SP 10 to 25 , the pure fractions were pooled to afford $4.9 \mathrm{mg}$ of the title compound in $5.5 \%$ overall yield. ESI MS $[\mathrm{M}+\mathrm{H}]^{+}$ expected: 553.3, experimental: 553.4. LC/MS Method A retention time $4.561 \mathrm{~min}$. LC/MS Method Iso 15 retention time $6.516 \mathrm{~min} .{ }^{1} \mathrm{H}$ NMR $\left(\mathrm{CD}_{3} \mathrm{OD}, 400 \mathrm{MHz}\right) \delta 4.34$ $(\mathrm{dd}, J=8.6,6.1 \mathrm{~Hz}, 1 \mathrm{H}), 4.25-4.14(\mathrm{~m}, 2 \mathrm{H}), 4.10$ (t, $J=8.1 \mathrm{~Hz}, 1 \mathrm{H}), 4.00(\mathrm{~d}, J=17.5$ $\mathrm{Hz}, 1 \mathrm{H}), 3.90$ (qd, $J=6.7,4.1 \mathrm{~Hz}, 1 \mathrm{H}), 3.35$ (dd, $J=4.3,1.0 \mathrm{~Hz}, 1 \mathrm{H}$ ), 3.01 (ddd, $J=8.9$, 6.4, $1.8 \mathrm{~Hz}, 1 \mathrm{H}), 2.75(\mathrm{td}, J=9.2,5.1 \mathrm{~Hz}, 1 \mathrm{H}), 2.35(\mathrm{ddd}, J=13.4,11.2,5.8 \mathrm{~Hz}, 1 \mathrm{H})$, $2.27(\mathrm{td}, J=7.1,3.6 \mathrm{~Hz}, 2 \mathrm{H}), 2.05(\mathrm{dtd}, J=14.4,7.3,4.5 \mathrm{~Hz}, 1 \mathrm{H}), 1.96-1.81(\mathrm{~m}, 3 \mathrm{H})$, 
$1.76(\mathrm{ddd}, J=13.8,10.0,7.2 \mathrm{~Hz}, 1 \mathrm{H}), 1.66-1.52(\mathrm{~m}, 3 \mathrm{H}), 1.25(\mathrm{~s}, 9 \mathrm{H}), 1.22(\mathrm{~d}, J=6.8$ $\mathrm{Hz}, 3 \mathrm{H}), 0.90-0.80(\mathrm{~m}, 6 \mathrm{H})$.

\section{am*[PGLk]}

Following purification in three parts by RP-HPLC SP 5 to 20, the pure fractions were pooled to afford $3.3 \mathrm{mg}$ of the title compound in $3.4 \%$ overall yield. ESI MS $[\mathrm{M}+\mathrm{H}]^{+}$ expected: 552.4, experimental: 552.4. LC/MS Method A retention time $4.115 \mathrm{~min} .{ }^{1} \mathrm{H}$ NMR ( $\left.\mathrm{CD}_{3} \mathrm{OD}, 600 \mathrm{MHz}\right) \delta 4.44(\mathrm{dd}, J=8.6,6.0 \mathrm{~Hz}, 1 \mathrm{H}), 4.21-4.17(\mathrm{~m}, 2 \mathrm{H}), 4.17-$ $4.07(\mathrm{~m}, 2 \mathrm{H}), 3.98(\mathrm{qd}, J=6.7,4.1 \mathrm{~Hz}, 1 \mathrm{H}), 3.44(\mathrm{dd}, J=4.3,1.6 \mathrm{~Hz}, 1 \mathrm{H}), 3.15-3.04$ (m, 1H), $2.89(\mathrm{t}, J=7.5 \mathrm{~Hz}, 2 \mathrm{H}), 2.85(\mathrm{td}, J=9.1,5.3 \mathrm{~Hz}, 1 \mathrm{H}), 2.51-2.37(\mathrm{~m}, 1 \mathrm{H}), 2.01$ -1.79 (m, 4H), $1.74-1.59$ (m, 6H), $1.47-1.36$ (m, 2H), 1.32 (s, 9H), 1.31 (d, $J=6.9$ $\mathrm{Hz}, 3 \mathrm{H}), 1.02-0.84(\mathrm{~m}, 6 \mathrm{H})$.

\section{am*[PGLn]}

Following purification in three parts by RP-HPLC SP 10 to 25 , the pure fractions were pooled to afford $6.0 \mathrm{mg}$ of the title compound in $6.9 \%$ overall yield. ESI MS $[\mathrm{M}+\mathrm{H}]^{+}$ expected: 538.3, experimental: 538.4. LC/MS Method A retention time 4.289 min. LC/MS Method Iso 15 retention time $4.527 \mathrm{~min} .{ }^{1} \mathrm{H} \mathrm{NMR}\left(\mathrm{CD}_{3} \mathrm{OD}, 400 \mathrm{MHz}\right) \delta 4.48(\mathrm{t}$, $J=5.8 \mathrm{~Hz}, 1 \mathrm{H}), 4.35(\mathrm{dd}, J=9.3,5.5 \mathrm{~Hz}, 1 \mathrm{H}), 4.16-4.07(\mathrm{~m}, 2 \mathrm{H}), 4.00-3.88(\mathrm{~m}, 2 \mathrm{H})$, 3.37 (d, $J=4.3 \mathrm{~Hz}, 1 \mathrm{H}), 3.01$ (ddd, $J=8.5,6.0,2.1 \mathrm{~Hz}, 1 \mathrm{H}), 2.76$ (td, $J=9.3,5.2 \mathrm{~Hz}$, $1 \mathrm{H}), 2.62(\mathrm{~d}, J=5.8 \mathrm{~Hz}, 2 \mathrm{H}), 2.36(\mathrm{td}, J=10.9,10.3,7.0 \mathrm{~Hz}, 1 \mathrm{H}), 1.93-1.82(\mathrm{~m}, 2 \mathrm{H})$, 1.77 (ddd, $J=13.7,10.3,7.5 \mathrm{~Hz}, 1 \mathrm{H}), 1.56$ (tq, $J=16.0,7.4,6.8 \mathrm{~Hz}, 3 \mathrm{H}), 1.25$ (s, 9H), $1.22(\mathrm{~d}, J=6.8 \mathrm{~Hz}, 3 \mathrm{H}), 0.85(\mathrm{dd}, J=15.6,5.9 \mathrm{~Hz}, 6 \mathrm{H})$.

\section{am*[PGLq]}

Following purification in three parts by RP-HPLC SP 10 to 25 , the pure fractions were pooled to afford $0.9 \mathrm{mg}$ of the title compound in $1.0 \%$ overall yield. ESI MS $[\mathrm{M}+\mathrm{H}]^{+}$ expected: 552.4, experimental: 552.4. LC/MS Method A retention time $4.378 \mathrm{~min}$. LC/MS Method Iso 15 retention time $5.007 \mathrm{~min} .{ }^{1} \mathrm{H}$ NMR $\left(\mathrm{CD}_{3} \mathrm{OD}, 400 \mathrm{MHz}\right) \delta 4.47$ (dd, $J=10.4,3.8 \mathrm{~Hz}, 1 \mathrm{H}), 4.37(\mathrm{~d}, J=17.5 \mathrm{~Hz}, 1 \mathrm{H}), 4.28(\mathrm{t}, J=5.7 \mathrm{~Hz}, 1 \mathrm{H}), 4.22(\mathrm{t}, J=$ $8.2 \mathrm{~Hz}, 1 \mathrm{H}), 4.11(\mathrm{~d}, J=17.5 \mathrm{~Hz}, 1 \mathrm{H}), 4.03(\mathrm{dd}, J=7.0,4.5 \mathrm{~Hz}, 1 \mathrm{H}), 3.50(\mathrm{~d}, J=4.3 \mathrm{~Hz}$, 
1H), $3.20-3.08(\mathrm{~m}, 1 \mathrm{H}), 2.92(\mathrm{td}, J=9.3,5.1 \mathrm{~Hz}, 1 \mathrm{H}), 2.50(\mathrm{q}, J=9.2,8.0 \mathrm{~Hz}, 1 \mathrm{H})$, $2.37-2.28(\mathrm{~m}, 2 \mathrm{H}), 2.18-2.10(\mathrm{~m}, 1 \mathrm{H}), 2.07-1.94(\mathrm{~m}, 2 \mathrm{H}), 1.89(\mathrm{t}, J=7.7 \mathrm{~Hz}, 1 \mathrm{H})$, $1.79-1.58(\mathrm{~m}, 3 \mathrm{H}), 1.37(\mathrm{~s}, 9 \mathrm{H}), 1.31(\mathrm{~d}, J=6.7 \mathrm{~Hz}, 3 \mathrm{H}), 0.97(\mathrm{dd}, J=17.8,5.7 \mathrm{~Hz}$, $6 \mathrm{H})$.

\section{am*[PGLr]}

Following purification in three parts by RP-HPLC SP 10 to 25, the pure fractions were pooled to afford $13.1 \mathrm{mg}$ of the title compound in $13 \%$ overall yield. ESI MS $[\mathrm{M}+\mathrm{H}]^{+}$ expected: 580.4, experimental: 580.4. LC/MS Method A retention time $4.164 \mathrm{~min}$. LC/MS Method Iso 15 retention time $4.076 \mathrm{~min} .{ }^{1} \mathrm{H}$ NMR $\left(\mathrm{CD}_{3} \mathrm{OD}, 400 \mathrm{MHz}\right) \delta 4.40$ $(\mathrm{dd}, J=9.7,5.1 \mathrm{~Hz}, 1 \mathrm{H}), 4.27(\mathrm{dd}, J=8.7,5.1 \mathrm{~Hz}, 1 \mathrm{H}), 4.15-4.09$ (m, 1H), $4.09-3.95$ $(\mathrm{m}, 2 \mathrm{H}), 3.90(\mathrm{tt}, J=6.9,3.3 \mathrm{~Hz}, 1 \mathrm{H}), 3.37(\mathrm{dd}, J=4.5,1.1 \mathrm{~Hz}, 1 \mathrm{H}), 3.11(\mathrm{td}, J=7.0,2.7$ $\mathrm{Hz}, 2 \mathrm{H}), 3.06-2.96(\mathrm{~m}, 1 \mathrm{H}), 2.75(\mathrm{dq}, J=9.8,6.0,5.4 \mathrm{~Hz}, 1 \mathrm{H}), 2.40-2.32(\mathrm{~m}, 1 \mathrm{H})$, 1.84 (dddd, $J=21.1,12.8,8.5,5.1 \mathrm{~Hz}, 4 \mathrm{H}), 1.78-1.64(\mathrm{~m}, 1 \mathrm{H}), 1.56$ (qt, $J=13.7,4.9$ $\mathrm{Hz}, 5 \mathrm{H}), 1.25(\mathrm{~s}, 9 \mathrm{H}), 1.23(\mathrm{~d}, J=7.0 \mathrm{~Hz}, 3 \mathrm{H}), 0.86(\mathrm{dd}, J=11.9,6.2 \mathrm{~Hz}, 6 \mathrm{H})$.

\section{am*[PGLv]}

Following purification in three parts by RP-HPLC SP 23 to 33, the pure fractions were pooled to afford $3.9 \mathrm{mg}$ of the title compound in $4.6 \%$ overall yield. ESI MS $[\mathrm{M}+\mathrm{H}]^{+}$ expected: 523.4, experimental: 523.4. LC/MS Method A retention time $5.406 \mathrm{~min}$. LC/MS Method Iso 30 retention time $3.843 \mathrm{~min} .{ }^{1} \mathrm{H}$ NMR $\left(\mathrm{CD}_{3} \mathrm{OD}, 400 \mathrm{MHz}\right) \delta 4.41$ $(\mathrm{dd}, J=8.8,5.9 \mathrm{~Hz}, 1 \mathrm{H}), 4.09$ (dd, $J=13.6,5.1 \mathrm{~Hz}, 3 \mathrm{H}), 3.97$ (d, $J=17.4 \mathrm{~Hz}, 1 \mathrm{H}), 3.93$ $-3.82(\mathrm{~m}, 1 \mathrm{H}), 3.36(\mathrm{~d}, J=4.2 \mathrm{~Hz}, 1 \mathrm{H}), 3.00(\mathrm{t}, J=7.5 \mathrm{~Hz}, 1 \mathrm{H}), 2.76(\mathrm{td}, J=9.6,9.2$, $5.7 \mathrm{~Hz}, 1 \mathrm{H}), 2.41-2.31(\mathrm{~m}, 1 \mathrm{H}), 2.14-2.01(\mathrm{~m}, 1 \mathrm{H}), 1.93-1.79(\mathrm{~m}, 2 \mathrm{H}), 1.75(\mathrm{dt}, J=$ 9.8, $6.8 \mathrm{~Hz}, 1 \mathrm{H}), 1.57(\mathrm{tq}, J=7.7,5.0,3.4 \mathrm{~Hz}, 3 \mathrm{H}), 1.24(\mathrm{~s}, 12 \mathrm{H}), 0.93-0.74(\mathrm{~m}, 12 \mathrm{H})$.

\section{am*[PGNo]}

Following purification in three parts by RP-HPLC SP 5 to 10, the pure fractions were pooled to afford $5.3 \mathrm{mg}$ of the title compound in $5.6 \%$ overall yield. ESI MS $[\mathrm{M}+\mathrm{H}]^{+}$ expected: 539.3, experimental: 539.4. LC/MS Method A retention time $2.670 \mathrm{~min}$. LC/MS Method Iso 5 retention time $2.736 \mathrm{~min} .{ }^{1} \mathrm{H}$ NMR $\left(\mathrm{CD}_{3} \mathrm{OD}, 600 \mathrm{MHz}\right) \delta 4.79(\mathrm{t}, J$ 
$=6.9 \mathrm{~Hz}, 1 \mathrm{H}), 4.43(\mathrm{dd}, J=8.3,4.9 \mathrm{~Hz}, 1 \mathrm{H}), 4.21(\mathrm{t}, J=8.1 \mathrm{~Hz}, 1 \mathrm{H}), 4.15(\mathrm{~d}, J=17.2$ $\mathrm{Hz}, 1 \mathrm{H}), 4.05$ (d, $J=17.2 \mathrm{~Hz}, 1 \mathrm{H}), 3.99$ (qd, $J=6.8,3.0 \mathrm{~Hz}, 1 \mathrm{H}), 3.45$ (dd, $J=4.4,1.6$

$\mathrm{Hz}, 1 \mathrm{H}), 3.14-3.07$ (m, 1H), 2.93 (tt, $J=7.6,3.8 \mathrm{~Hz}, 2 \mathrm{H}), 2.87-2.76(\mathrm{~m}, 2 \mathrm{H}), 2.66$ $(\mathrm{dd}, J=15.6,6.7 \mathrm{~Hz}, 1 \mathrm{H}), 2.49-2.42(\mathrm{~m}, 1 \mathrm{H}), 2.03-1.90(\mathrm{~m}, 3 \mathrm{H}), 1.90-1.81(\mathrm{~m}, 1 \mathrm{H})$, $1.80-1.66(\mathrm{~m}, 3 \mathrm{H}), 1.34(\mathrm{~s}, 9 \mathrm{H}), 1.30(\mathrm{~d}, J=6.8 \mathrm{~Hz}, 3 \mathrm{H})$.

\section{am*[PGSo]}

Following purification in three parts by RP-HPLC SP 10 to 25, the pure fractions were pooled to afford $5.3 \mathrm{mg}$ of the title compound in $5.9 \%$ overall yield. ESI MS $[\mathrm{M}+\mathrm{H}]^{+}$ expected: 512.3, experimental: 512.4; $[\mathrm{M}+2 \mathrm{H}]^{2+}$ expected: 256.7 , experimental: 256.8 . LC/MS Method A retention time $2.535 \mathrm{~min}$. LC/MS Method Iso 10 retention time 2.474 $\min .{ }^{1} \mathrm{H}$ NMR $\left(\mathrm{CD}_{3} \mathrm{OD}, 400 \mathrm{MHz}\right) \delta 4.49(\mathrm{t}, J=5.1 \mathrm{~Hz}, 1 \mathrm{H}), 4.35-4.10(\mathrm{~m}, 4 \mathrm{H}), 4.08-$ $4.00(\mathrm{~m}, 1 \mathrm{H}), 3.95(\mathrm{dd}, J=11.0,5.4 \mathrm{~Hz}, 1 \mathrm{H}), 3.86(\mathrm{dd}, J=11.0,4.9 \mathrm{~Hz}, 1 \mathrm{H}), 3.46$ (d, $J=$ $4.2 \mathrm{~Hz}, 1 \mathrm{H}), 3.15(\mathrm{~m}, 1 \mathrm{H}), 2.99(\mathrm{~m}, 2 \mathrm{H}), 2.92-2.80(\mathrm{~m}, 1 \mathrm{H}), 2.57-2.43(\mathrm{~m}, 1 \mathrm{H}), 2.06-$ $1.84(\mathrm{~m}, 4 \mathrm{H}), 1.83-1.66(\mathrm{~m}, 3 \mathrm{H}), 1.38(\mathrm{~s}, 9 \mathrm{H}), 1.35(\mathrm{~d}, J=6.8 \mathrm{~Hz}, 3 \mathrm{H})$.

\section{am*[PGV-D-Dab]}

The synthesis was performed at $0.1 \mathrm{mmol}$ scale in peptide. Following purification in three parts by RP-HPLC SP 5 to 10, the pure fractions were pooled to afford $2.4 \mathrm{mg}$ of

the title compound in $4.7 \%$ overall yield. ESI MS $[\mathrm{M}+\mathrm{H}]^{+}$expected: 510.3 , experimental: 510.4. LC/MS Method B retention time $2.799 \mathrm{~min} .{ }^{1} \mathrm{H}$ NMR $\left(\mathrm{CD}_{3} \mathrm{OD}, 500 \mathrm{MHz}\right) \delta 4.34$ $(\mathrm{t}, J=6.7 \mathrm{~Hz}, 1 \mathrm{H}), 4.27(\mathrm{~d}, J=6.8 \mathrm{~Hz}, 1 \mathrm{H}), 4.24-4.06(\mathrm{~m}, 3 \mathrm{H}), 4.02-3.96(\mathrm{~m}, 1 \mathrm{H})$, $3.49-3.44(\mathrm{~m}, 1 \mathrm{H}), 3.11(\mathrm{t}, J=7.7 \mathrm{~Hz}, 1 \mathrm{H}), 3.07-2.97(\mathrm{~m}, 2 \mathrm{H}), 2.89-2.83(\mathrm{~m}, 1 \mathrm{H})$, $2.50-2.43(\mathrm{~m}, 1 \mathrm{H}), 2.25-2.10(\mathrm{~m}, 2 \mathrm{H}), 2.05-1.81(\mathrm{~m}, 4 \mathrm{H}), 1.35(\mathrm{~s}, 9 \mathrm{H}), 1.32(\mathrm{~d}, J=$ $6.8 \mathrm{~Hz}, 3 \mathrm{H}), 0.99(\mathrm{t}, J=7.1 \mathrm{~Hz}, 6 \mathrm{H})$.

\section{am*[PGVo]}

Following purification in three parts by RP-HPLC SP 10 to 25, the pure fractions were pooled to afford $4.7 \mathrm{mg}$ of the title compound in $5.1 \%$ overall yield. ESI MS $[\mathrm{M}+\mathrm{H}]^{+}$ expected: 524.4, experimental: 524.4; $[\mathrm{M}+2 \mathrm{H}]^{2+}$ expected: 262.7, experimental: 262.6. LC/MS Method A retention time $3.667 \mathrm{~min}$. LC/MS Method Iso 15 retention time 3.063 
min. ${ }^{1} \mathrm{H}$ NMR $\left(\mathrm{CD}_{3} \mathrm{OD}, 400 \mathrm{MHz}\right) \delta 4.18-3.95(\mathrm{~m}, 5 \mathrm{H}), 3.93-3.84(\mathrm{~m}, 1 \mathrm{H}), 3.36(\mathrm{~d}, J$ $=4.3 \mathrm{~Hz}, 1 \mathrm{H}), 3.01(\mathrm{t}, J=7.4 \mathrm{~Hz}, 1 \mathrm{H}), 2.86(\mathrm{t}, J=6.9 \mathrm{~Hz}, 2 \mathrm{H}), 2.75(\mathrm{dt}, J=9.0,4.8 \mathrm{~Hz}$, $1 \mathrm{H}), 2.42-2.29(\mathrm{~m}, 1 \mathrm{H}), 2.06(\mathrm{~h}, J=6.8 \mathrm{~Hz}, 1 \mathrm{H}), 1.89-1.71(\mathrm{~m}, 4 \mathrm{H}), 1.63(\mathrm{dq}, J=$ 17.6, 7.2 Hz, 3H), 1.25 (s, 9H), $1.22(\mathrm{~d}, J=6.8 \mathrm{~Hz}, 3 \mathrm{H}), 0.88$ (t, $J=6.7 \mathrm{~Hz}, 6 \mathrm{H})$.

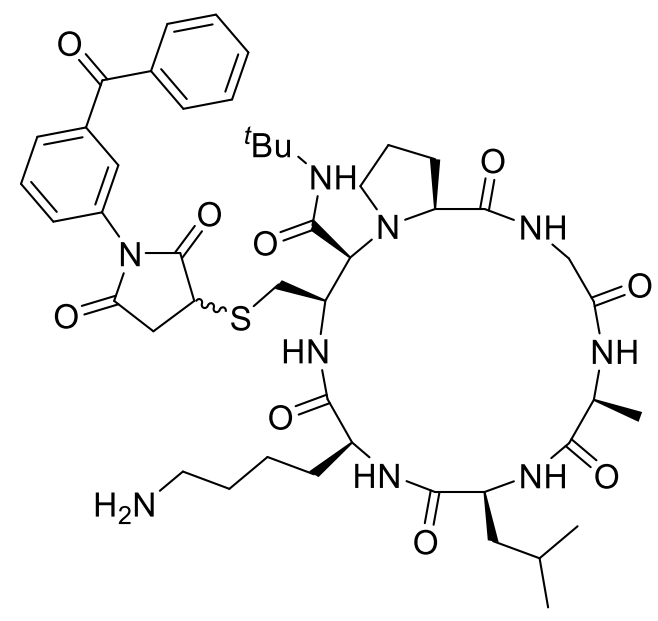

\section{photo-c*[PGALK]}

PGALK(Boc) $(87.7 \mathrm{mg}, 0.15 \mathrm{mmol}$ ) was added to a two-dram vial, followed by parent aziridine aldehyde dimer stock solution $(0.56 \mathrm{~mL}, 0.2 \mathrm{M}$ in TFE) and additional DCM (0.56 mL). tert-butylisocyanide $(25.4 \mu \mathrm{L}, 0.225 \mathrm{mmol})$ and a stirbar were then added and the reaction was left to stir for $4 \mathrm{~h}$. Thiobenzoic acid $(58 \mu \mathrm{L}, 0.44 \mathrm{mmol})$ was then added and the reaction was left to stir for an additional $90 \mathrm{~min}$ before the solvent was evaporated by a stream of nitrogen. The mixture was precipitated from $\mathrm{Et}_{2} \mathrm{O}$. To the precipitated mixture (133 mg) was added $\mathrm{K}_{2} \mathrm{CO}_{3}(64.2 \mathrm{mg}, 0.47 \mathrm{mmol})$, DTT (24.0 mg, $0.16)$ and $\mathrm{MeOH}(3.00 \mathrm{~mL})$. The reaction was allowed to stir at room temperature for 80 min, after which it was concentrated under reduced pressure and purified by flash column chromatography (75\% EtOAc/Hex $\rightarrow$ EtOAc $\rightarrow \mathrm{MeOH})$. The pure fractions were pooled and concentrated to afford $30.0 \mathrm{mg}$ of thiol $\mathbf{S 4}$ as yellow solid in $23 \%$ yield. $\mathbf{S 4}$ was then redissolved in DMF $(1.0 \mathrm{~mL})$ and $\mathbf{5 . 1}(22.0 \mathrm{mg}, 0.08 \mathrm{mmol})$ was added. The reaction was left to stir for $20 \mathrm{~min}$ at room temperature, after which another portion of $\mathbf{S 1}(20.0 \mathrm{mg}$, $0.073 \mathrm{mmol}$ ) was added and the reaction left to stir for 90 additional min. DMF was evaporated under reduced pressure. Any remaining DMF was evaporated under high-vac and the mixture was redissolved in TFA/DCM $(1: 1,2 \mathrm{~mL})$ and left to stir for $90 \mathrm{~min}$ to 
deprotect the peptide. The solvent was then removed with a stream of nitrogen, and the mixture was precipitated twice from $\mathrm{Et}_{2} \mathrm{O}$. Finally, photo-c*[PGALK] was isolated by RP-Combiflash 30 to 70 as $3.2 \mathrm{mg}$ of an off-white solid in $8.6 \%$ yield over all steps from S4. ESI MS $[\mathrm{M}+\mathrm{H}]^{+}$expected: 932.5, experimental: 932.7; $[\mathrm{M}+2 \mathrm{H}]^{2+}$ expected: 466.7, experimental: 466.8. LC/MS Method $\mathrm{C}_{8}$ retention time $14.739 \mathrm{~min}$.<smiles>CC(C)CNC(=O)[C@@H]1[C@H](CS[C@H]2CC(=O)N(c3cccc(C(=O)c4ccccc4)c3)C2=O)NC(=NCC(=O)N[C@@H](CC(C)C)C(=O)N[C@@H](CCCN)C(=O)O)[C@H]2CCCN12</smiles>

\section{photo-am*[PGLo]}

PGLo(Boc) (100 mg, $0.20 \mathrm{mmol}$ ) was added to a two-dram vial, followed by parent aziridine aldehyde dimer stock solution $(0.75 \mathrm{~mL}, 0.2 \mathrm{M}$ in TFE) and additional TFE (1.25 mL). tert-butylisocyanide $(34 \mu \mathrm{L}, 0.3 \mathrm{mmol})$ and a stirbar were then added and the reaction was left to stir for $4 \mathrm{~h}$. Thiobenzoic acid $(58 \mu \mathrm{L}, 0.44 \mathrm{mmol})$ was then added and the reaction was left to stir for an additional $80 \mathrm{~min}$ before the solvent was evaporated by a stream of nitrogen. The mixture was precipitated from $\mathrm{Et}_{2} \mathrm{O}$ and then purified by RPCombiflash 20 to 50 to isolate $18.5 \mathrm{mg}$ thioester $\mathbf{S 7}$, in $11.9 \%$ yield. To a portion of $\mathbf{S 7}$ (15.3 mg, $0.02 \mathrm{mmol}$ ), was added $\mathrm{K}_{2} \mathrm{CO}_{3}$ (16.6 mg, $0.12 \mathrm{mmol}$ ), TCEP (4.9 mg, 0.02 $\mathrm{mmol})$, DTT $(3.1 \mathrm{mg}, 0.02)$ and $\mathrm{MeOH}(1.00 \mathrm{~mL})$. The reaction was allowed to stir at room temperature for $2.5 \mathrm{~h}$, after which it was acidified with TFA and then solvent was evaporated under reduced pressure. The crude mixture was then redissolved in DMF (2.0 $\mathrm{mL}$ ) and $\mathbf{S 1}$ (16.6 $\mathrm{mg}, 0.06 \mathrm{mmol}$ ) was added. The reaction was left to stir for $10 \mathrm{~min}$ at room temperature before solvent was evaporated under reduced pressure. Any remaining DMF was evaporated under high-vac and the mixture was redissolved in TFA/DCM $(1: 1$, $2 \mathrm{~mL}$ ) and left to stir for $90 \mathrm{~min}$ to deprotect the peptide. The solvent was then removed with a stream of nitrogen, and the mixture was precipitated twice from $\mathrm{Et}_{2} \mathrm{O}$. Finally, photo-am*[PGLo] was isolated by RP-Combiflash 15 to 40 as $4.5 \mathrm{mg}$ of an off-white 
solid in 27\% yield over all steps from S7. ESI MS [M+H] ${ }^{+}$expected: 847.4, experimental: 847.4; [M+2H] ${ }^{2+}$ expected: 424.2, experimental: 424.2. LC/MS Method A retention time $5.558 \mathrm{~min}$. 
NMR spectra
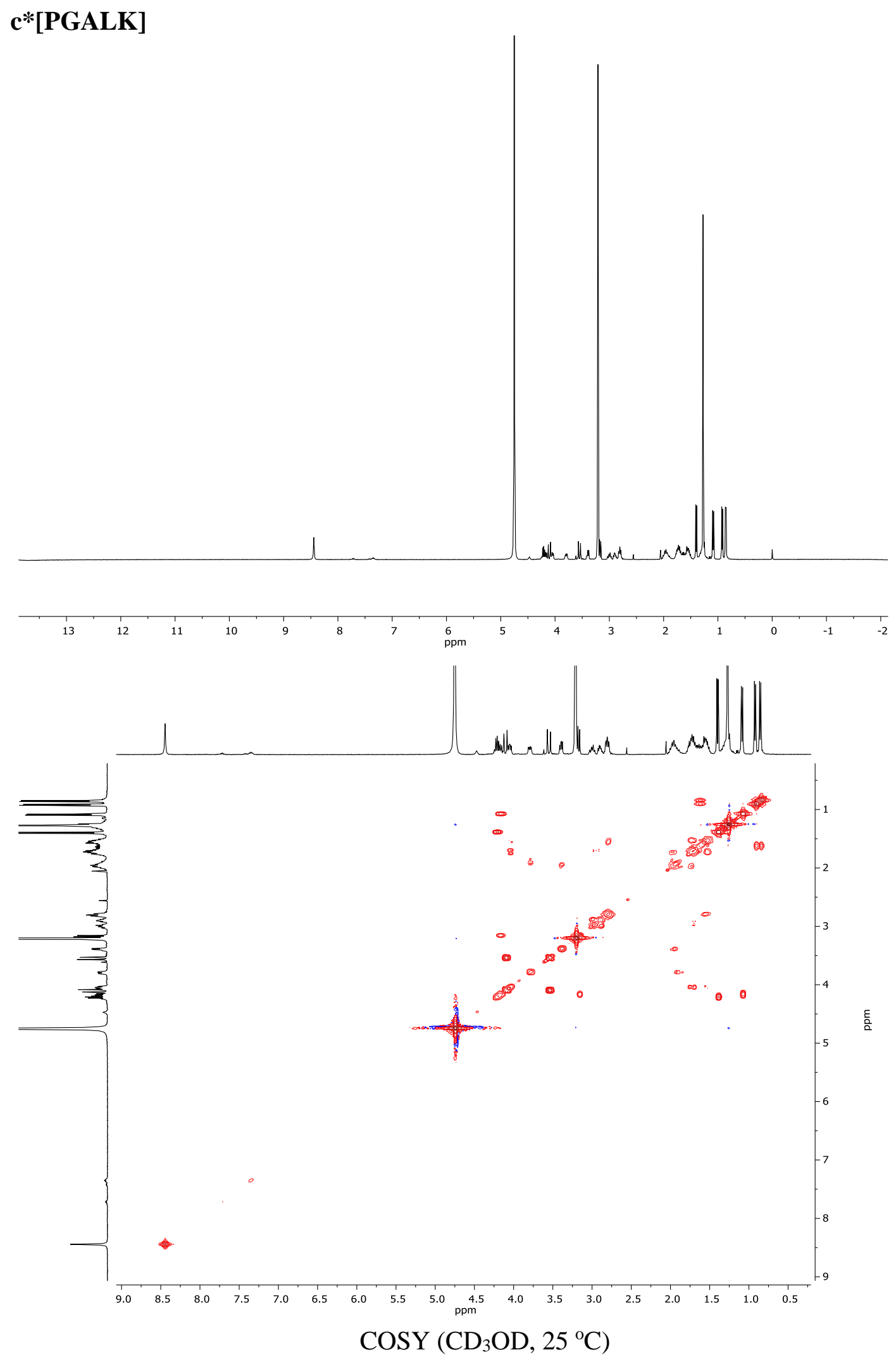
c*[PGAlk]
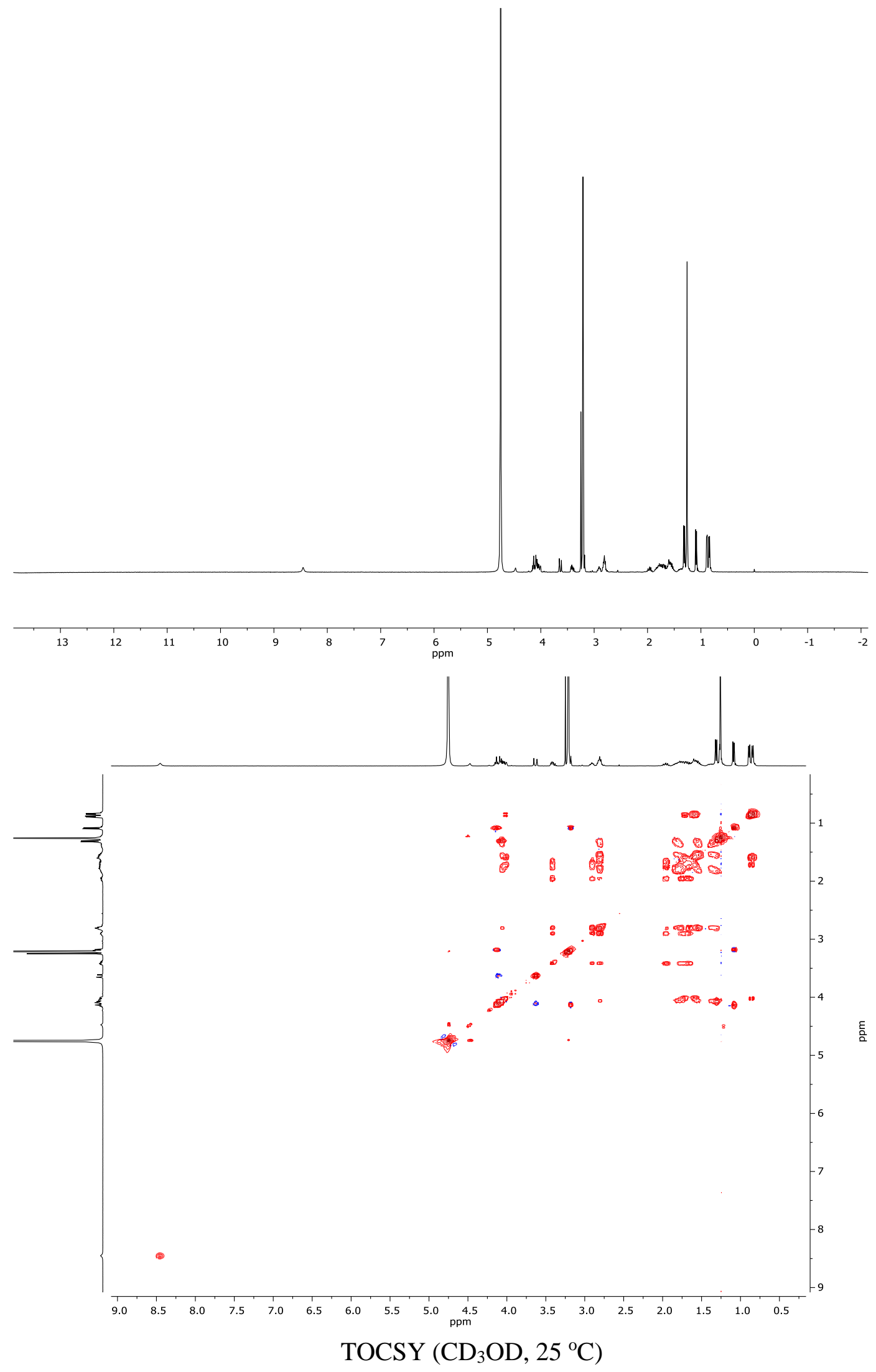
c*[PGLGDab]
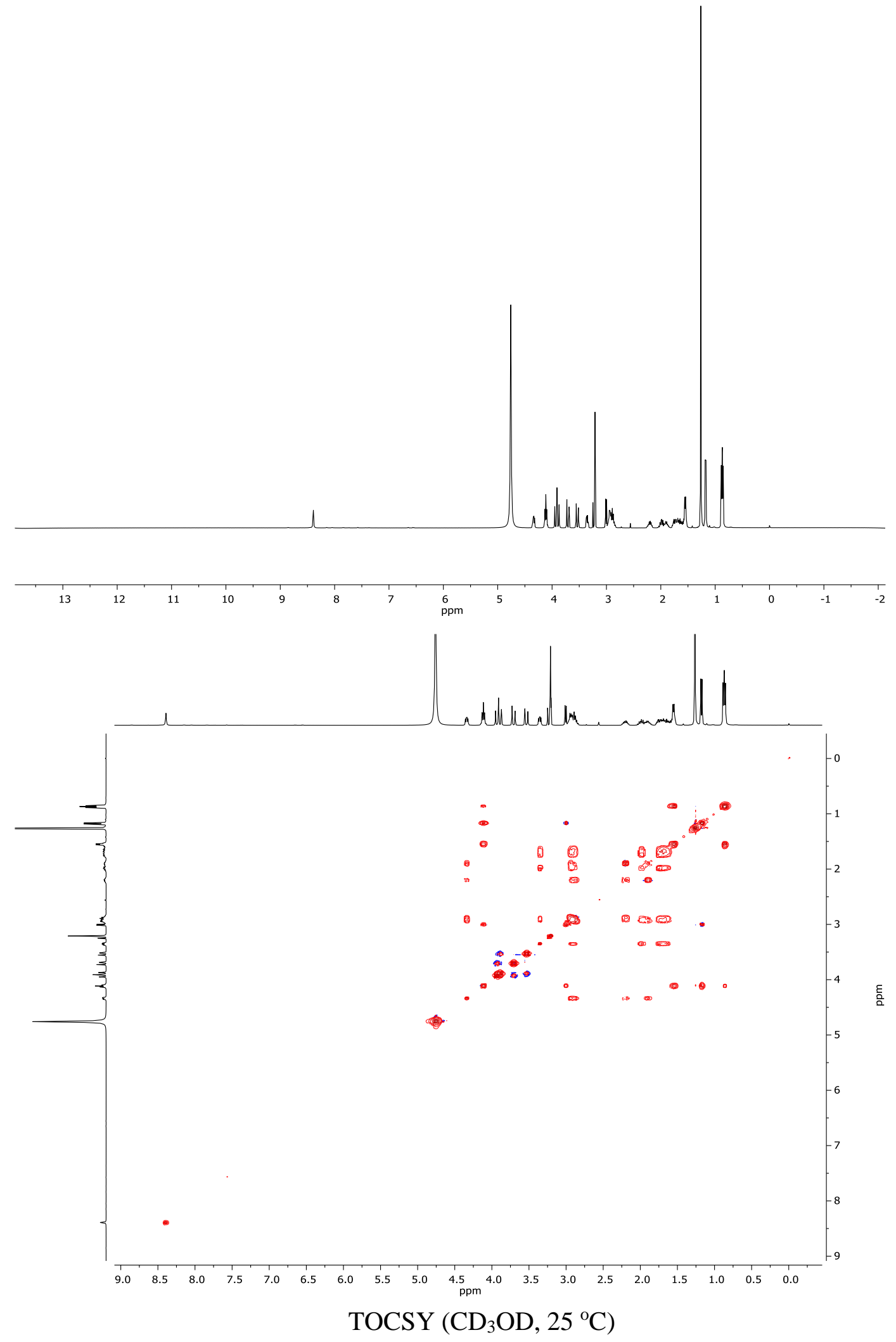
c*[PGLGDap]
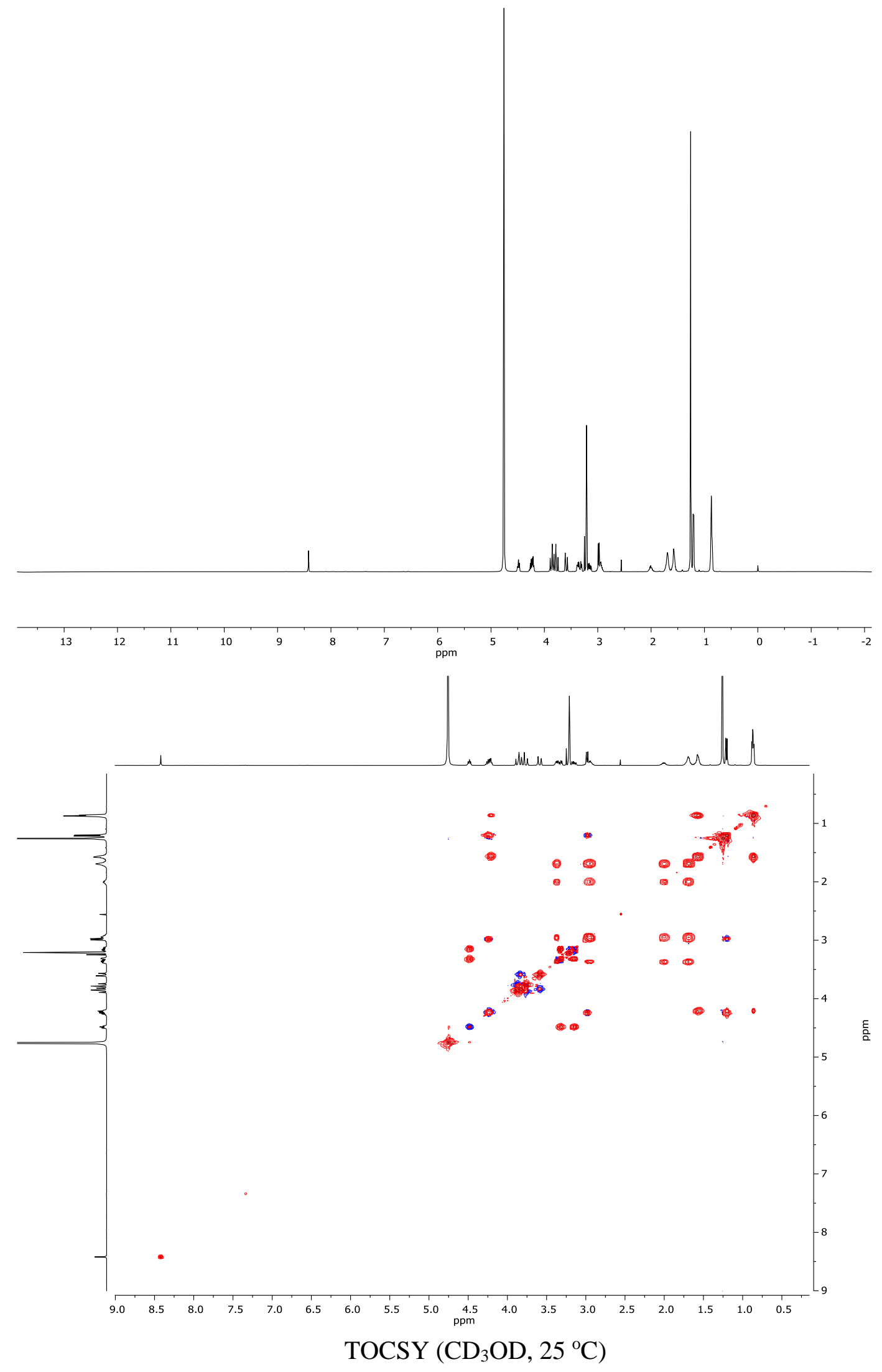


\section{c*[PGLGK]}

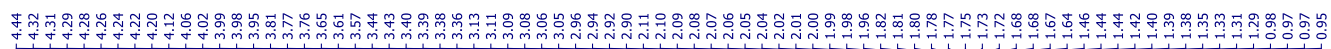

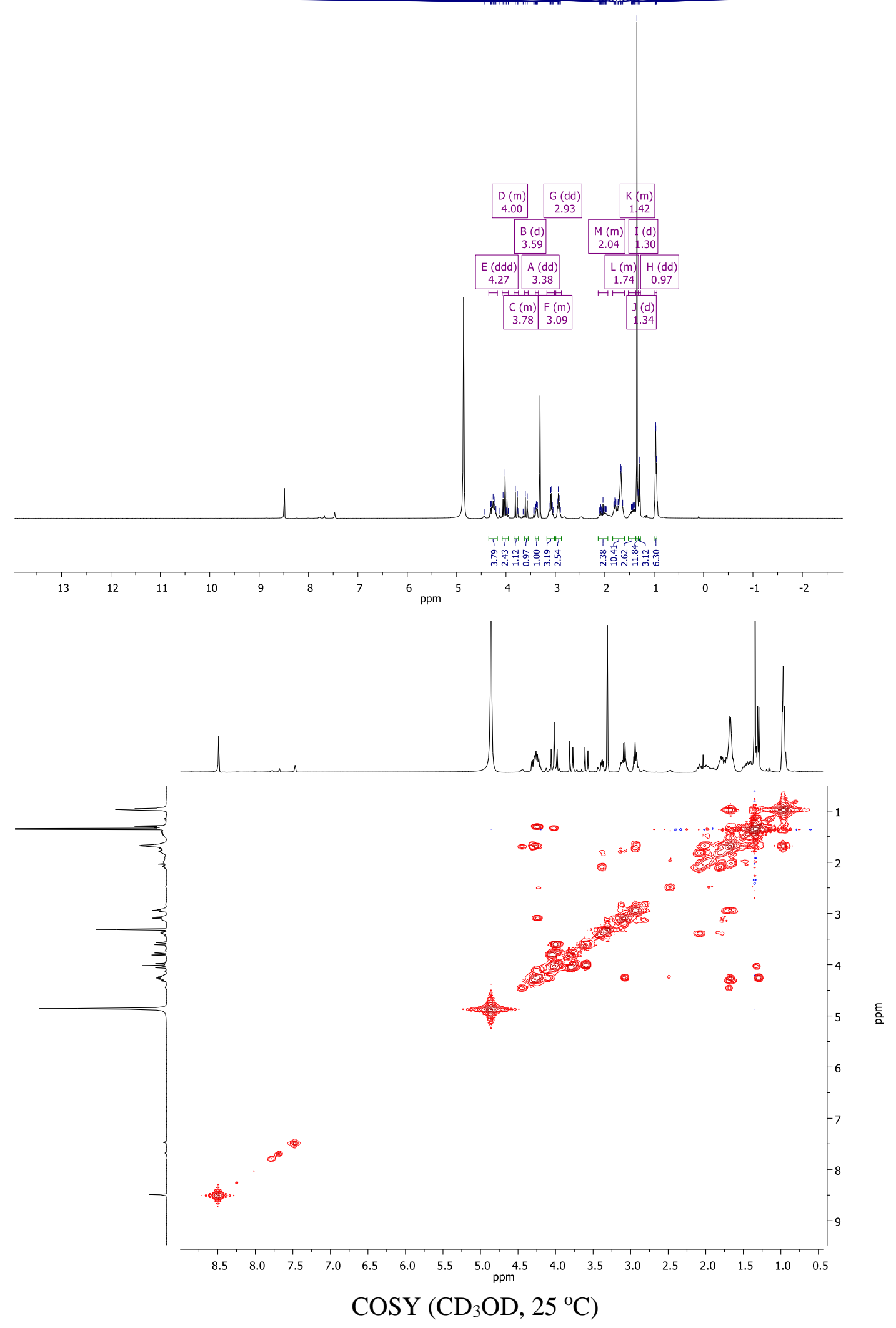



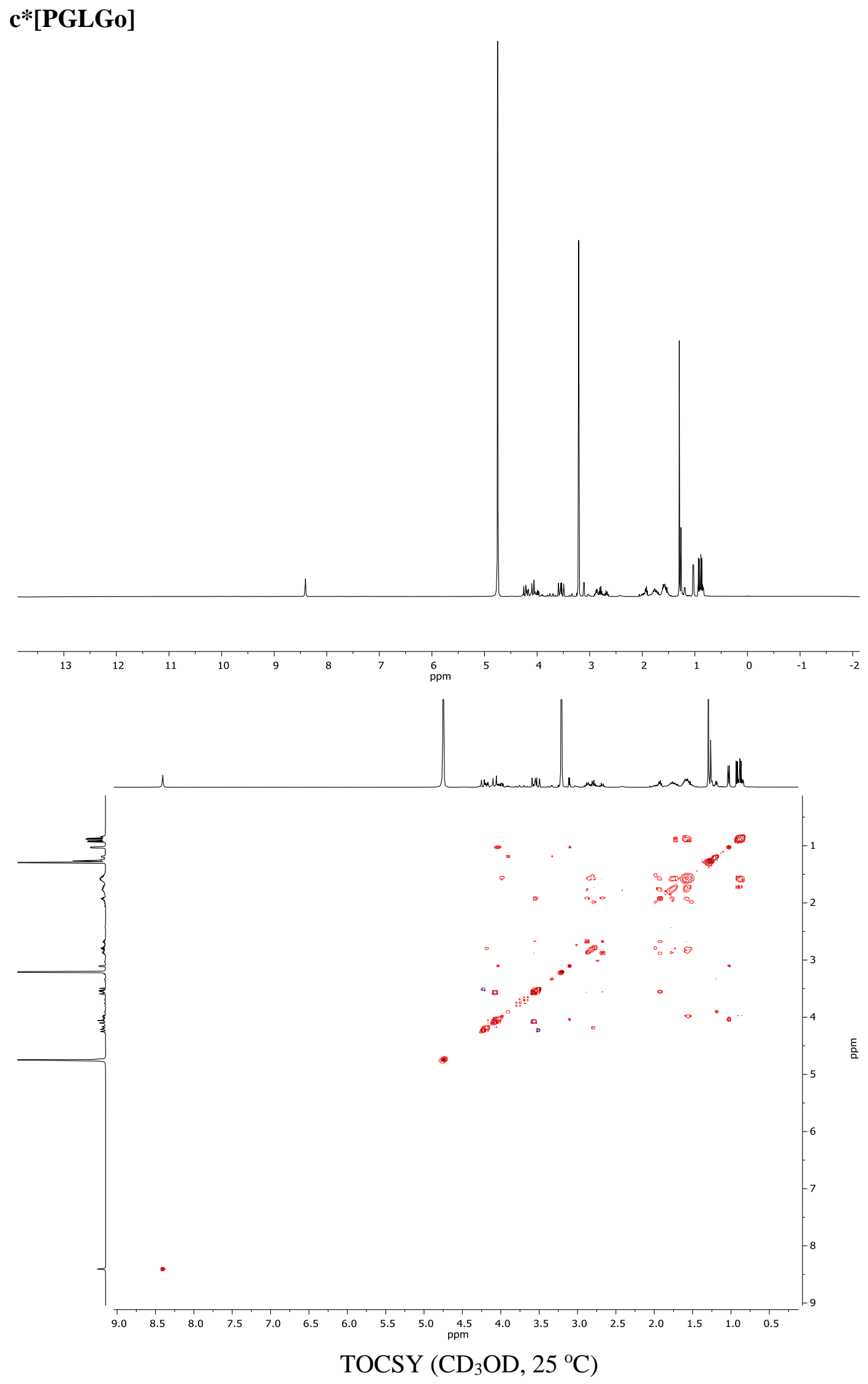

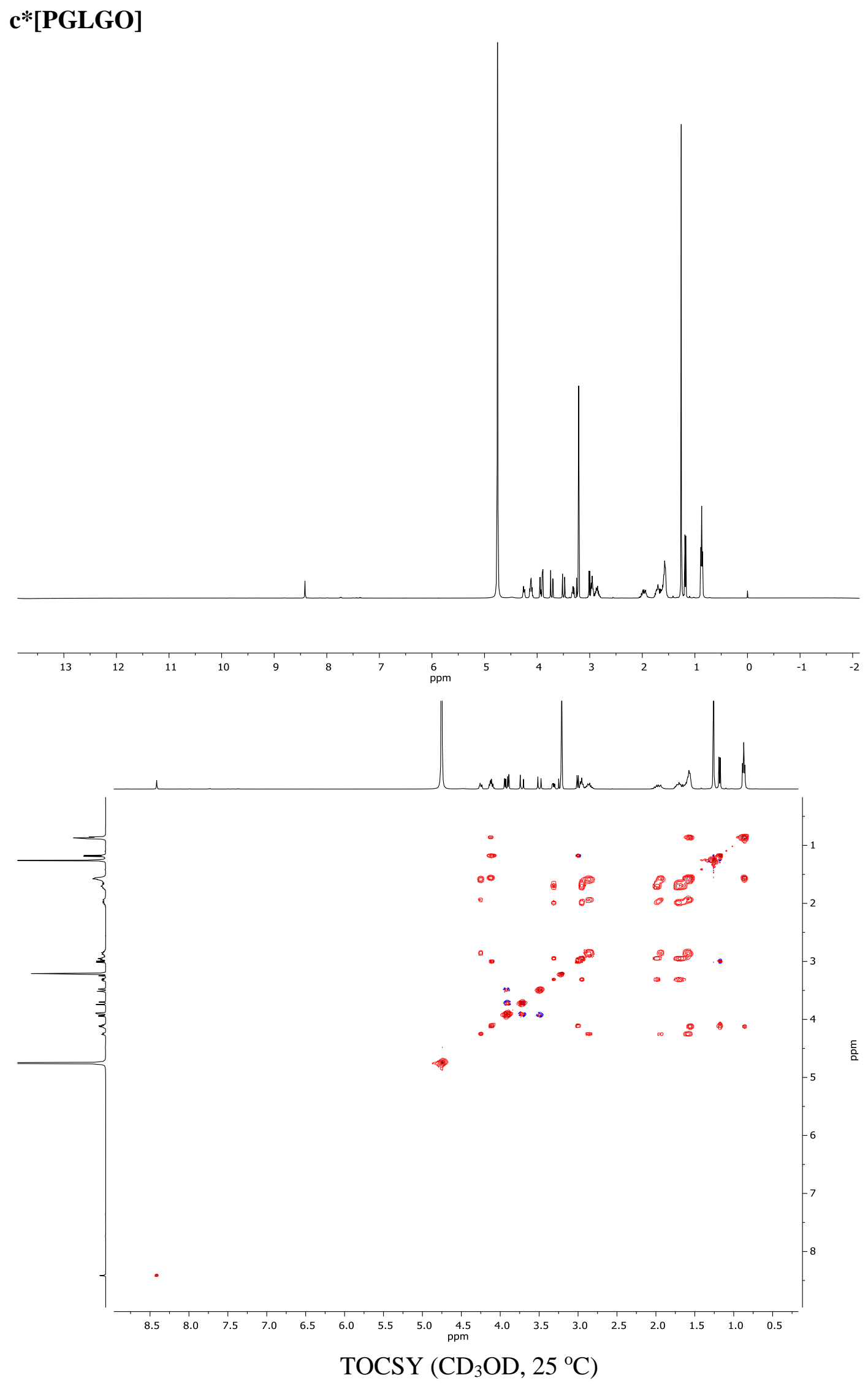


\section{$\mathrm{c}^{*}[$ PGLOF $]$}
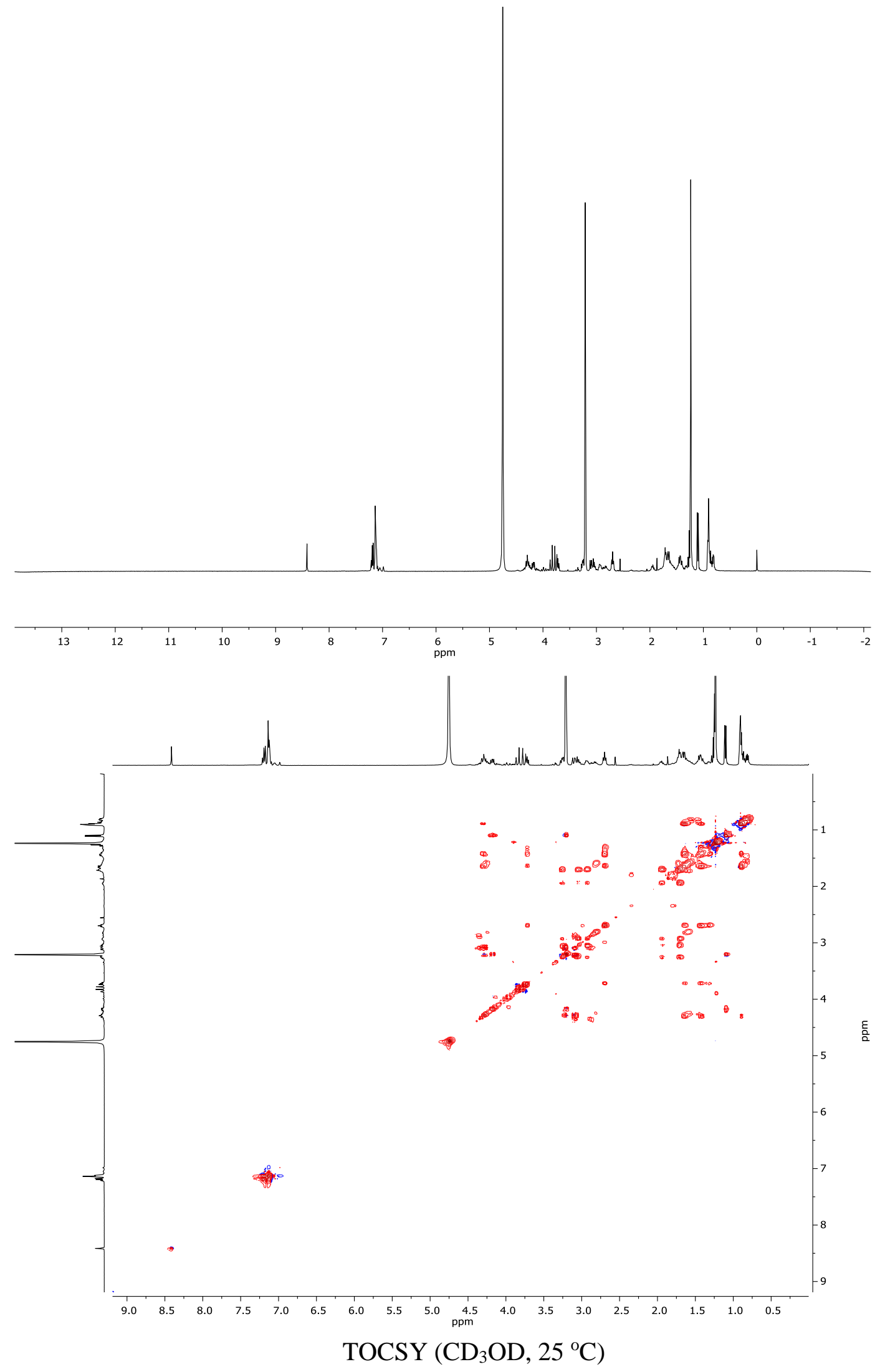
S37

c*[PGSGO]
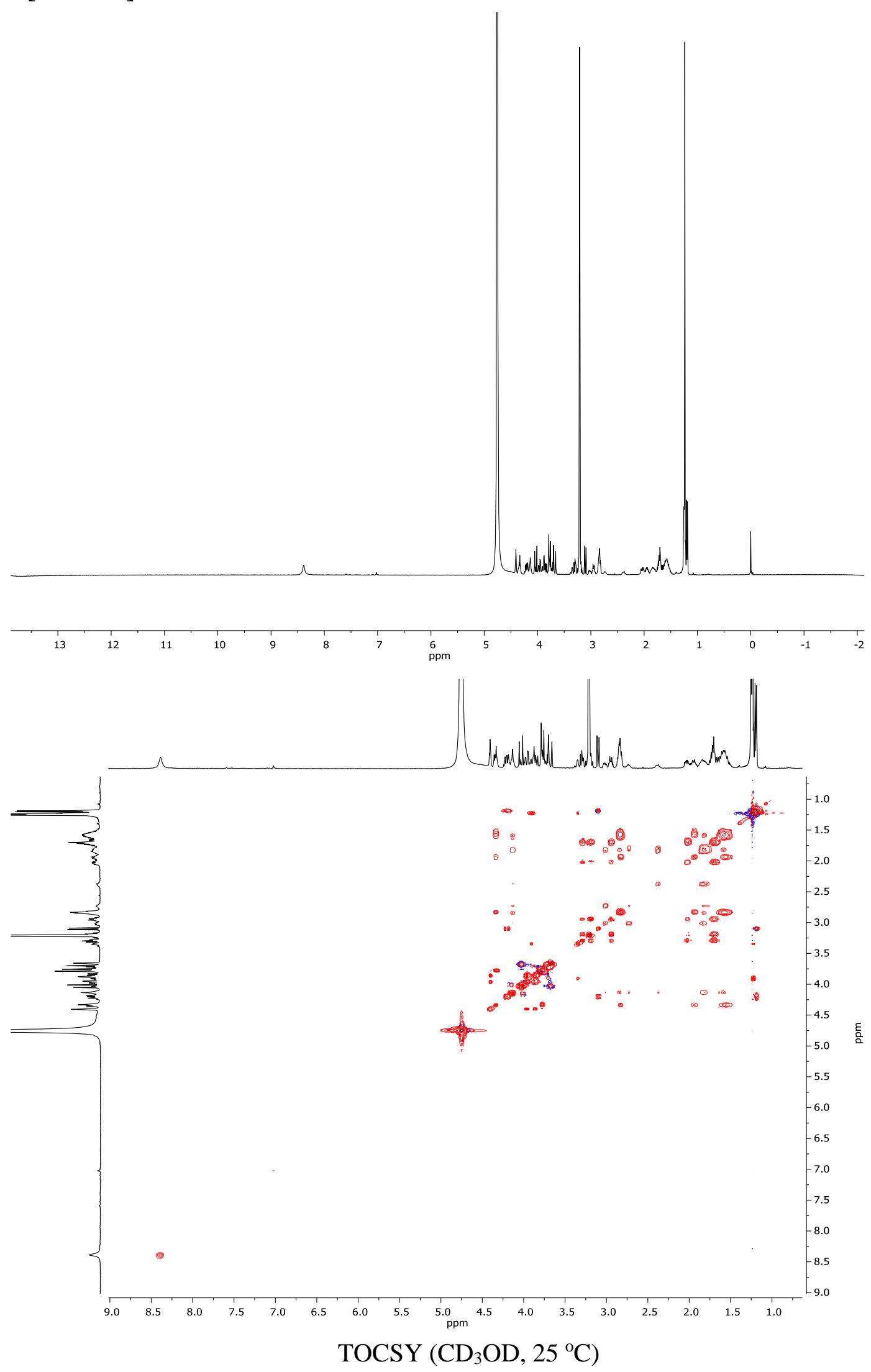


\section{c* ${ }^{*}$ PLKGF $]$}
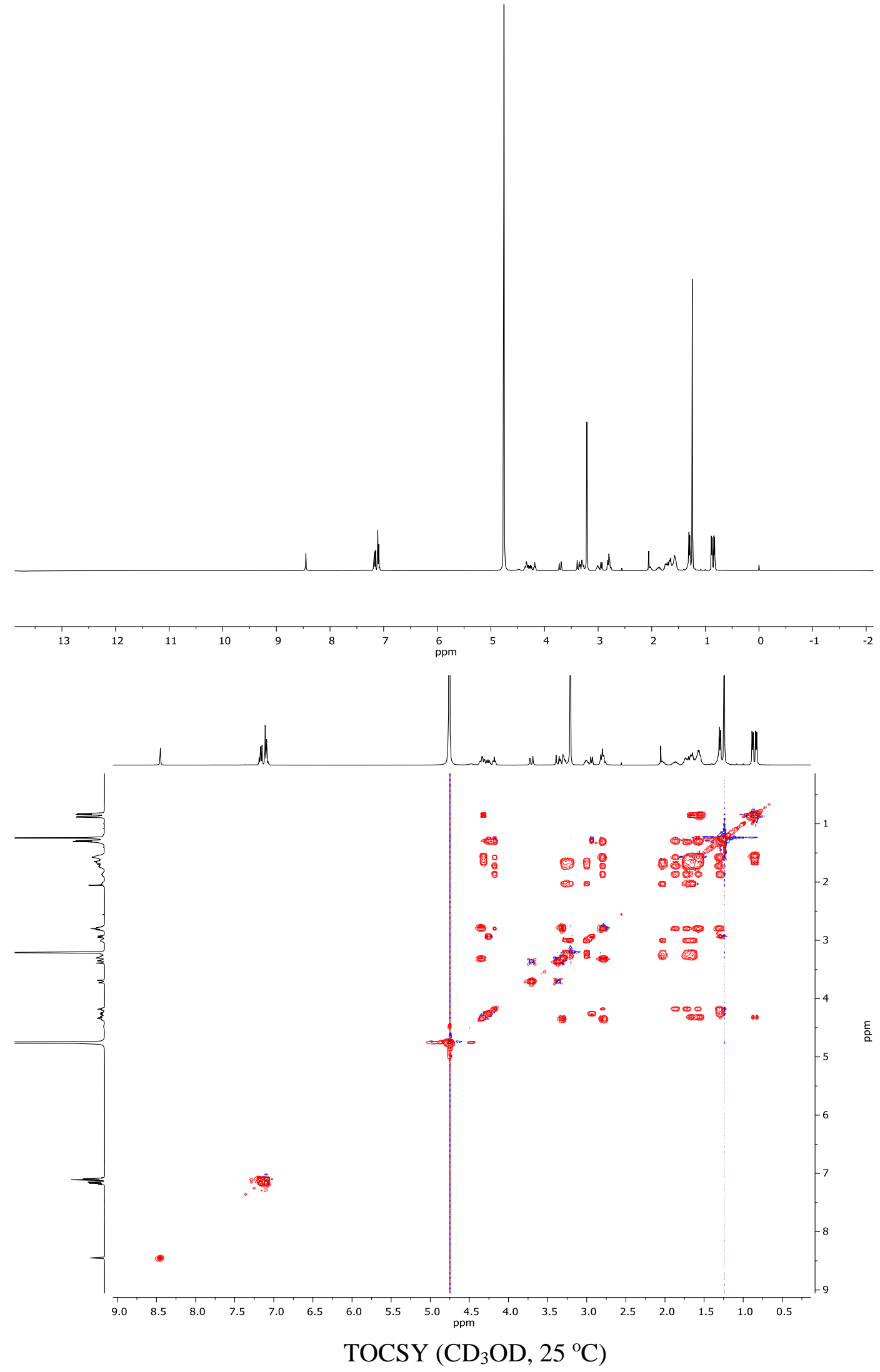

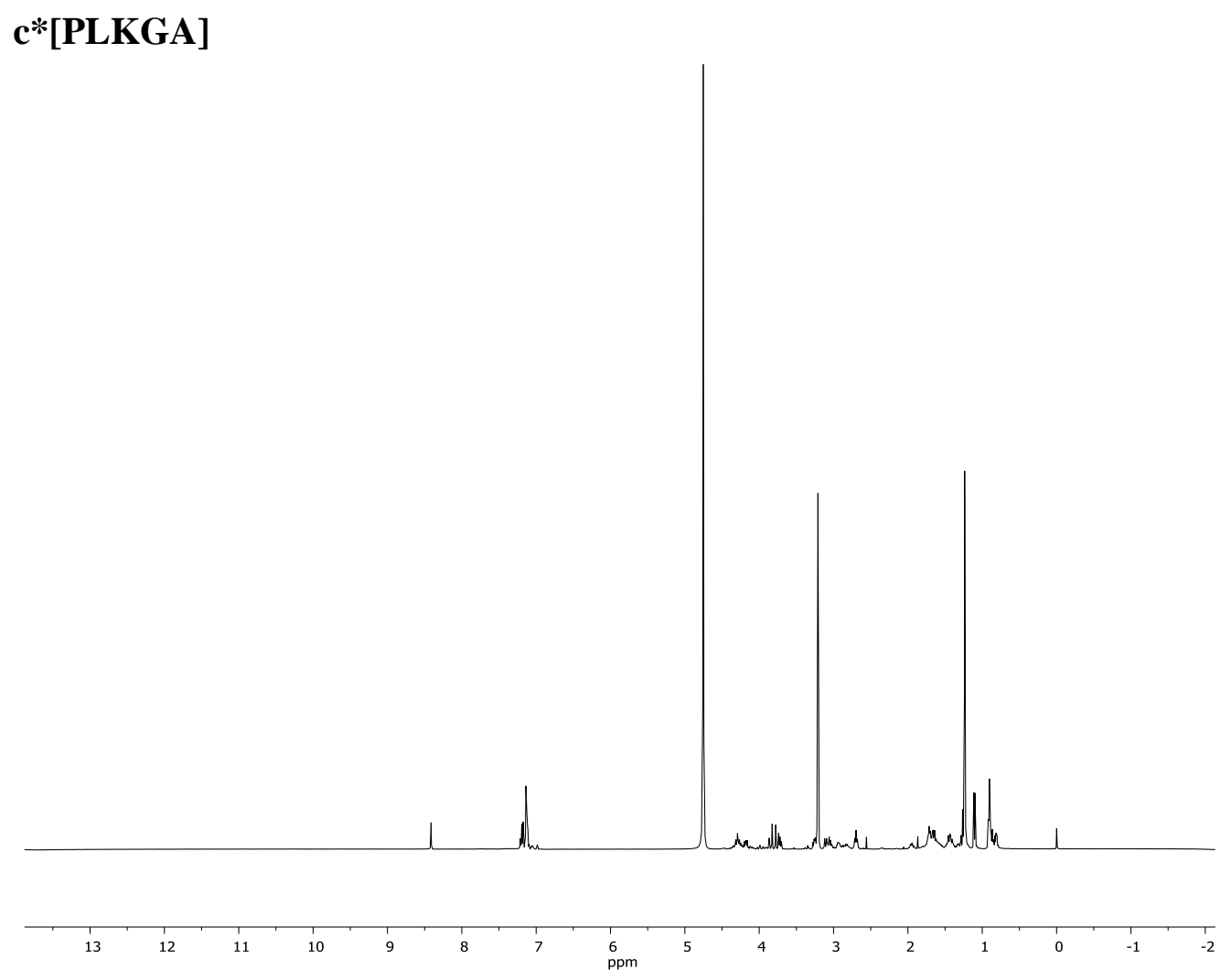

TOCSY $\left(\mathrm{CD}_{3} \mathrm{OD}, 25^{\circ} \mathrm{C}\right)$

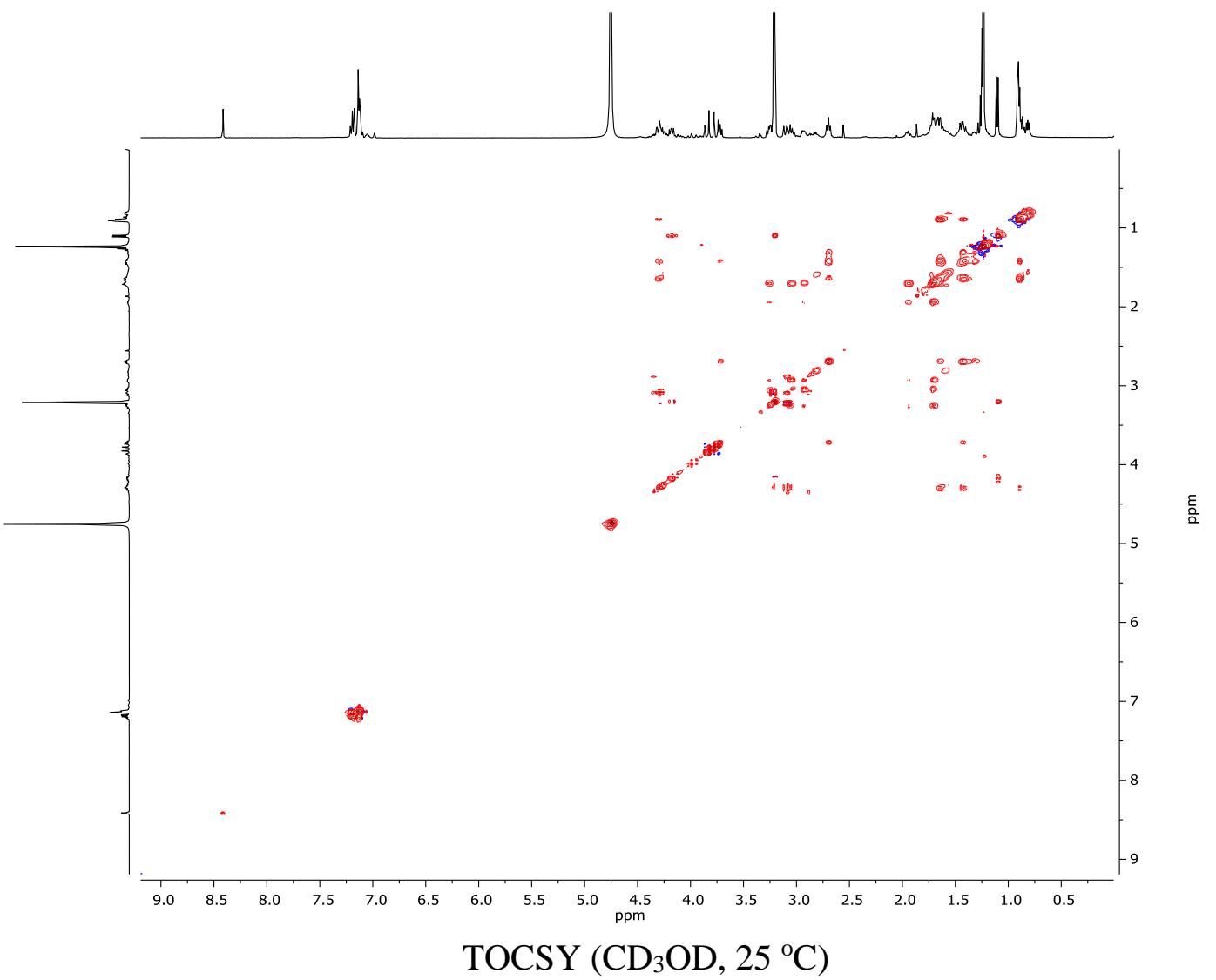


am*[PGIGk]
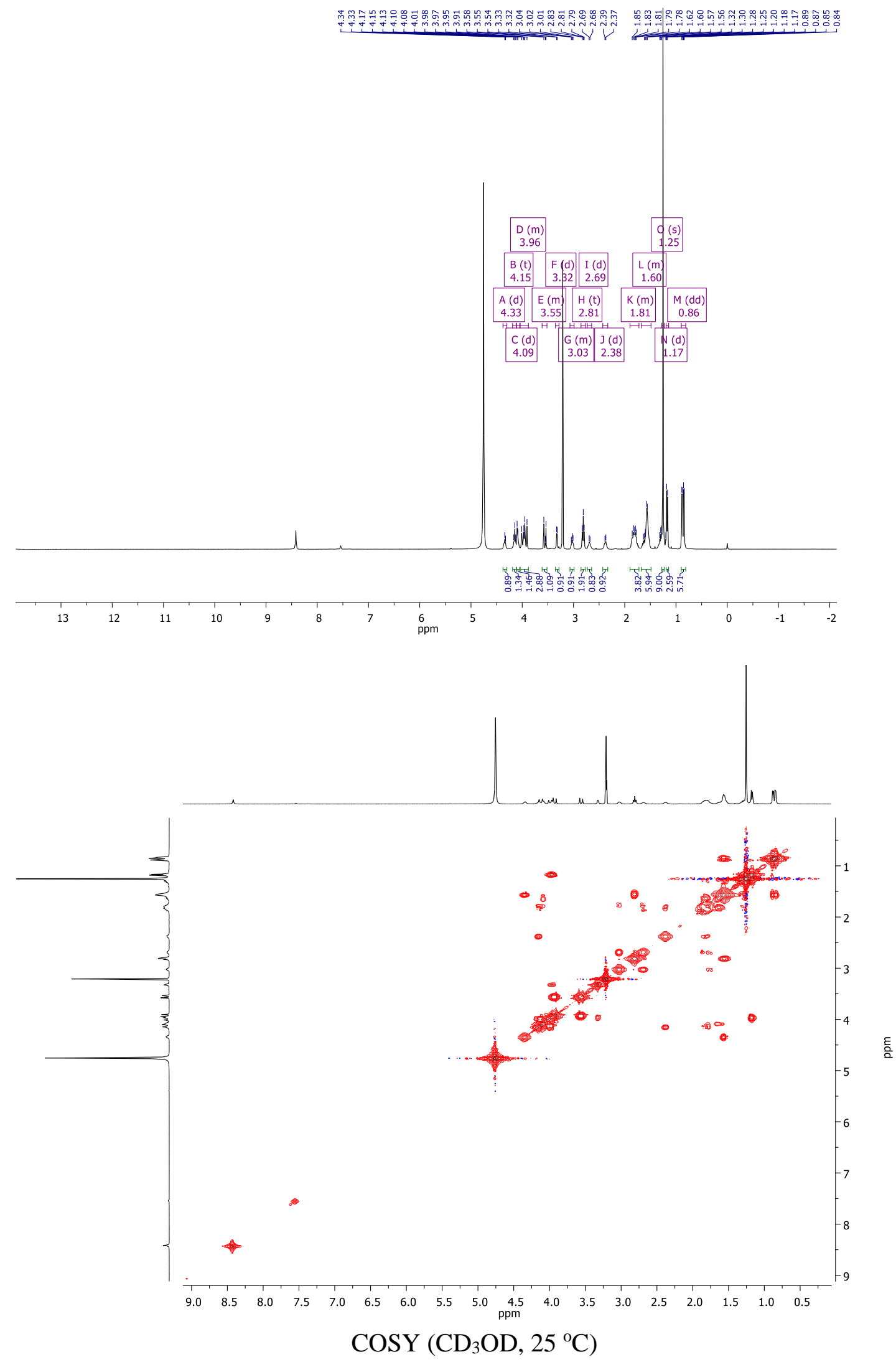


\section{am*[PGlk]}

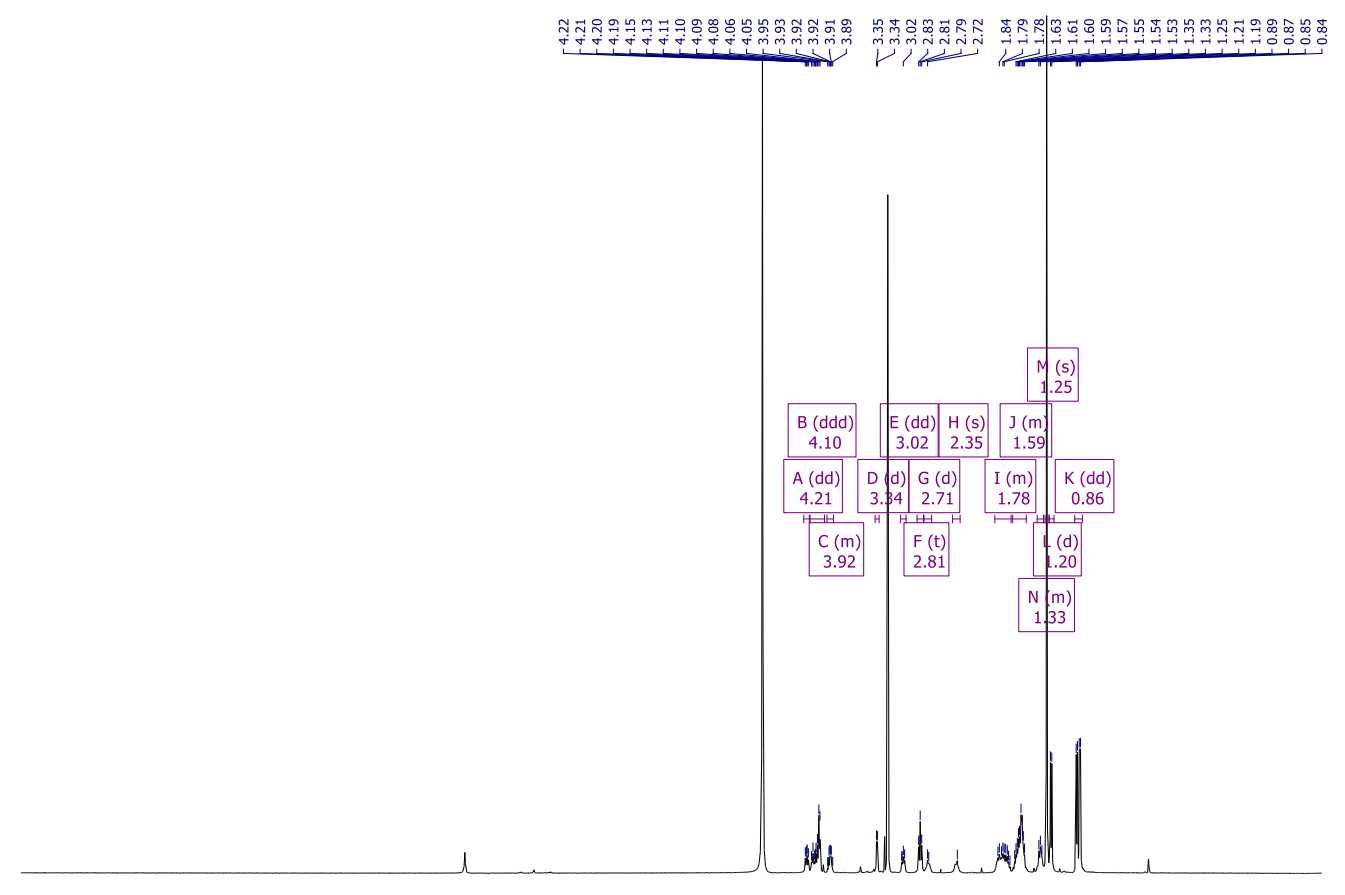

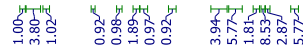

\begin{tabular}{llllllllllllllllll}
\hline & 13 & 12 & 11 & 10 & 9 & 8 & 7 & 6 & 5 & 4 & 3 & 2 & 1 & 0 & -1 & -2
\end{tabular}

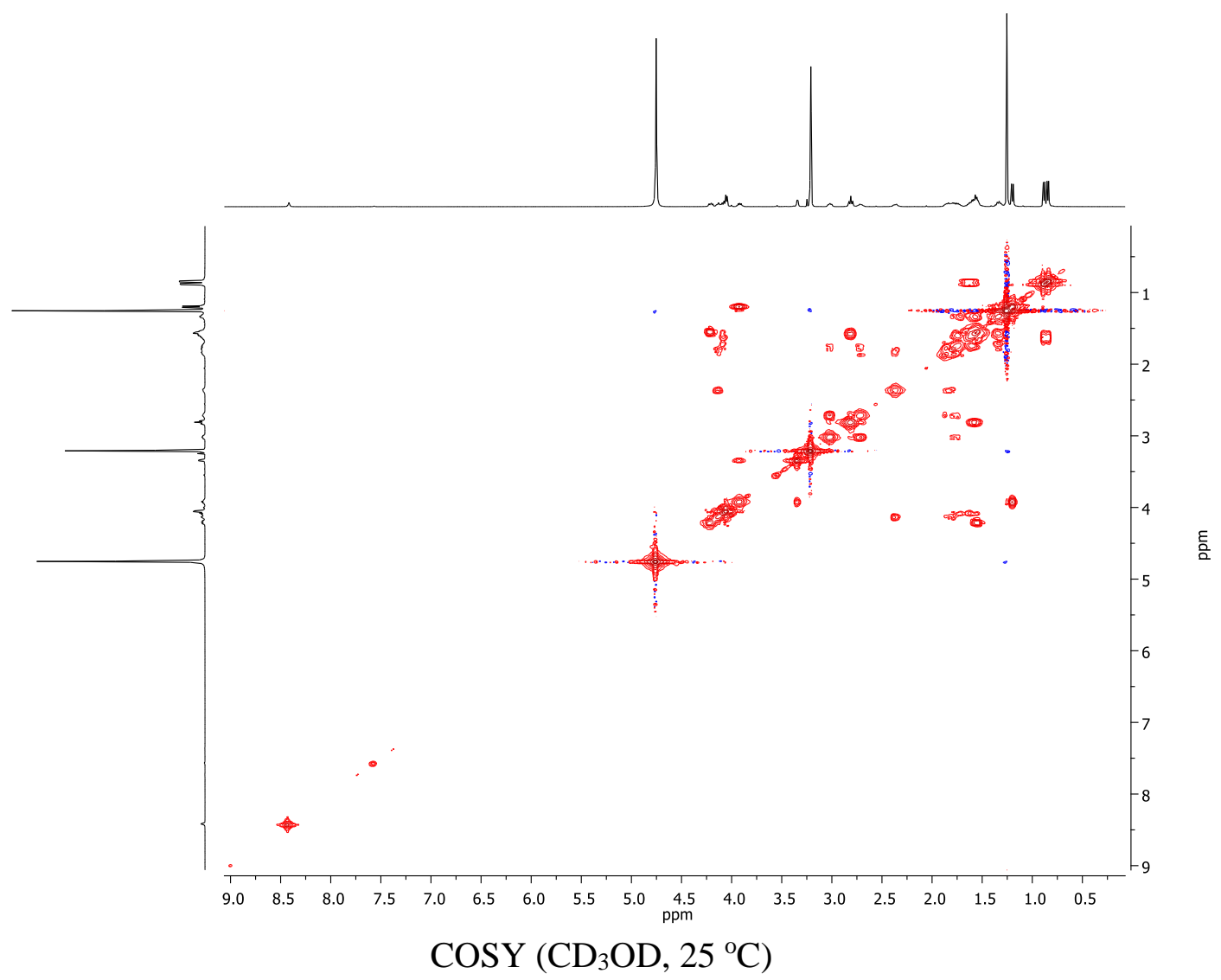




\section{am*[PGLK]}

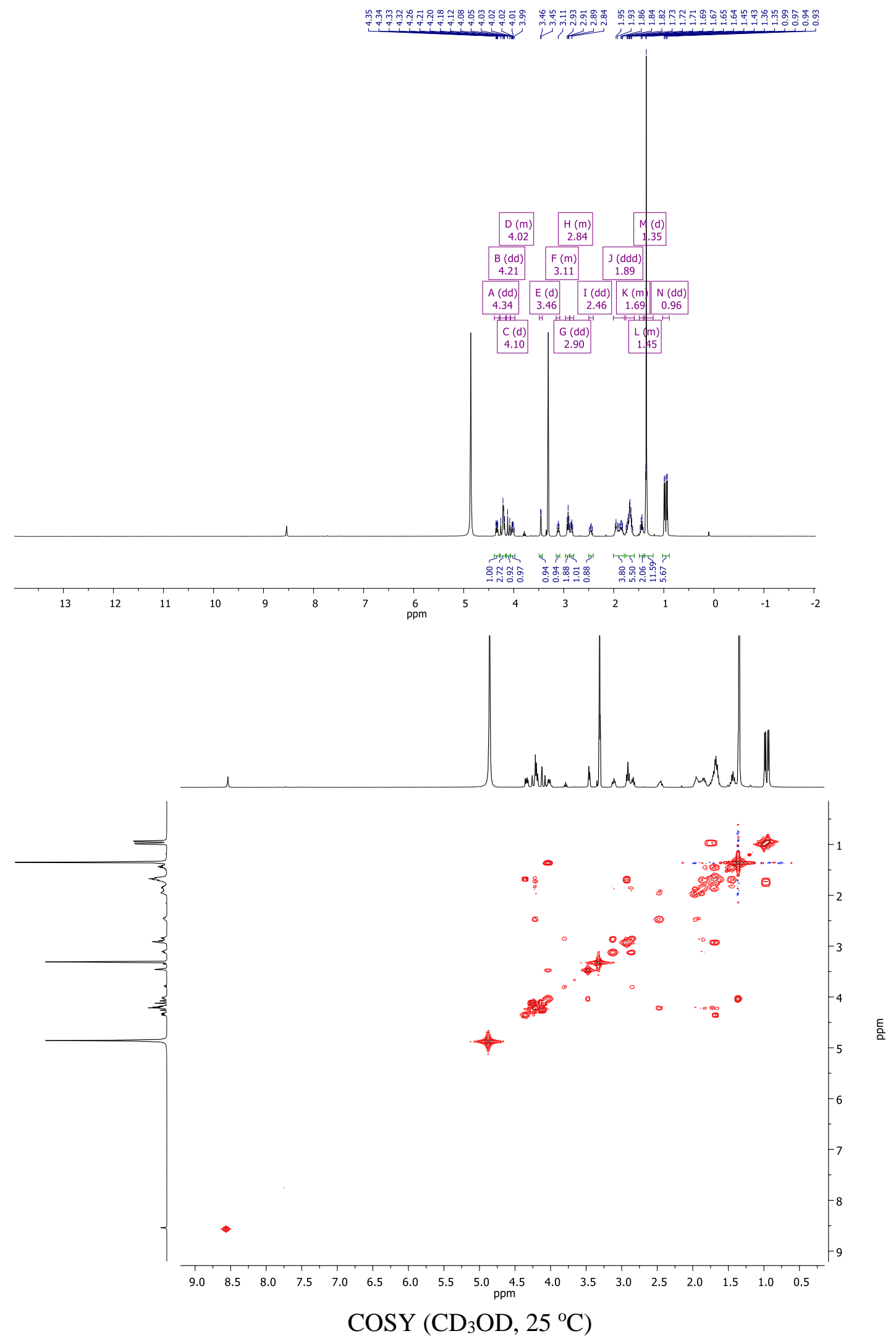




\section{am*[PGlkF]}
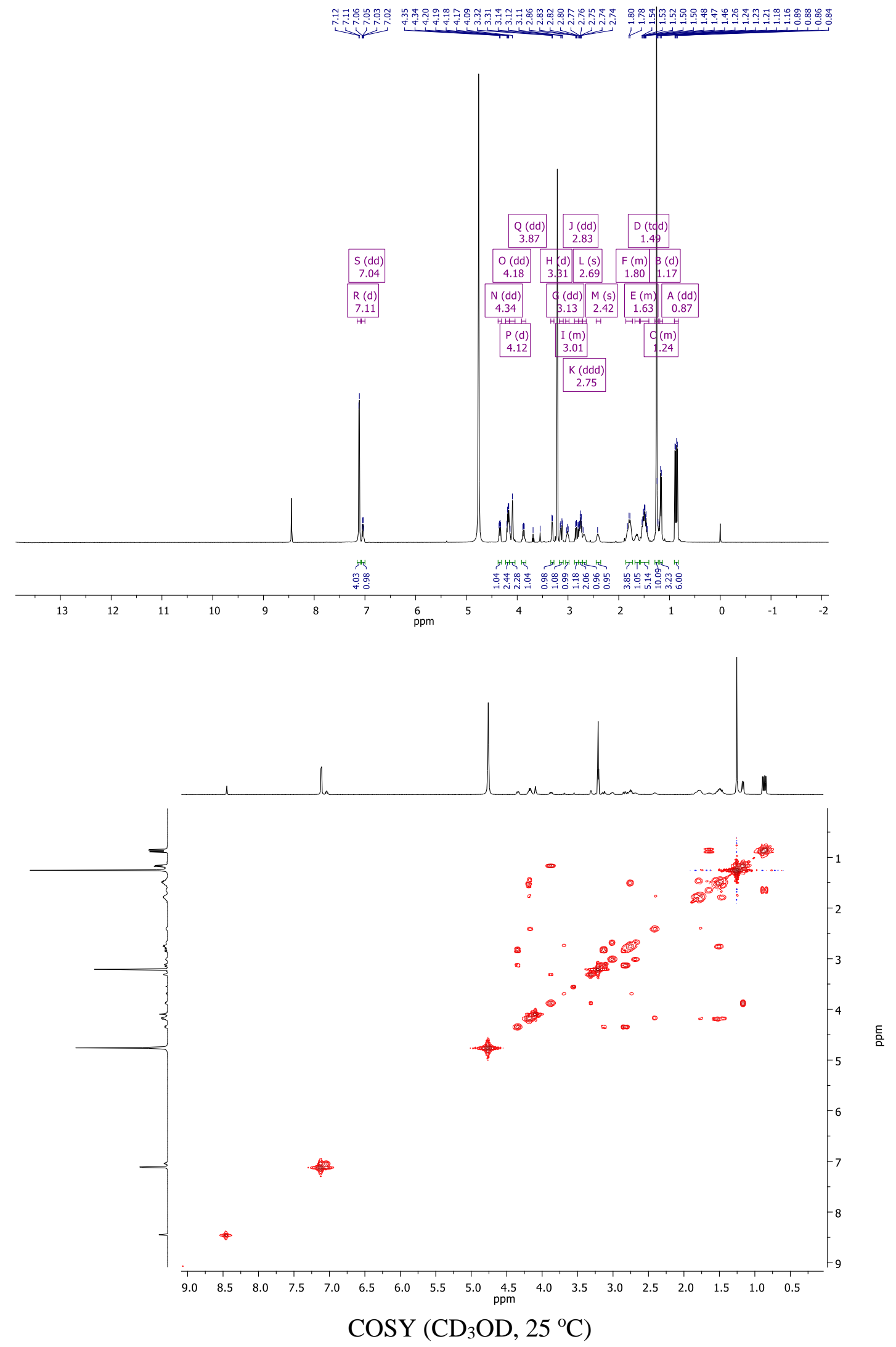
am*[PGlo]
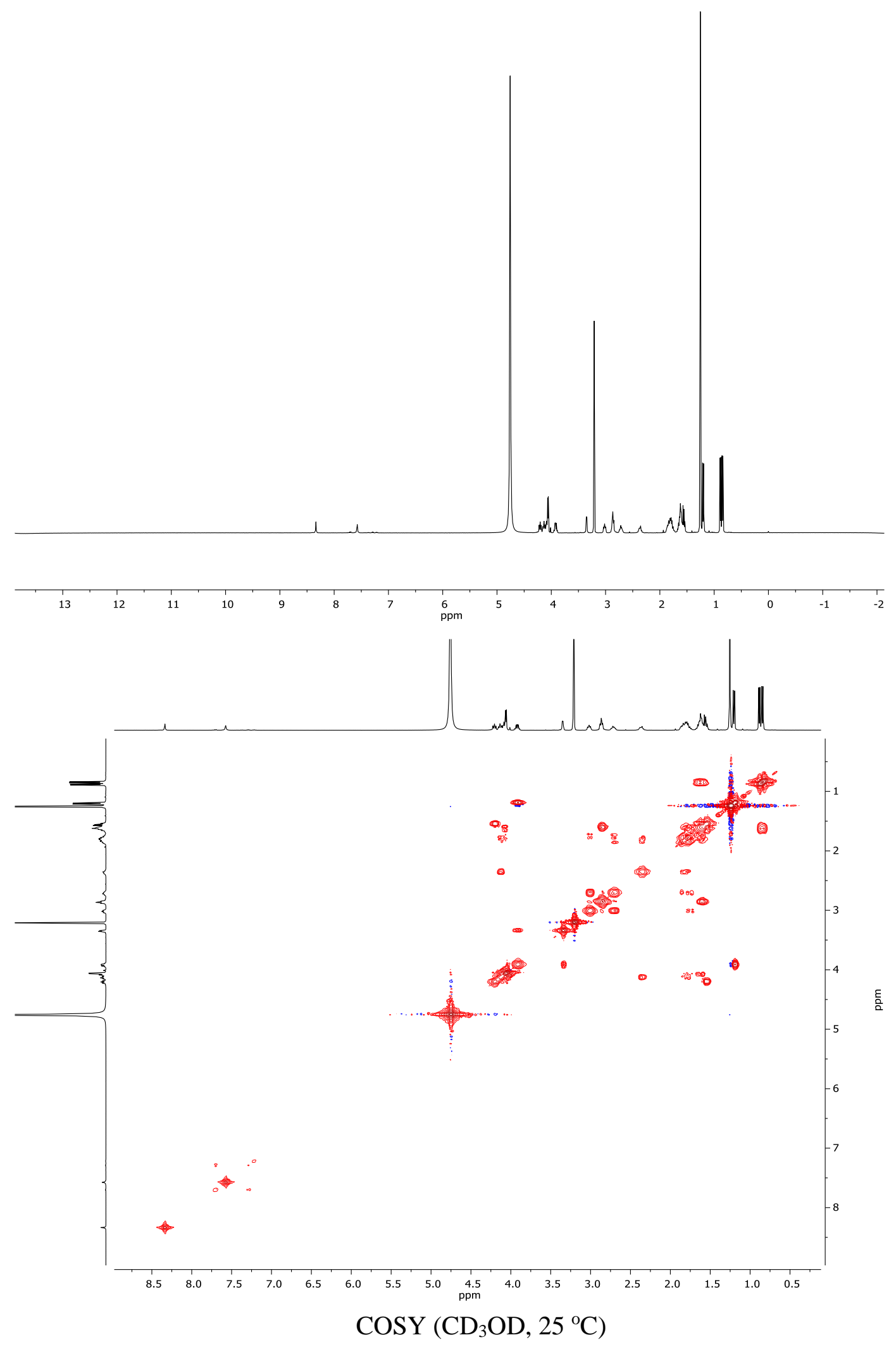


\section{am*[PGIO]}
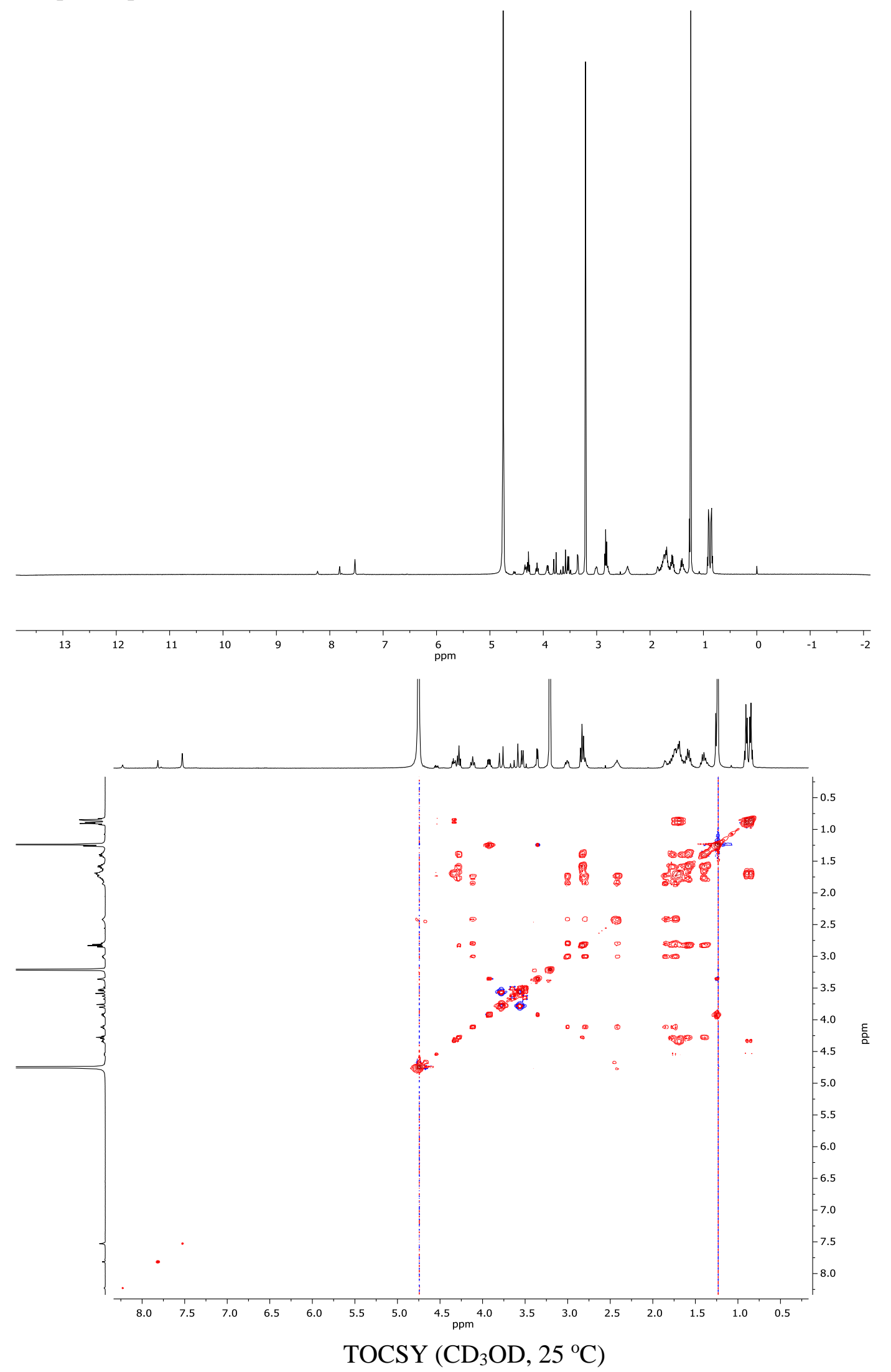
am*[PGLO]
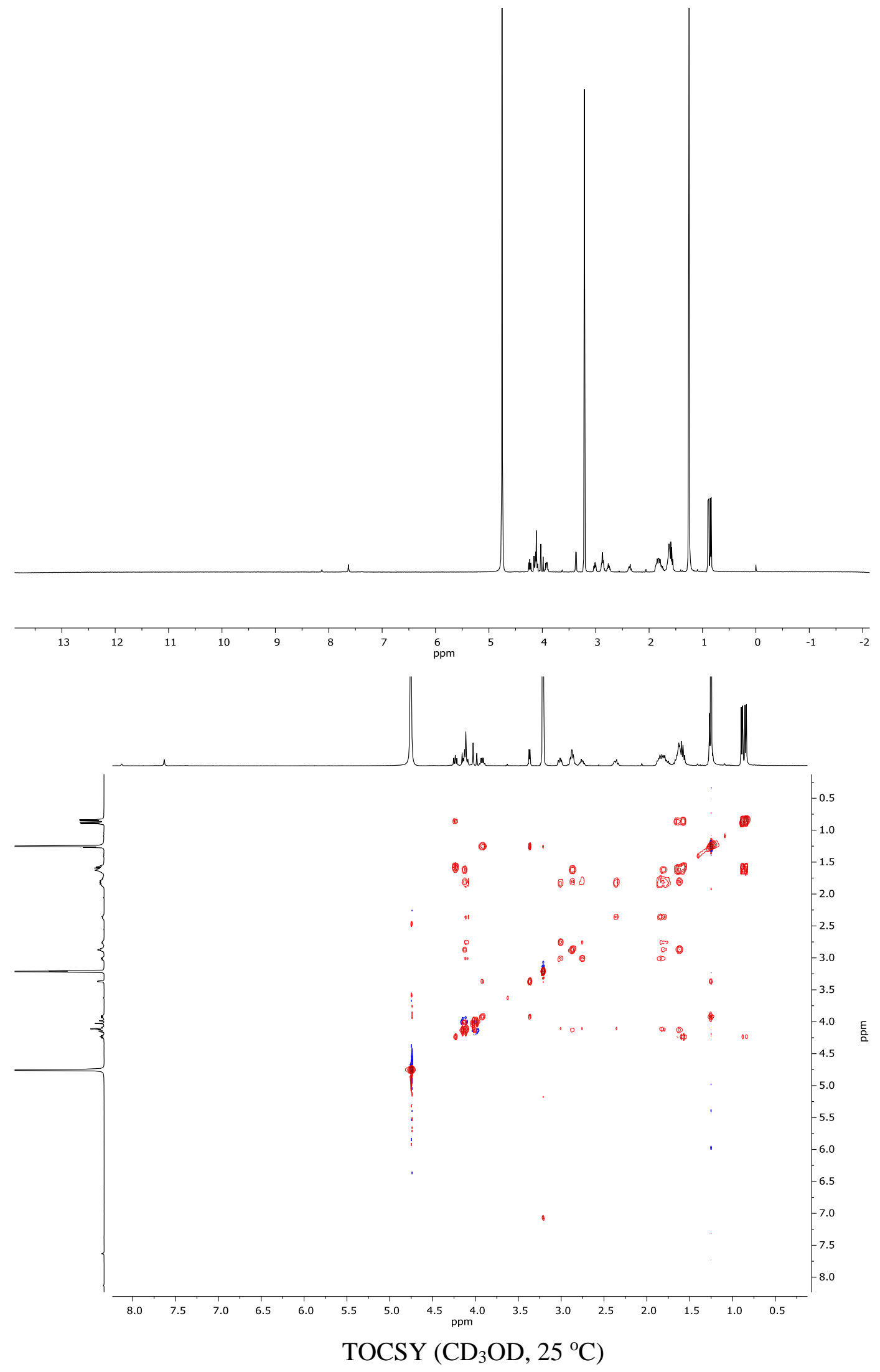
S47

am*[PGloF]
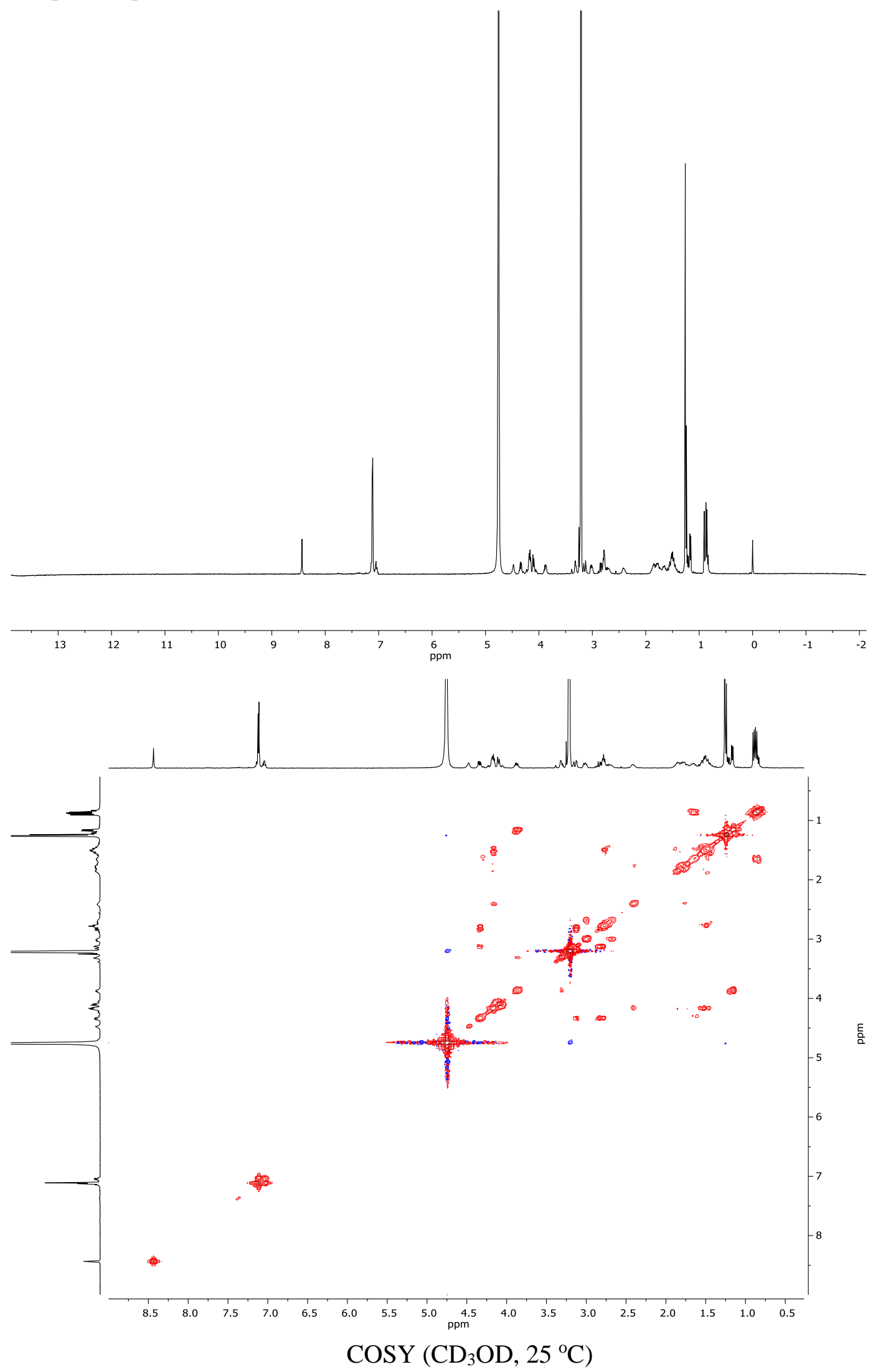


\section{$\mathbf{a m} *[\mathbf{P l k F}]$}
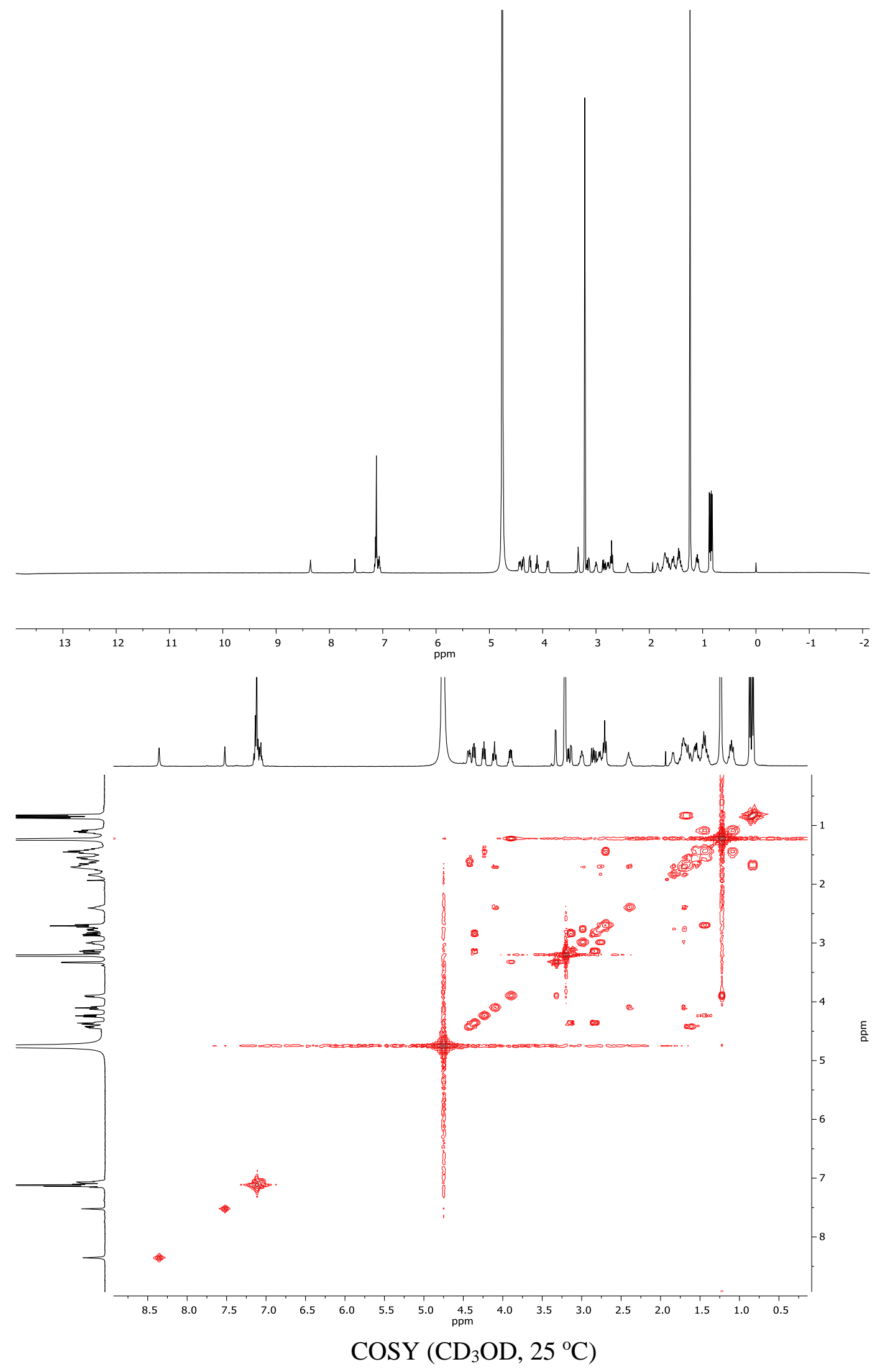


\section{am*[PLKF $]$}
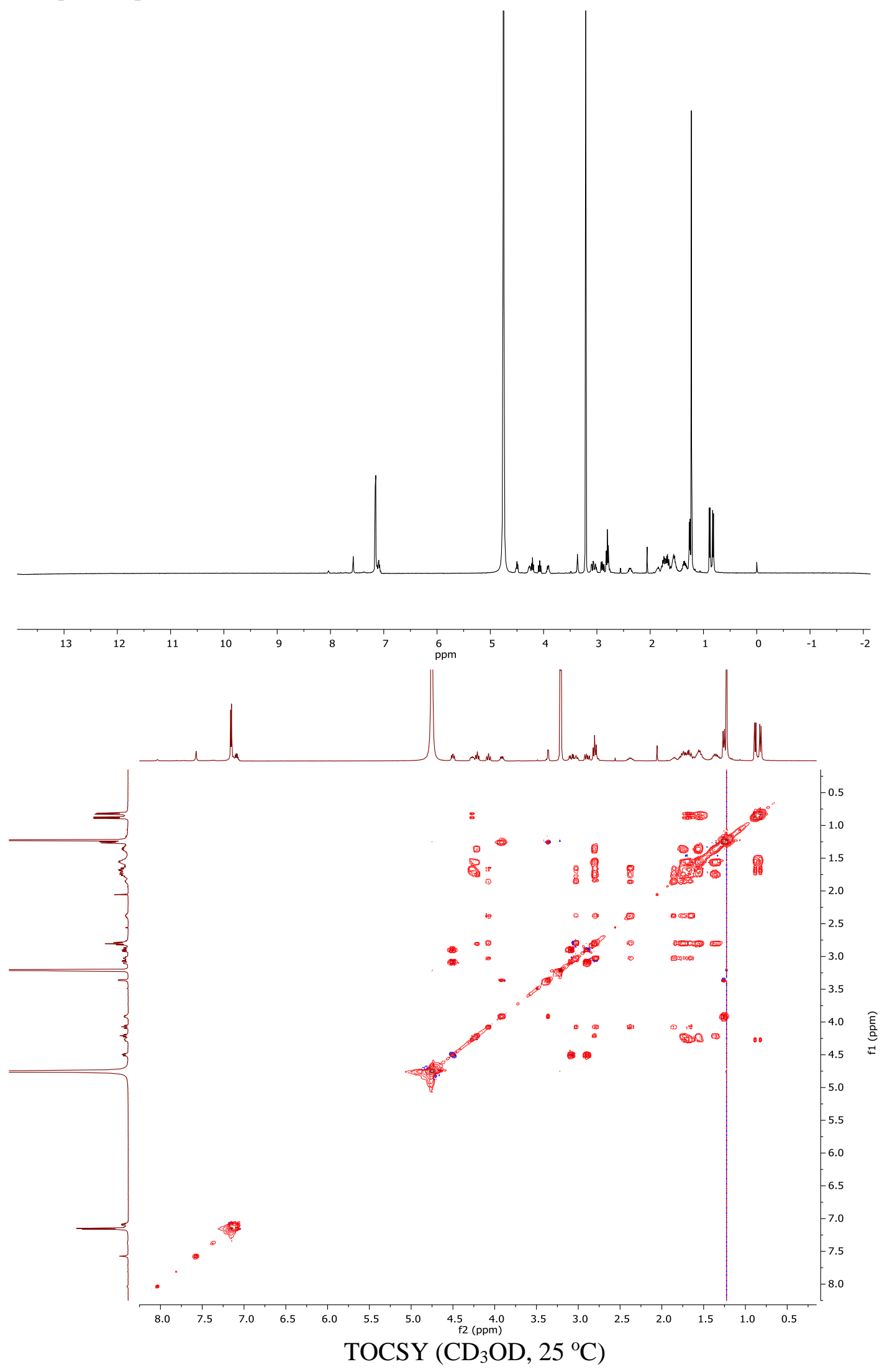
am*[PlkG]
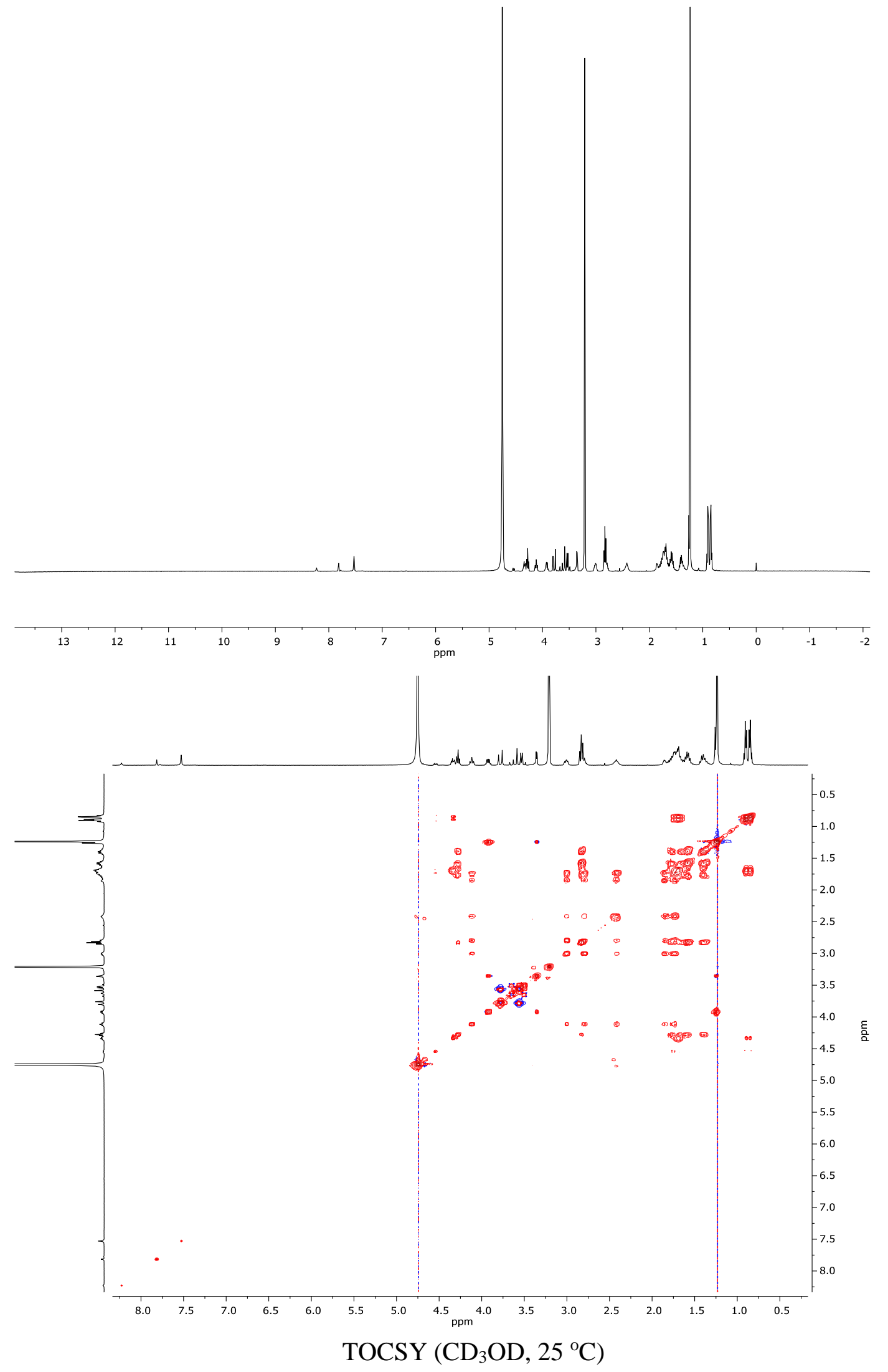
am*[PLKG]
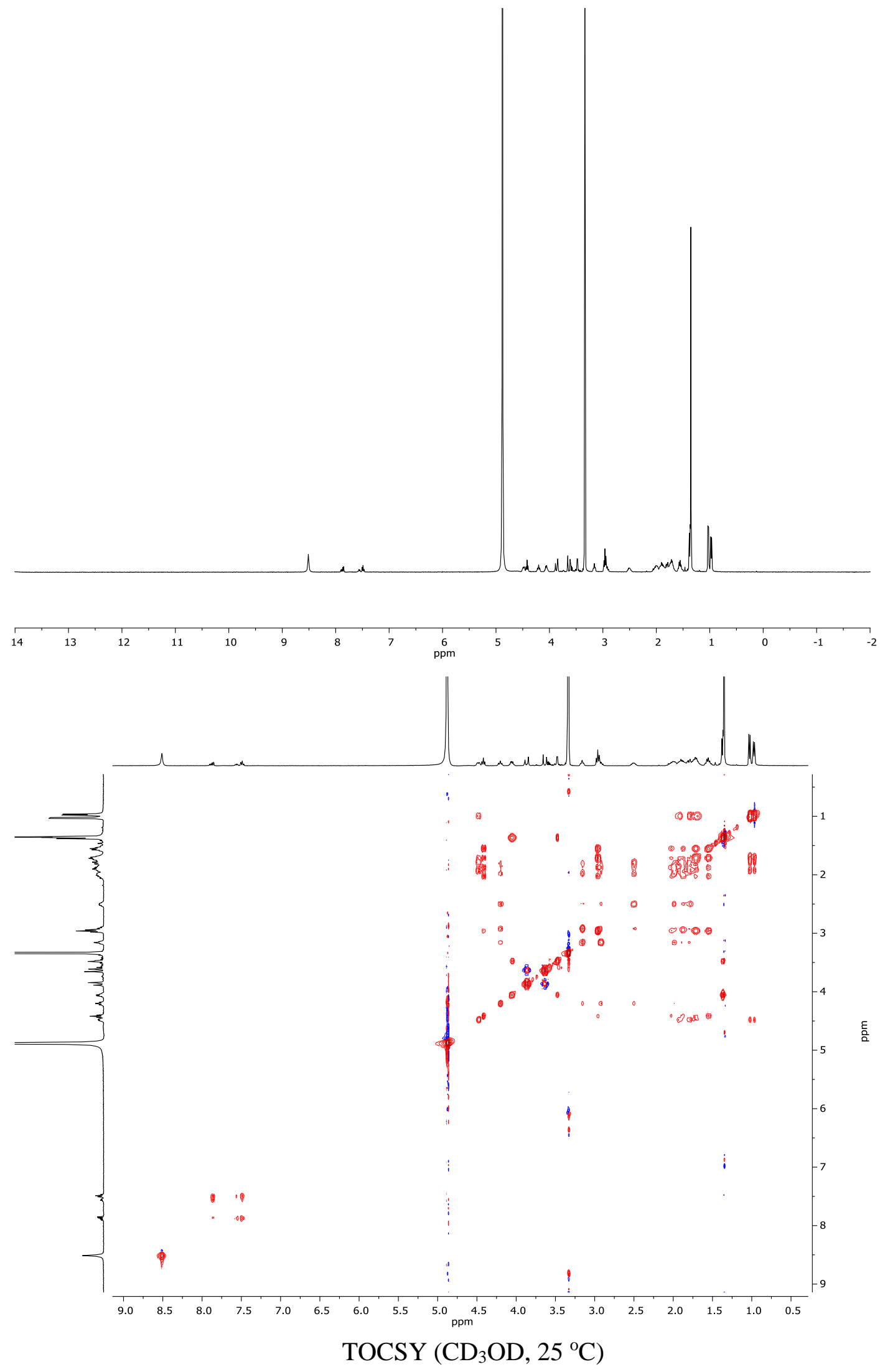
am*[PIkGA]
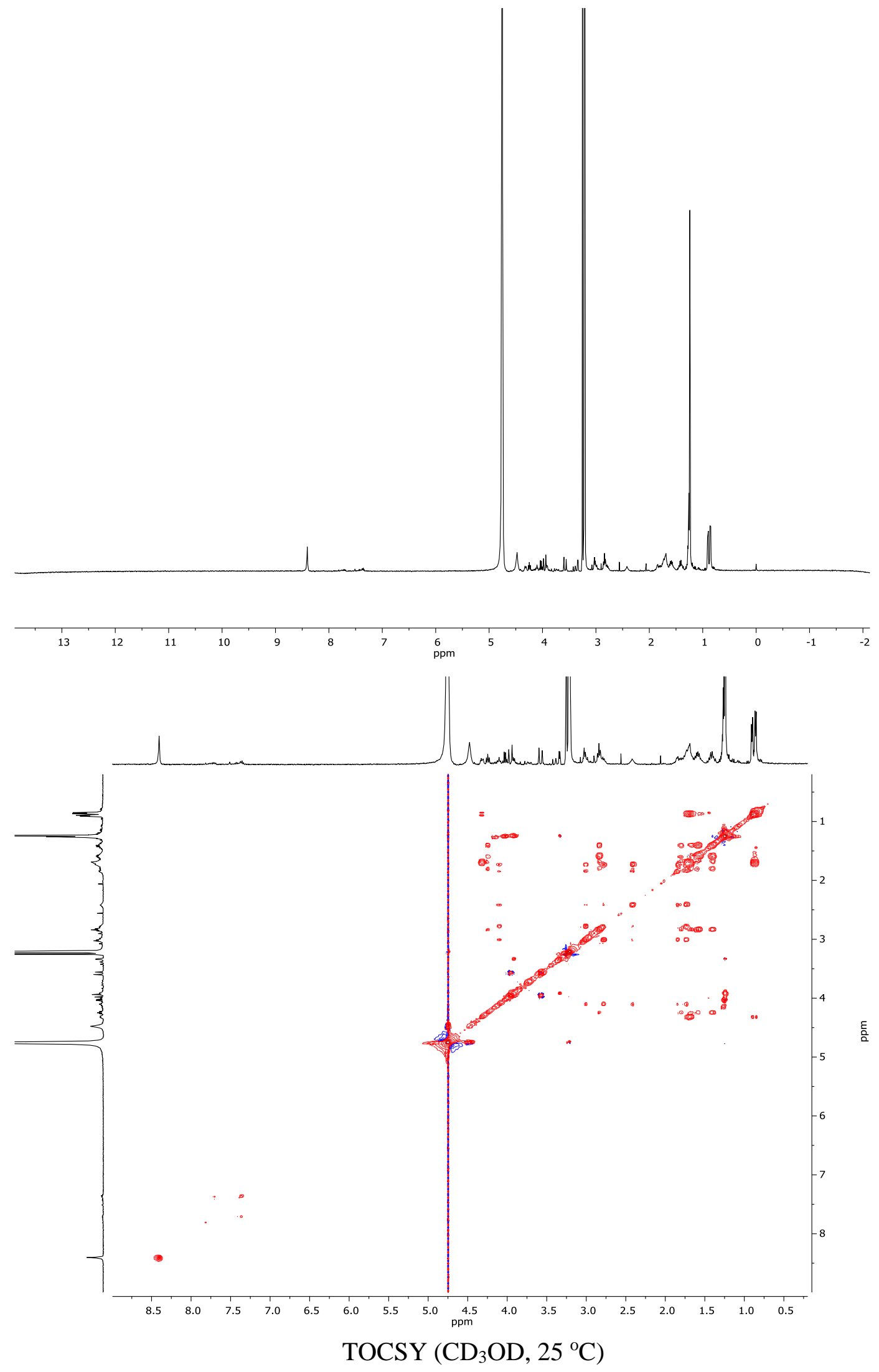


\section{am*[PlkGF]}
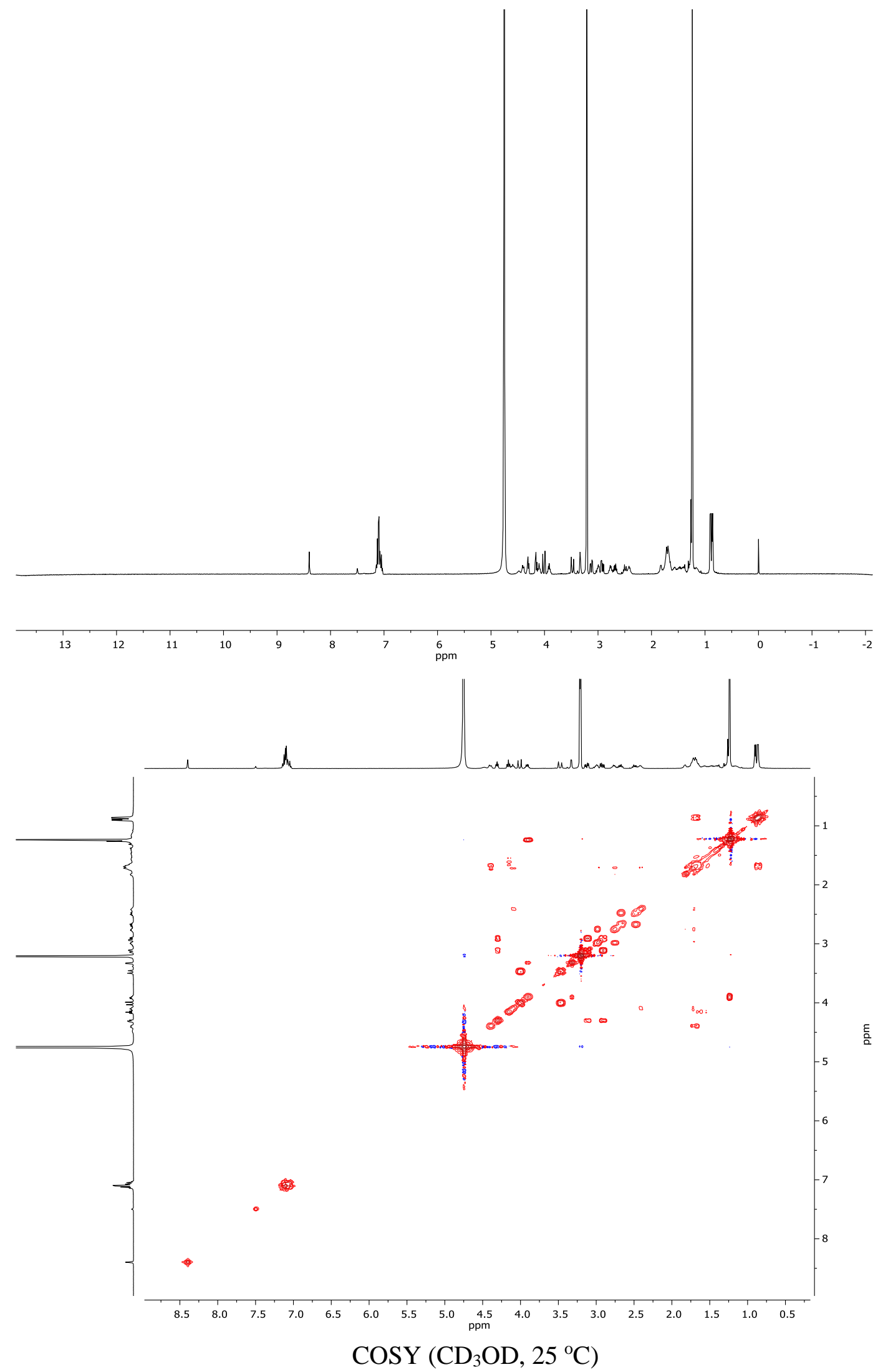
am*[PGDo]
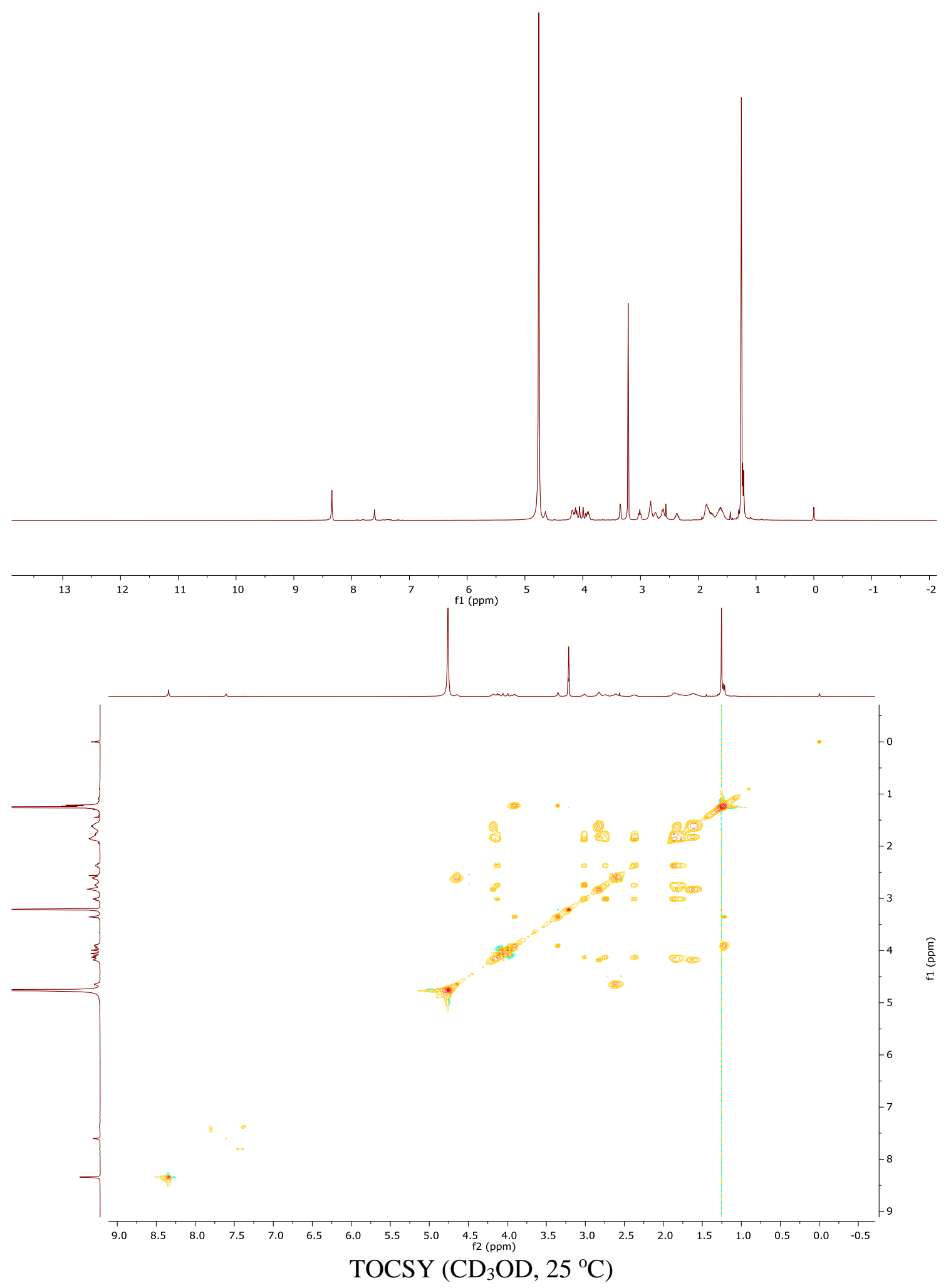


\section{am*[PGFo]}
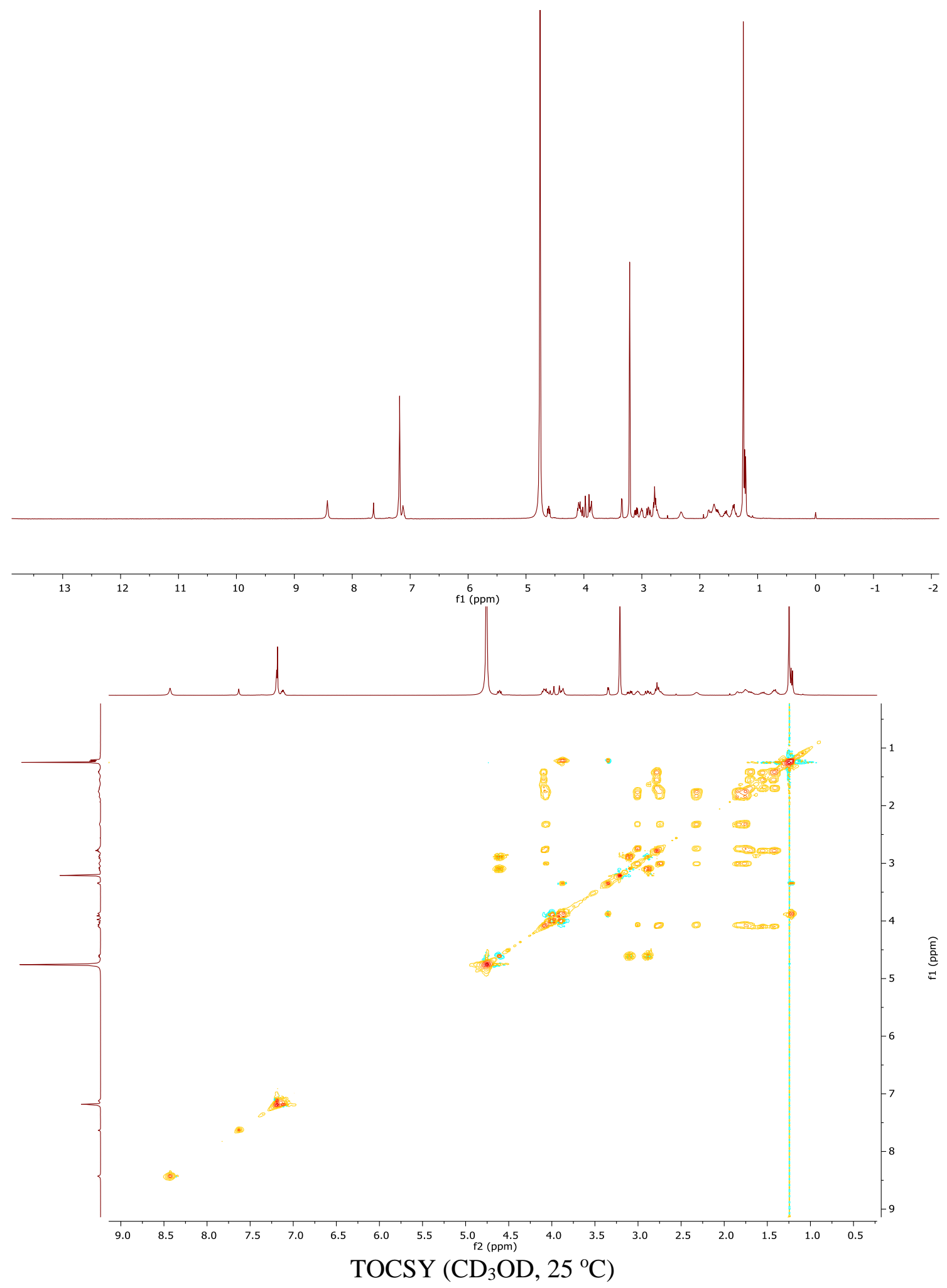
am*[PGI-D-Dab]
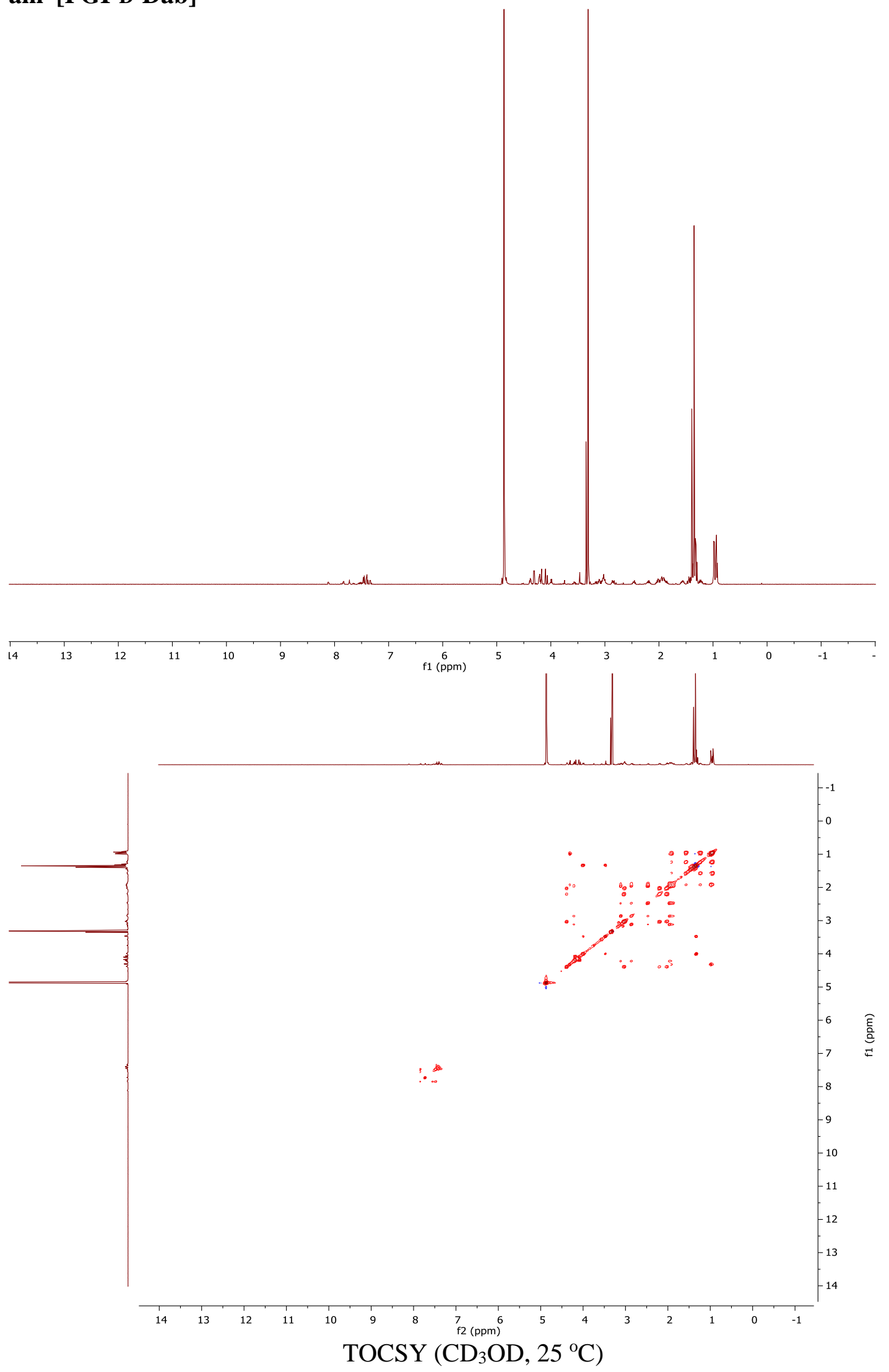


\section{am*[PGIo]}
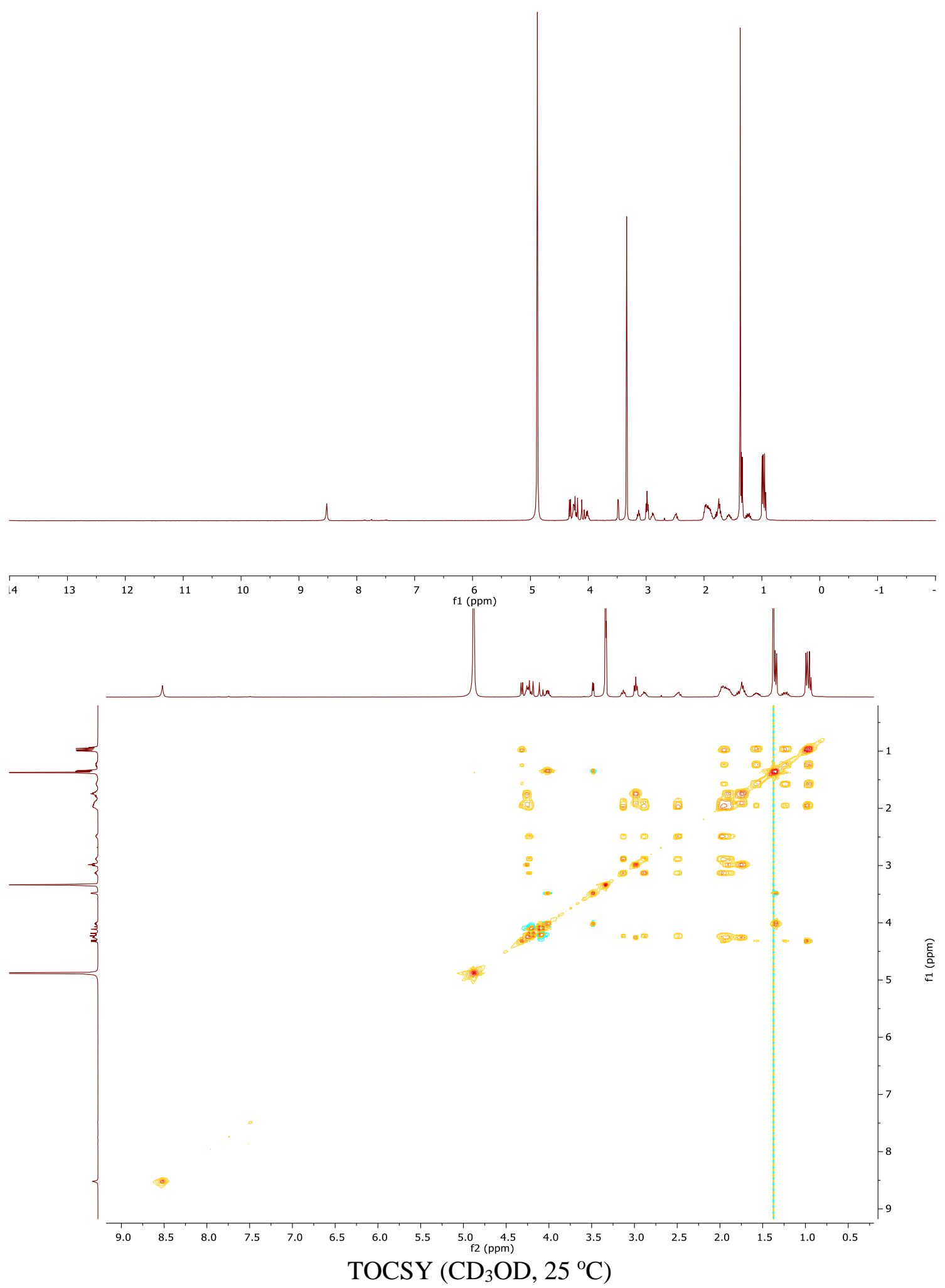


\section{am*[PGLd]}

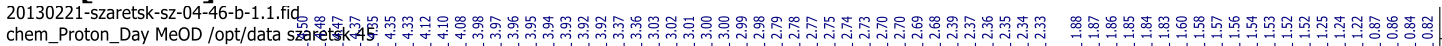

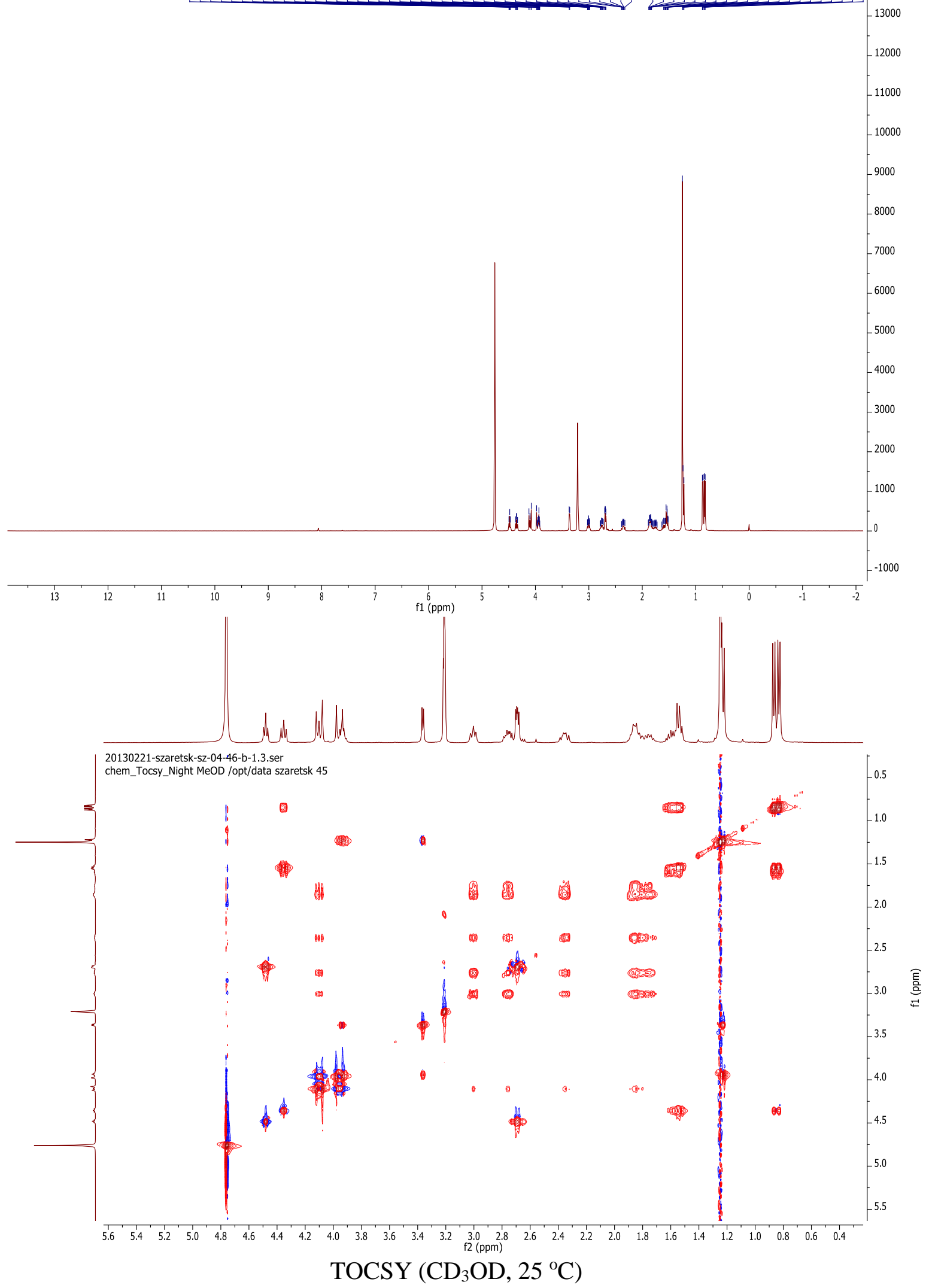




\section{am*[PGL-D-Dab]}

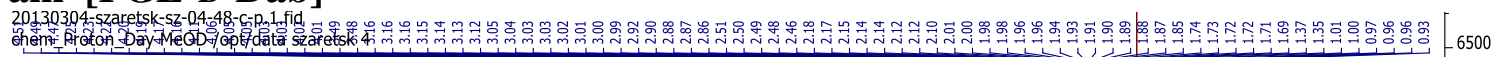
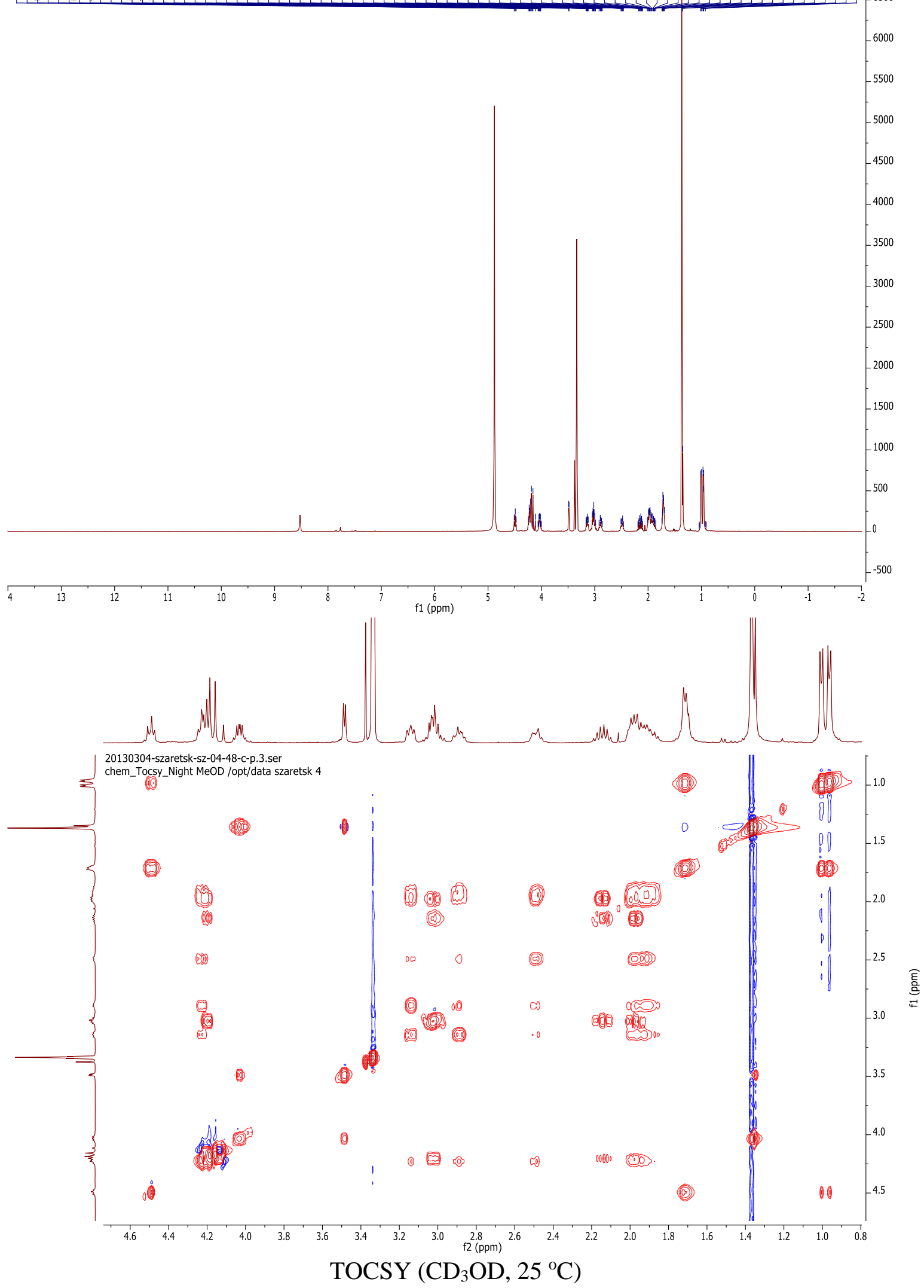


\section{am*[PGL-D-Dap]}

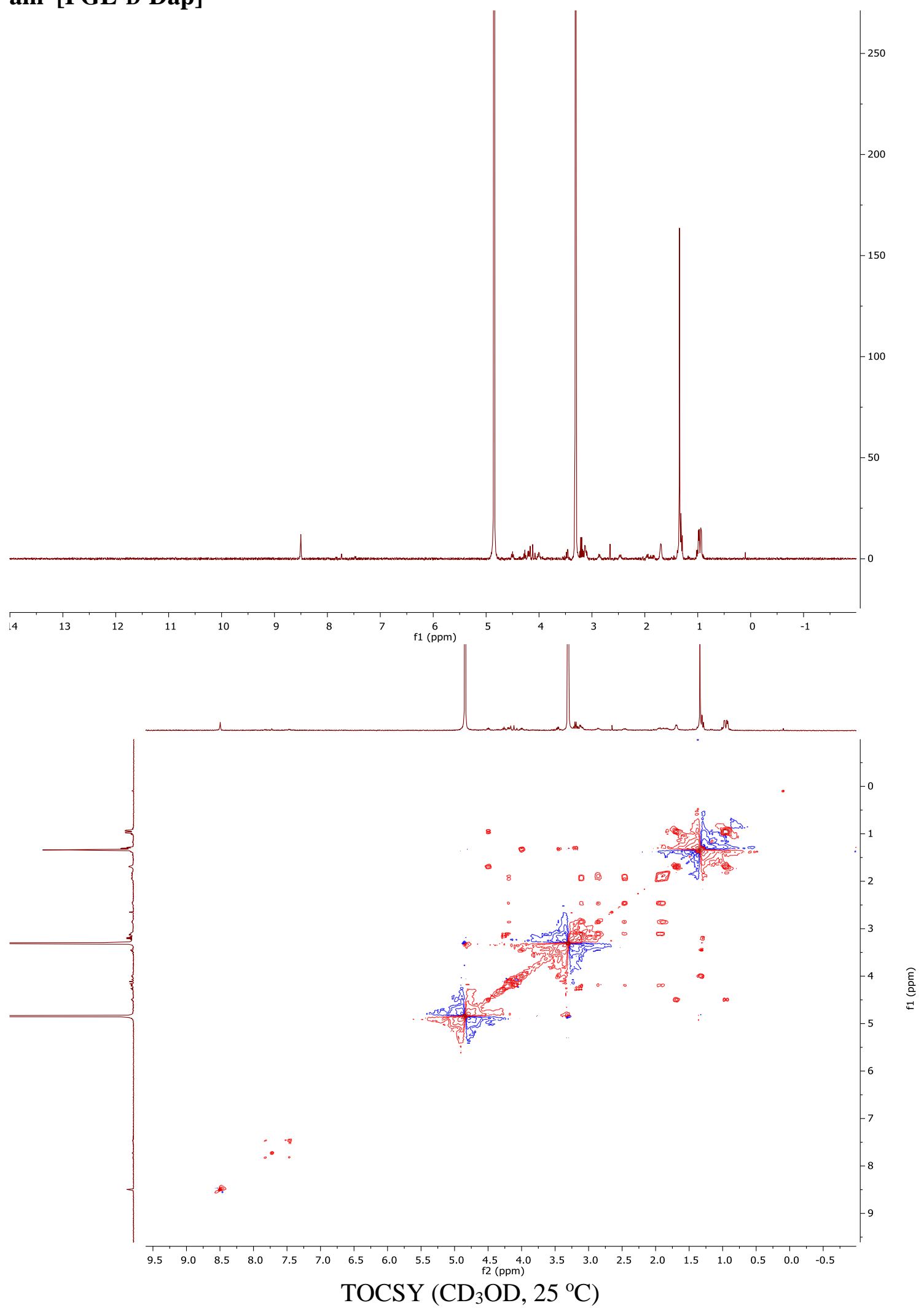




\section{am*[PGLe]}

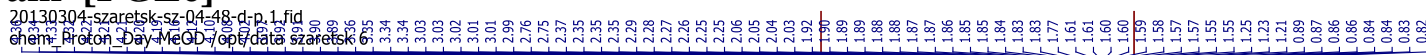

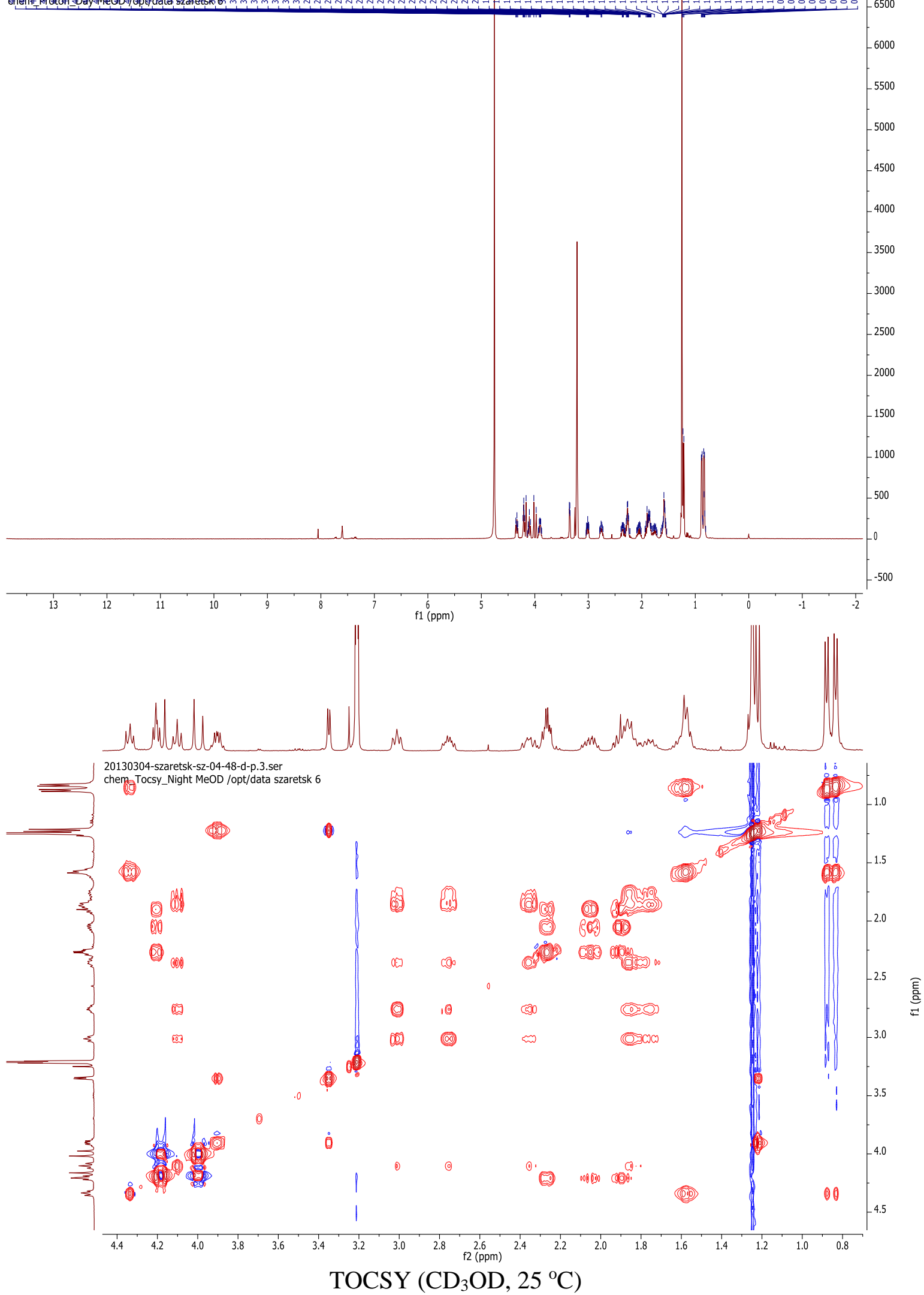




\section{am*[PGLk]}

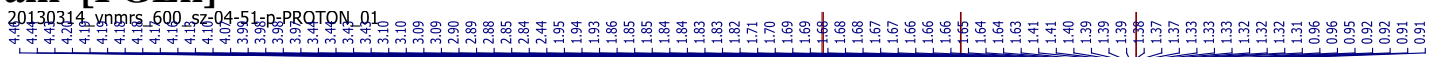

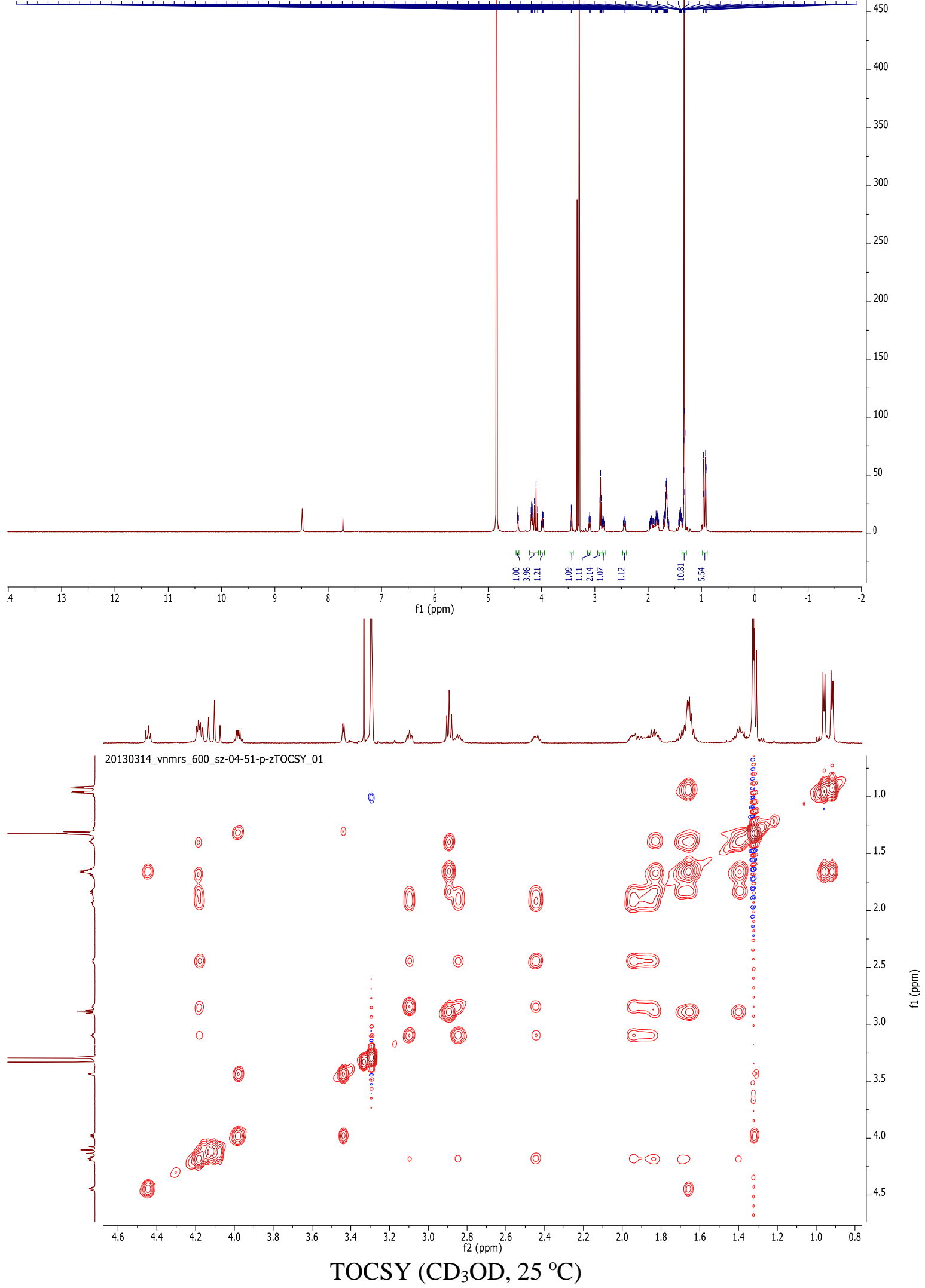




\section{am*[PGLn]}

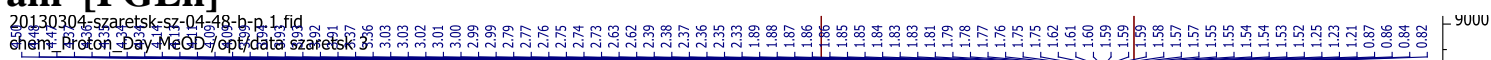
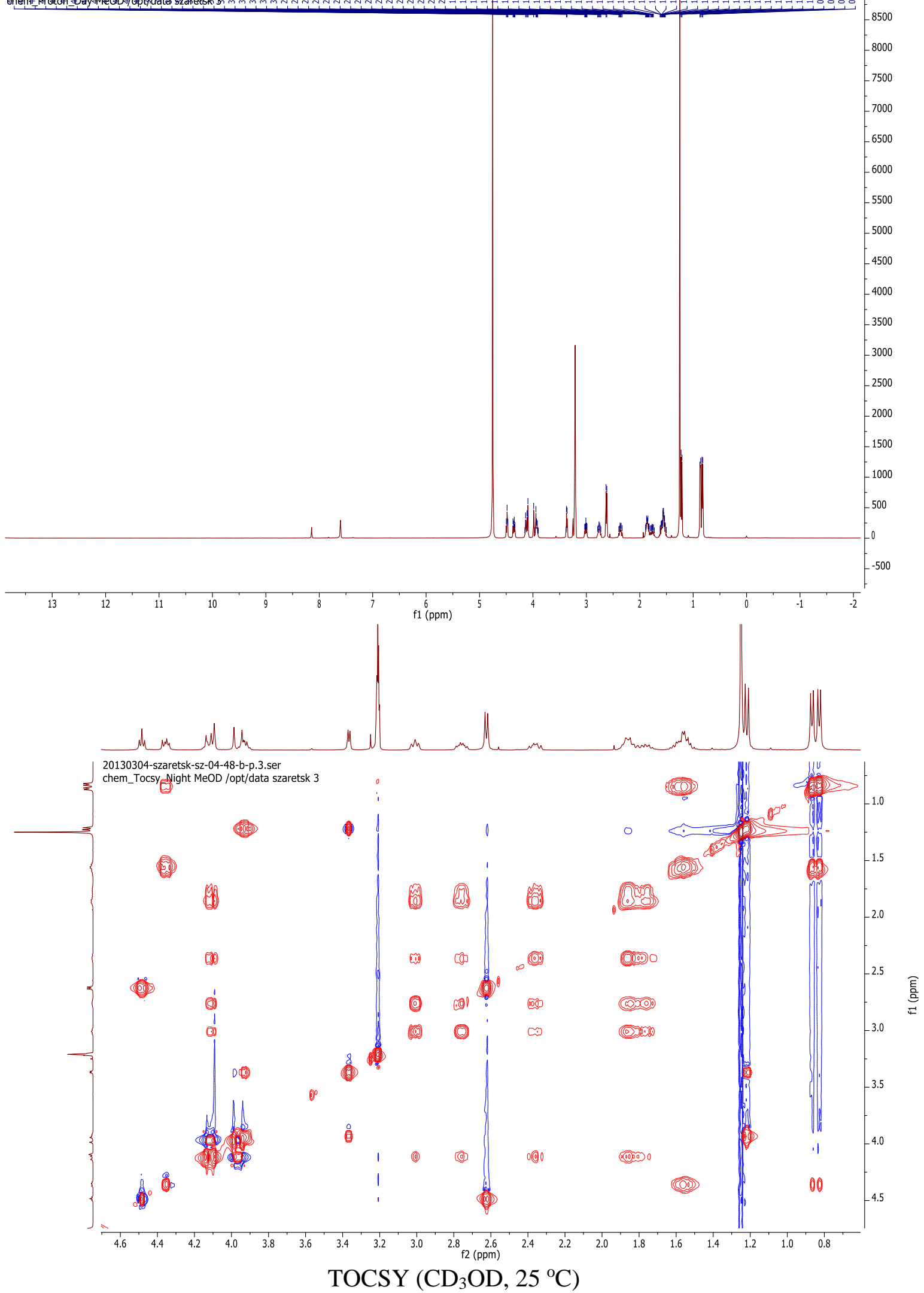


\section{am*[PGLq]}

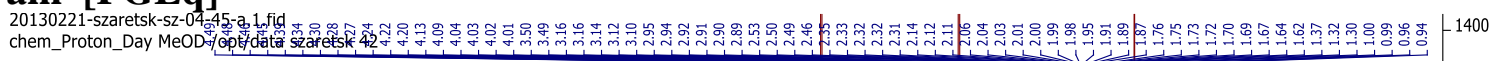

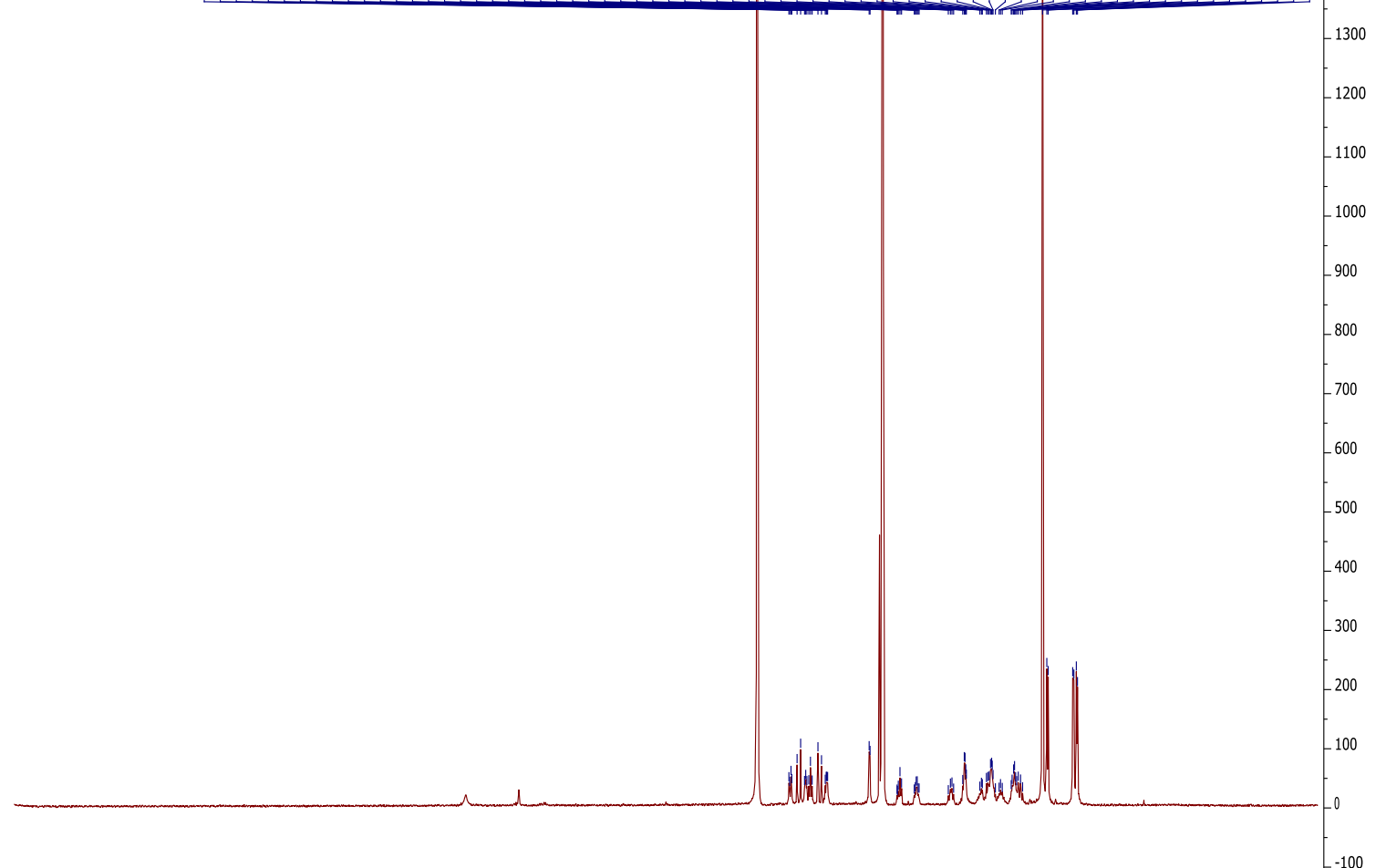

$-100$

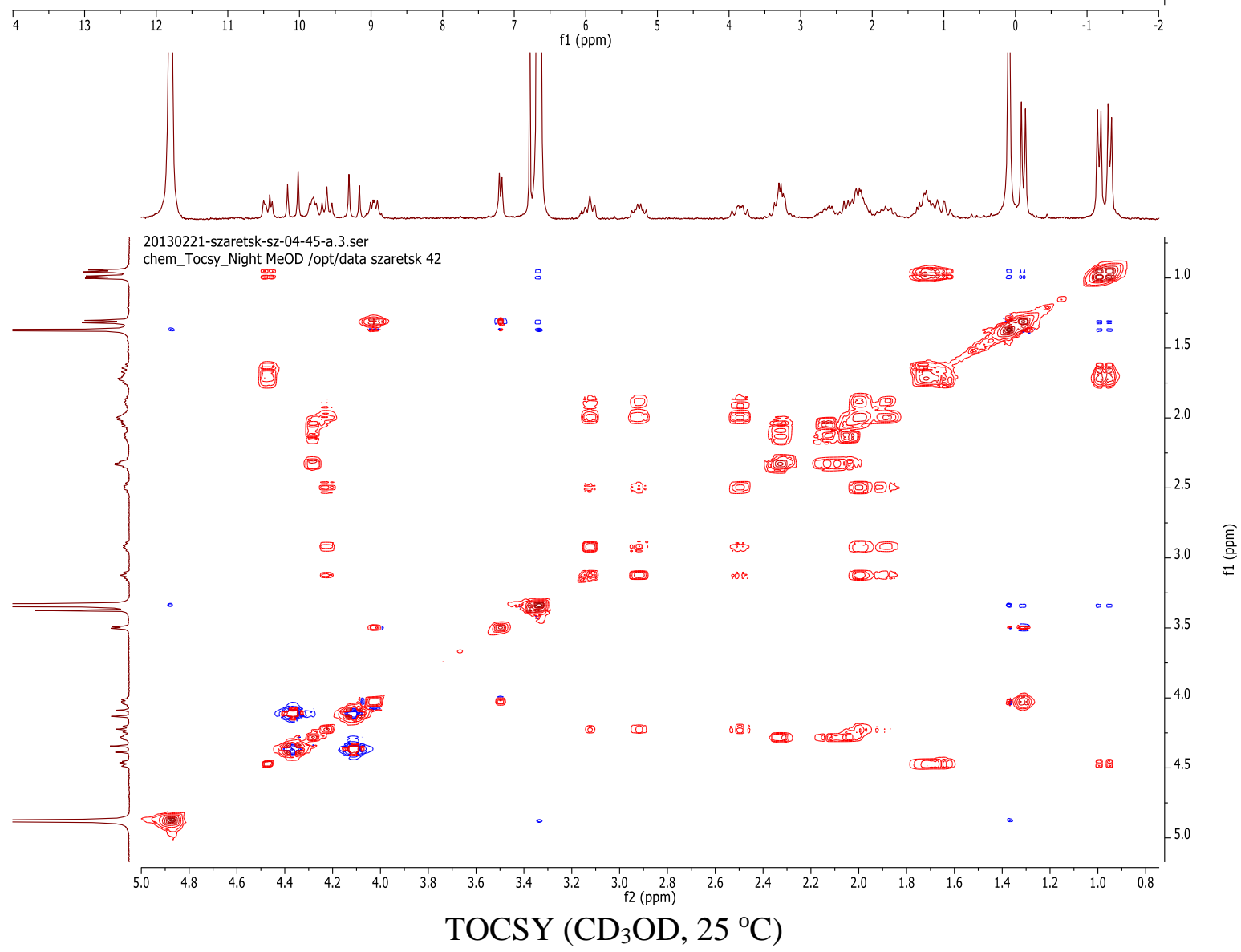




\section{am*[PGLr]}

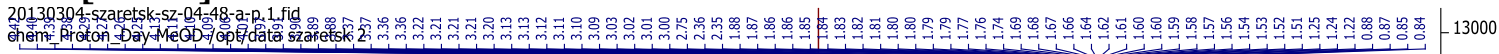
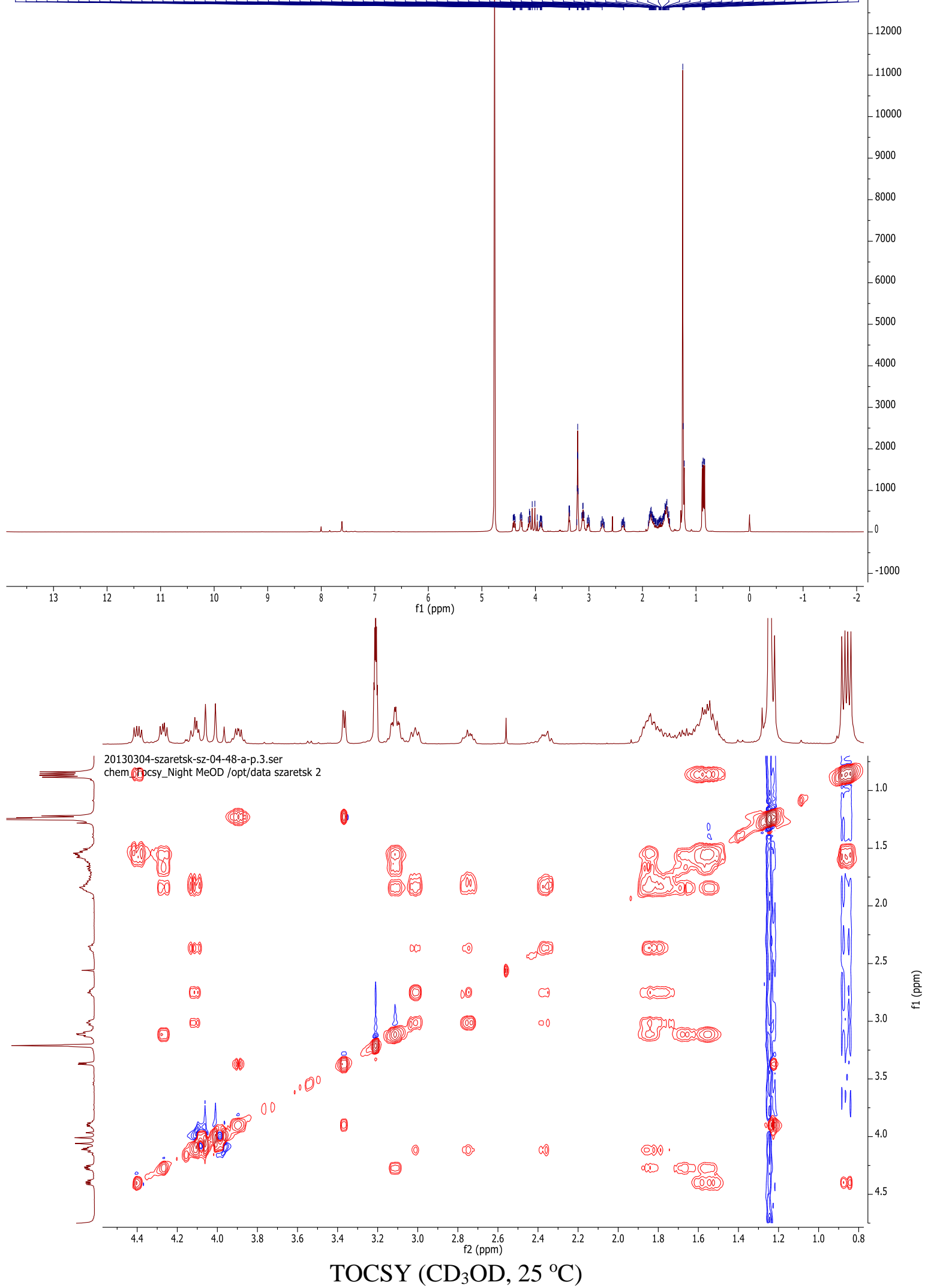


\section{am*[PGLv]}

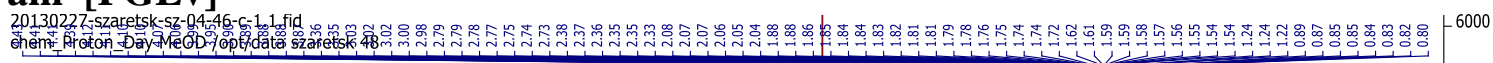

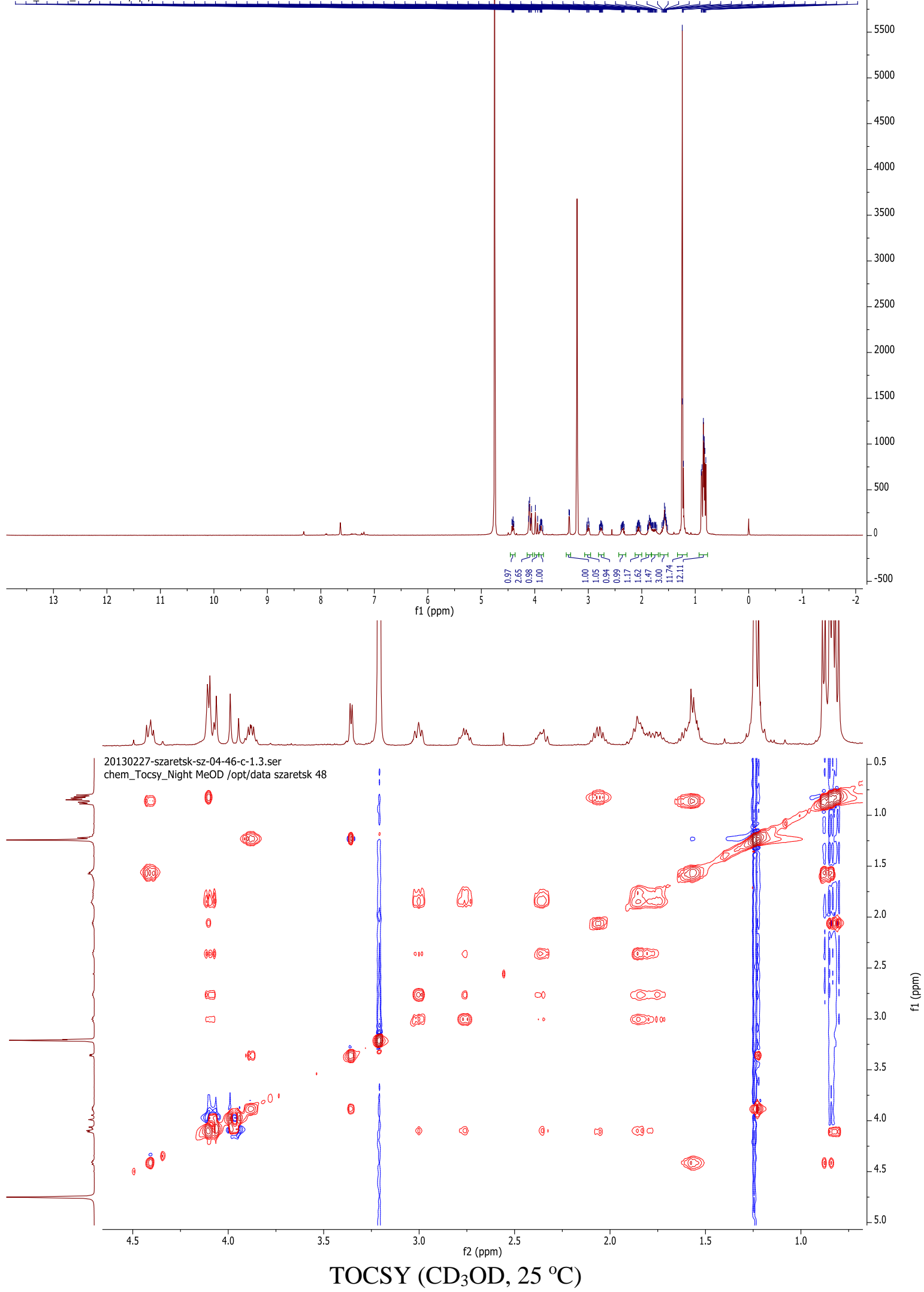




\section{am*[PGNo]}

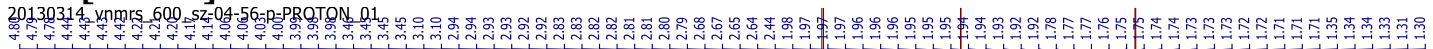

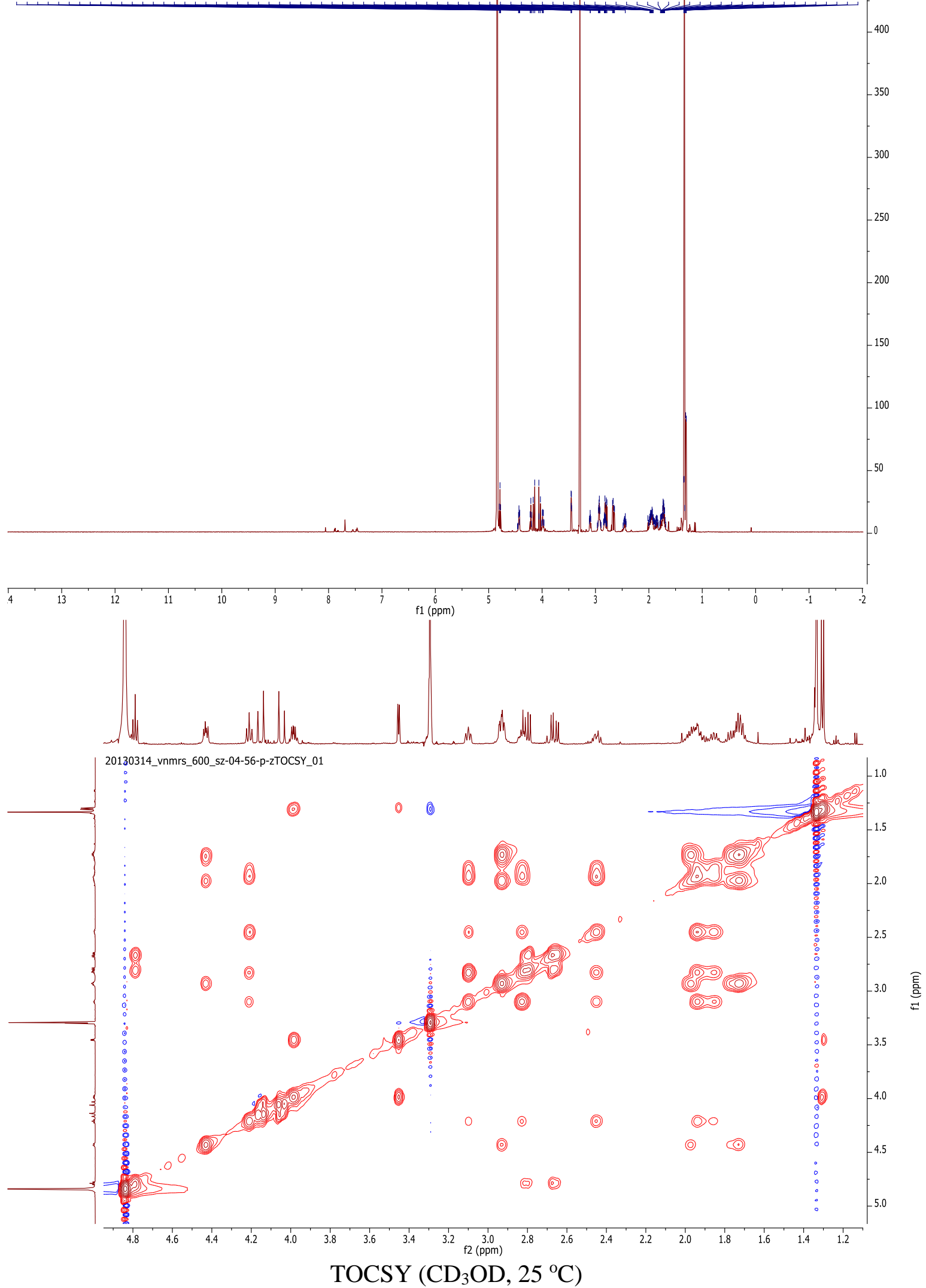




\section{am*[PGSo]}
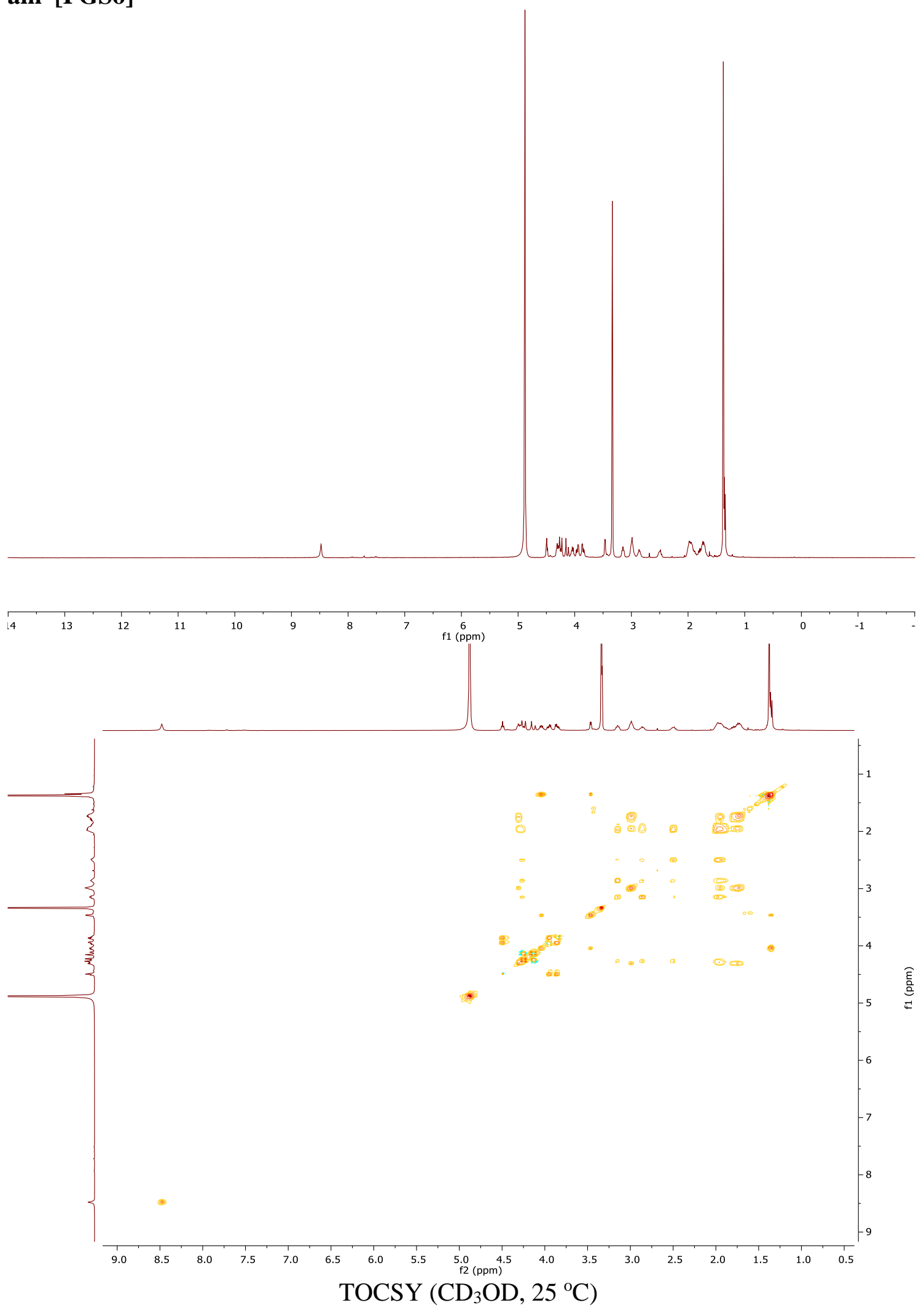
am*[PGV-D-Dab]
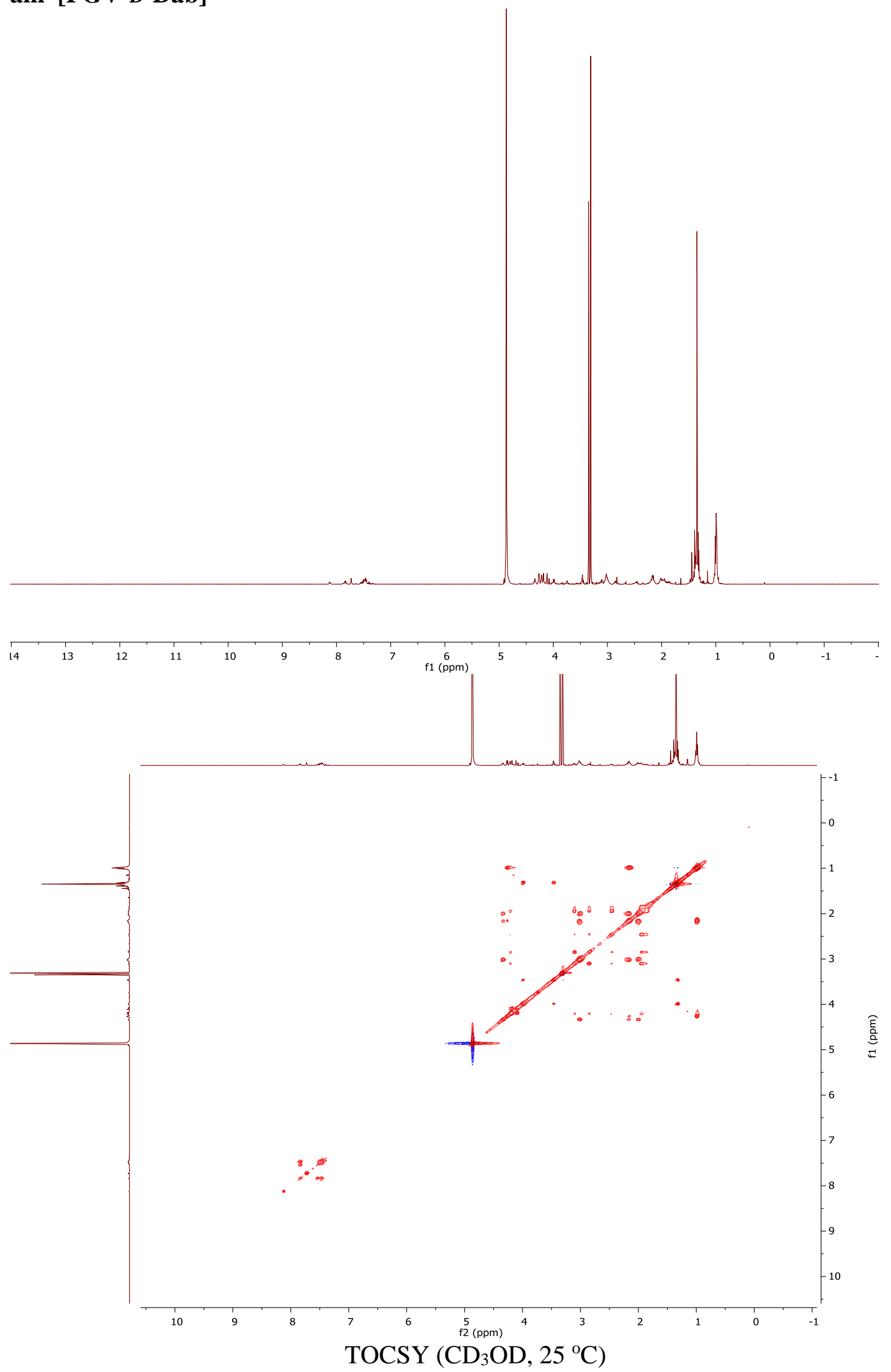


\section{am*[PGVo]}
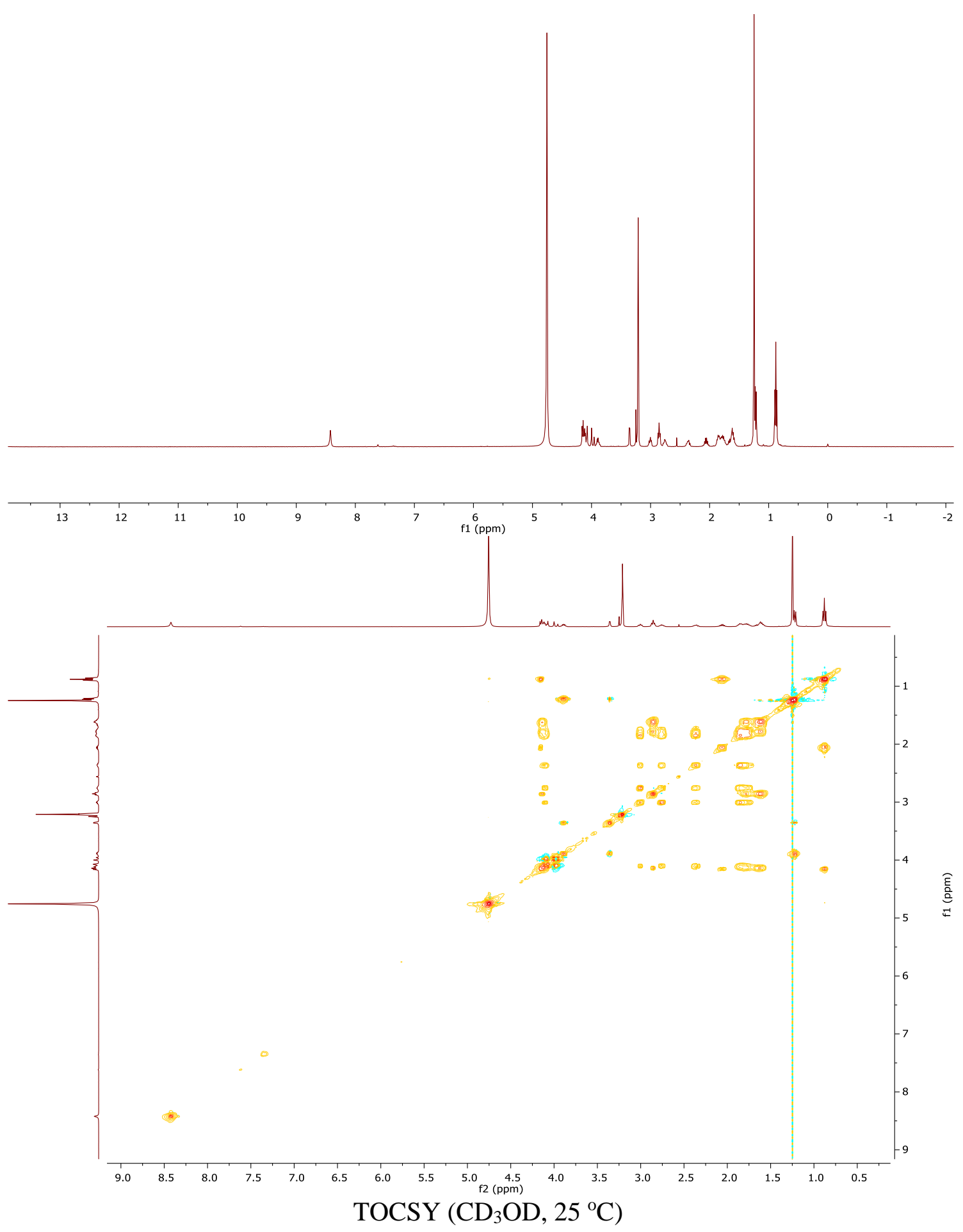


\section{References}

(1) Zaretsky, S.; Tan, J.; Hickey, J. L.; Yudin, A. K. In Methods in Molecular Biology (Springer): Peptide Libraries.; Derda, R., Ed.; Springer Science+Business Media: New York, 2015; Vol. 6, pp. 67-80.

(2) Stenzel, M. H. ACS Macro Lett. 2013, 2, 14.

(3) Arora, S.; Kumar, S. Optoelectron. Adv. Mater. Rapid Commun. 2009, 3, 1359.

(4) Grenier-Loustalot, M.-F.; Aycaguer, N. Eur. Polym. J. 1998, 34, 1705. 